\author{
Universidade de São Paulo \\ Instituto de Física
}

\title{
OSCILADOR PARAMÉTRICO ÓTICO BASEADO EM MISTURA DE QUATRO ONDAS EM VAPOR DE RUBÍDIO
}

\author{
Alvaro Montaña Guerrero
}

Orientador: Prof. Dr. Paulo Nussenzveig

Dissertação de mestrado apresentada ao Instituto de

Física da Universidade de São Paulo, como requisito

parcial para a obtenção do título de Mestre em Ciências.

Banca Examinadora:

Prof. Dr. Paulo Nussenzveig (IFUSP)

Prof. Dr. Antonio Zelaquett Khoury (UFF)

Prof. Dr. Lino Misoguti (IFSC) 
FICHA CATALOGRÁFICA

Preparada pelo Serviço de Biblioteca e Informação do Instituto de Física da Universidade de São Paulo

\section{Montaña Guerrero, Alvaro}

Oscilador paramétrico ótico baseado em mistura de quatro ondas em vapor de rubídio. São Paulo, 2017.

Dissertação (Mestrado) - Universidade de São Paulo. Instituto de Física. Depto. de Física Experimental.

Orientador: Prof. Dr. Paulo Alberto Nussenzveig

Área de Concentração: Ótica Quântica

Unitermos: 1. Óptica quântica; 2. Oscilador paramétrico ótico; 3. Interação da luz com a matéria; 4. Física atômica; 5. Óptica não linear.

USP/IF/SBI-114/2017 
University of São Paulo

Physics Institute

\section{OPTICAL PARAMETRIC OSCILLATOR BASED ON FOUR-WAVE MIXING IN RUBIDIUM VAPOUR}

\section{Alvaro Montaña Guerrero}

Supervisor: Prof. Dr. Paulo Nussenzveig

Dissertation submitted to the Physics Institute of the University of São Paulo in partial fulfillment of the requirements for the degree of Master of Science.

Examining Committee:

Prof. Dr. Paulo Nussenzveig (IFUSP)

Prof. Dr. Antonio Zelaquett Khoury (UFF)

Prof. Dr. Lino Misoguti (IFSC) 

Aos meus pais, irmãos e avó .. 



\section{Agradecimentos}

Quero agradecer profundamente aos meus pais Mariela Guerrero e Jose Alvaro Montaña, meus irmãos Mauricio, Luis Alberto e Andres Felipe, cujo apoio incondicional em momentos difíceis e companhia em momentos de felicidade, nunca me faltava. A honestidade, humildade e respeito que expresso aos que me rodeiam, e o meu esforço no que eu gosto de fazer, são apenas um reflexo dos valores que me ensinaram e que sempre serão primordial em os momentos que virão. Sua companhia no transcurso da mi formação como Físico, Mestre e como humano é inestimável. Agradeço ao meu orientador Paulo Nussenzveig e co-orientador Marcelo Martinelli, pelo exemplo como pesquisadores e a constante curiosidade pela física. Sinceros agradecimentos pelos ensinamentos diretos e indiretos, e pela grande oportunidade de trabalhar neste ótimo grupo de pesquisa.

Agradeço aos colegas de laboratório: Harold Rojas, Raul Rincon, Pablo Palacios, Carlos Gonzalez, Túlio Brito, Rayssa Bruzaca, Igor Konieczniak, Renato Domeneguetti, Luiz Couto, Bárbara Ribeiro e Breno Teixeira. Especialmente ao Harold com quem compartilhei momentos difíceis e de alegria no experimento, e ao Raul e Pablo pela amizade.

Agradeço ao CNPq pelo suporte financeiro. 



\section{Resumo}

No presente trabalho, descrevemos a construção de um oscilador paramétrico ótico (OPO) com meio atômico de ganho de susceptibilidade $\chi^{(3)}$, e a caracterização de seu limiar de oscilação.

O processo base para a construção deste OPO é a Mistura de Quatro Ondas (4WM), que acontece em meios não lineares tipo $\chi^{(3)}$, como é o caso dos isótopos de ${ }^{85} \mathrm{Rb}$ $\mathrm{e}^{87} \mathrm{Rb}$. Realizou-se uma revisão da teoria atômica do rubídio, do 4WM e da teoria clássica do OPO.

Obtivemos e caracterizamos o processo de 4WM em função de três parâmetros experimentais: a dessintonia do feixe de bombeio $\Delta$ em relação ao pico do crossover da transição $5 S_{1 / 2}(F=2) \rightarrow 5 P_{1 / 2}\left(F^{\prime}\right)$ do ${ }^{85} \mathrm{Rb}$ na linha $\mathrm{D}_{1}$, da potência do bombeio e da temperatura da célula de rubídio. Encontrou-se uma ótima região de frequências em torno a $\Delta=0.77 \mathrm{GHz}$ para a construção do OPO com os átomos de rubídio como meio não linear. Nesta região obteve-se uma amplificação máxima de $450 \%$ para o feixe de prova com absorção nula e uma intensidade do conjugado alta, para o feixe de prova com frequência $\omega=\Delta+3 \mathrm{GHz}$ (anti-Stokes).

A elevada amplificação observada permite, em princípio, um limiar de oscilação menos abrupto: o surgimento de oscilação aparece de forma menos sensível a variações da potência de bombeio. Com efeito, para a dessintonia $\Delta=0.38 \mathrm{GHz}$ o limiar é suave.

A caracterização do 4WM e do limiar de oscilação do OPO é importante para a possível geração de estados não gaussianos. Um limiar suave permite, em princípio, operação e estudo muito próximo do limiar, região em que há previsões indicando a geração de estados não gaussianos que são relevantes para aplicações em informação quântica.

Palavras chave: Ótica quântica, Oscilador paramétrico ótico, Interação da luz com a matéria, Física atômica, Ótica não linear 



\begin{abstract}
In the present work, we describe the construction of a optical parametric oscillator (OPO) with atomic gain medium with susceptibility $\chi^{(3)}$ and the caracterization of the oscilation threshold.

The basic process for the construction of this OPO is the Four Wave Mixing (4WM), a process that takes place in nonlinear media type $\chi^{(3)}$, as is the case of the isotopes of ${ }^{85} \mathrm{Rb}$ and ${ }^{87} \mathrm{Rb}$. A review of the atomic theory of rubidium, $4 \mathrm{WM}$ and the classical theory of the OPO was carried out.

The 4WM process was obtained and characterized as a function of three experimental parameters: the pump beam detunning $\Delta$ with respect to the transition crossover peak $5 S_{1 / 2}(F=2) \rightarrow 5 P_{1 / 2}\left(F^{\prime}\right)$ of ${ }^{85} \mathrm{Rb} \mathrm{D} 1$ line, the pumping power and the temperature of the rubidium cell. A good region of frequencies around $\Delta=0.77 \mathrm{GHz}$ was found for the construction of the OPO with the rubidium atoms as a non-linear medium. In this region, it was obtained a maximum amplification of $450 \%$ for the prove beam with zero absorption and a high intensity for the conjugate beam with frequency $\omega=\Delta+3 \mathrm{GHz}$ (anti-Stokes).

The high observed amplification allows, in principle, an oscillation threshold less abrupt: the oscillation appears in a less sensitive way with variations in pumping power. In fact, for the detunning $\Delta=0.38 \mathrm{GHz}$ the threshold is smooth. The characterization of the $4 \mathrm{WM}$ and oscillation threshold of the OPO is important for the possible generation of non-Gaussian states. A smooth threshold allows, in principle, operation and study very close to this region, where there is predictions indicating the generation of non-Gaussian states that are relevant for applications in quantum information.
\end{abstract}

Key words: Quantum Optics, Optical Parametric Oscillator, Light-Matter Interaction, Atomic Physics, Nonlinear Optics 



\section{Lista de figuras}

Figura I Esquema geral da cavidade OPO $\chi^{3}$ com átomos de Rubídio. . . . . . . xiii

Figura II Representação do processo de Mistura de quatro ondas. . . . . . . . . . xiv

Figura 1.1 Estrutura hiperfina de transição do ${ }^{85} \mathrm{Rb}$ na linha D1. . . . . . . . . 4

Figura 1.2 Estrutura hiperfina de transição do ${ }^{87} \mathrm{Rb}$ na linha D1. . . . . . . . . 5

Figura 1.3 Efeito Doppler ...................... 6

Figura 1.4 Absorção dos átomos em função da velocidade. . . . . . . . . . . . . . 7

Figura 1.5 Absorção saturada. . . . . . . . . . . . . . . . . . 9

Figura 1.6 Possíveis processos num meio não linear quadrático. . . . . . . . . . . 10

Figura 1.7 Possíveis processos num meio não linear de terceira ordem. . . . . . . . . 12

Figura 1.8 Possíveis canais no espalhamento Raman. . . . . . . . . . . . . . . . . 13

Figura 1.9 Mistura de Quatro Ondas . . . . . . . . . . . . . . . . . . . 17

Figura 1.10 Cavidade Fabry-Perot . . . . . . . . . . . . . . 20

Figura 1.11 Esquema geral de um oscilador paramétrico ótico OPO . . . . . . . 23

Figura 2.1 Exemplo da estrutura de um diodo laser. . . . . . . . . . . . . . . 30

Figura 2.2 Montagem do laser de diodo sintonizável ao redor do comprimento de

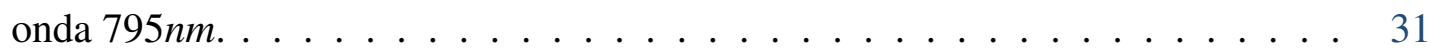

Figura 2.3 Obtenção do laser Monomodo e Dessintonia. . . . . . . . . . . . . . . 32

Figura 2.4 Configuração experimental dessintonia e espectroscopia. . . . . . . . . 34

Figura 2.5 Célula de Rubídio. . . . . . . . . . . . . . . . . . . . . 35

Figura 2.6 Espectroscopia de absorção saturada para o Rubídio 85 e 87 na linha D1. 36

Figura 2.7 Potência de amplificação do SDL8630 em função do comprimento de onda de entrada. . . . . . . . . . . . . . . . . . . . . 37

Figura 2.8 Esquema de uma cavidade ótica tipo borboleta sintonizável. . . . . . . . 39

Figura 2.9 Acoplamento da fibra ótica. . . . . . . . . . . . . . . . . . . . 39

Figura 2.10 Ruído gerado pela fibra ótica. . . . . . . . . . . . . . . . . . 40 
Figura 3.1 Montagem para obtenção da Mistura de Quatro Ondas (4WM) . . . . . 42

Figura 3.2 Mistura de Quatro Ondas (4WM) para os canais Stokes, AntiStokes, e

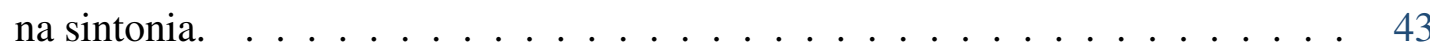

Figura 3.3 Obtenção do fenômeno de Mistura de Quatro Ondas (Exemplo 1). $\Delta=$ $1,5 \mathrm{GHz} \ldots \ldots \ldots \ldots \ldots \ldots \ldots$

Figura 3.4 Obtenção do fenômeno de Mistura de Quatro Ondas (Exemplo 2). $\Delta=$ $-2 \mathrm{GHz} \ldots \ldots \ldots \ldots \ldots \ldots$. . . . . . . . . . . . . 47

Figura 3.5 Ganhos dos feixes de prova e conjugado em função da dessintonia $\Delta$ do bombeio . . . . . . . . . . . . . . . . . . . 53

Figura 3.6 Ganho dos feixes conjugado e prova em função da Intensidade do bom-

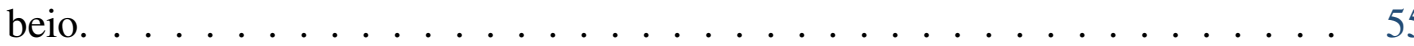

Figura 3.7 Ganho dos feixes conjugado e prova em função da Intensidade do bombeio. . . . . . . . . . . . . . . . . . . 56

Figura 3.8 Ganho dos feixes conjugado e prova em função da Intensidade do bombeio. . . . . . . . . . . . . . . . . . . 57

Figura 3.9 Ganho dos feixes conjugado e prova em função da Intensidade do bombeio. . . . . . . . . . . . . . . . . . . . 58

Figura 3.10 Ganhos do feixe de prova em função da potência entregue pelo resistor (Temperatura) . . . . . . . . . . . . . . . . . . . . 60

Figura 3.11 Montagem do OPO com uma célula de $\mathrm{Rb}$ dentro de uma cavidade. . . 62

Figura 3.12 Foto da cavidade OPO real. . . . . . . . . . . . . . . . . . . . 65

Figura 3.13 Finesse e Transmissão da cavidade em função do ângulo da lâmina de onda $(\mathrm{QWP}) . \ldots \ldots \ldots \ldots \ldots 6$

Figura 3.14 Intensidade dos picos da cavidade OPO em função da potência do bombeio. . . . . . . . . . . . . . . . . . . 70

Figura 3.15 Intensidade dos picos da cavidade OPO em função da potência do bom-

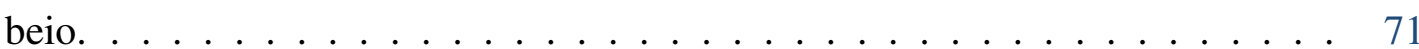

Figura 3.16 Cavidades de Separação dos dois feixes gêmeos e o bombeio. . . . . . . 72 


\section{Sumário}

Introdução xiii

I Conceitos teóricos 1

1 Mistura de quatro ondas e OPO com átomos de rubídio 3

1.1 Estrutura hiperfina do ${ }^{85} \mathrm{Rb}$ e ${ }^{87} \mathrm{Rb} \ldots \ldots \ldots \ldots$

1.1 .1 Alargamento Doppler . . . . . . . . . . . . . . 6

1.2 Polarizabilidade não linear e mistura de quatro ondas . . . . . . . 8

1.2.1 Processos de segunda ordem $\chi^{(2)} \ldots \ldots \ldots \ldots \ldots \ldots$

1.2.2 Processos de terceira ordem $\chi^{(3)} \ldots \ldots \ldots \ldots \ldots \ldots \ldots$

1.2 .3 Espalhamento $\operatorname{Raman} \ldots \ldots \ldots \ldots \ldots \ldots$

1.3 Mistura de quatro ondas $(4 \mathrm{WM}) \ldots \ldots \ldots \ldots \ldots$

1.3.1 Abordagem clássica do $4 \mathrm{WM} \ldots \ldots \ldots \ldots$

1.3.2 Abordagem quântica do $4 \mathrm{WM} \ldots \ldots \ldots \ldots$

1.4 Cavidades óticas . . . . . . . . . . . . . . . . . . . . . . . . . . 19

1.4 .1 Feixes gaussianos . . . . . . . . . . . . . . . . . . . 19

1.4.2 Reflexão e transmissão numa cavidade ótica . . . . . . . . . . . . . . 20

1.5 Descrição clássica do $\mathrm{OPO} \ldots \ldots \ldots$. . . . . . . . . . . 22

II Desenvolvimento e resultados 27

2 Instrumentação 29

2.1 Laser de prova: Laser de diodo . . . . . . . . . . . . . . . . . . . 29

2.1.1 Laser de diodo $795 \mathrm{~nm}$ e cavidade Fabry-Perot . . . . . . . . . . 31

$2.1 .2 \quad$ AOM e dessintonia . . . . . . . . . . . . . . 32

2.1.3 Espectroscopia de absorção saturada . . . . . . . . . . . . . . . 34

2.2 Laser de bombeio: Laser titânio-safira . . . . . . . . . . . . 36 
2.2.1 Primeira tentativa: SDL8630 e laser de diodo . . . . . . . . . . . 36

2.2.2 Laser titânio-safira $795 \mathrm{~nm} \ldots \ldots$. . . . . . . . . . . . 37

2.3 Fibra ótica e ruídos não desejados . . . . . . . . . . . . . . . . 38

\section{Resultados e discussão 41}

3.1 Obtenção da mistura de quatro ondas . . . . . . . . . . . . . . . . . 41

3.1.1 Exemplo 1: Mistura de quatro ondas com dessintonia do bombeio de $\Delta=1.5 \mathrm{GHz} \ldots \ldots \ldots \ldots \ldots \ldots$

3.1.2 Exemplo 2: Mistura de quatro ondas com dessintonia do bombeio de $\Delta=-2.0 \mathrm{GHz} \ldots \ldots \ldots \ldots \ldots \ldots$

3.1.3 Caracterização da mistura de quatro ondas em função de diferentes parâmetros

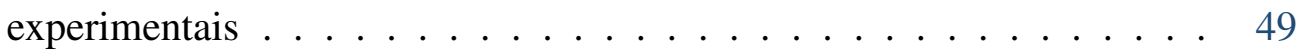

3.1.3.1 Coeficientes de absorção e amplificação . . . . . . . . . . . . 50

3.1.3.2 Ganho em função da dessintonia do bombeio . . . . . . . . . . . 51

3.1.3.3 Ganho em função da potência de bombeio . . . . . . . . . . . 54

3.1.3.4 Ganho em função da temperatura da célula . . . . . . . . . . . 59

3.2 Cavidade $\mathrm{OPO} \chi^{(3)} \ldots \ldots \ldots \ldots \ldots \ldots$. . . . . . . . . . . 61

3.2.1 Caracterização da finesse e transmissão fora do regime 4WM . . . . . . 63

3.2.2 Obtenção do OPO e caracterização do limiar de oscilação . . . . . . . . . 67

3.2.3 Próximos passos: Cavidades Fabry-Perot e de separação dos feixes . . . 72 


\section{Introdução}

O crescente interesse na área de informação quântica levou a diversos avanços na compreensão dos fundamentos da mecânica quântica, em especial do papel de correlações em sistemas complexos. Graças ao conceito do emaranhamento é possível realizar processos computacionais com maior eficiência baseando-se na manipulação quântica de informação, quando comparado a processos baseados em lógica binária clássica [30].

Infelizmente, limitações envolvendo a fragilidade do emaranhamento de estados à medida que sua complexidade aumenta impõem sérias limitações. Os limites de escalabilidade em eventuais processadores quânticos é um exemplo disso.

Por outro lado, sistemas óticos tem se mostrado uma excelente bancada de testes de fundamentos da informação quântica. Um dos melhores exemplos disso está no estudo da morte súbita de emaranhamento em variáveis discretas e contínuas [1, 3].

Além disso, pelo acoplamento controlado entre luz e átomos, a transferência de informação entre estes sistemas permite esperar que átomos alcalinos sejam empregados como memórias em etapas de processamento de informação. Tais sistemas são objeto de estudo no grupo LMCAL, e o uso de emaranhamento sintonizável permite a integração entre estes diversos componentes.

O Laboratório de Manipulação Coerente de Átomos e Luz (LMCAL) tem experiência no uso do Oscilador Paramétrico Ótico (OPO), sendo este um sistema gerador de feixes emaranhados. Um OPO consiste em um meio não linear inserido em uma cavidade ótica (fig. I), o

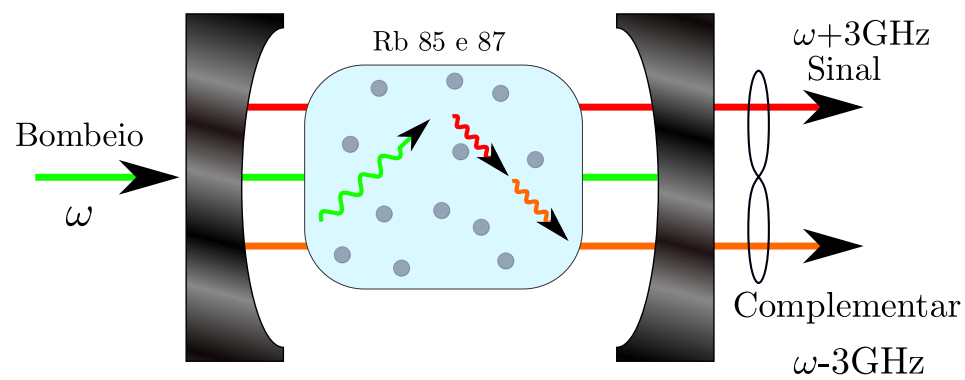

Figura I - Esquema geral da cavidade OPO $\chi^{3}$ com gás de átomos. Nesse trabalho, o meio de ganho são os átomos de Rubídio. 
qual é bombeado externamente por um feixe de frequência $\omega$. Dois fótons desse feixe são convertidos em um fóton do feixe sinal e um do fixe complementar, cada um deles com frequências diferentes. O interessante desses três feixes são as propriedades quânticas que eles compartilham. De fato uma das conquistas do grupo foi a primeira medida de emaranhamento entre mais de dois subsistemas produzidos diretamente por uma única fonte em um sistema de variáveis continuas. Esse corresponde ao emaranhamento tripartido entre os feixes de bombeio, sinal e complementar [11, 45].

Um exemplo de um meio não linear usado no OPO é um cristal com susceptibilidade quadrática $\left(\chi^{(2)}\right)$. Uma característica importante de um OPO desse tipo é a transição abrupta no limiar de oscilação. Esta transição vem como resultado da baixa porcentagem de ganho que o cristal tem da ordem de $4 \%$, levando assim à construção de cavidades muito fechadas. Como consequência são poucos os trabalhos experimentais que estudam propriedades quânticas perto do limiar de oscilação do OPO.

A mistura de quatro ondas é um processo paramétrico que acontece em meios com susceptibilidade cúbica $\left(\chi^{(3)}\right)$. Dois fótons de um feixe de bombeio são convertidos em um fóton do feixe sinal e um do feixe complementar (fig. II). No caso de meios atômicos como o ${ }^{85} \mathrm{Rb}$ os feixes sinal e complementar serão gerados a uma frequência de $\Delta \pm 3 \mathrm{GHz}$ respectivamente, em relação a dessintonia $\Delta$ de um feixe de intensidade alta. $\mathrm{O}$ valor $3 \mathrm{GHz}$ corresponde à diferença de frequência da separação hiperfina do estado fundamental (fig. IIa).

Esses feixes apresentam correlações quânticas e ganhos da ordem de $450 \%$. De fato já foram observadas a geração de estados de squeezing e estados emaranhados em sistemas de vapor de rubídio quente $[15,26,38]$.

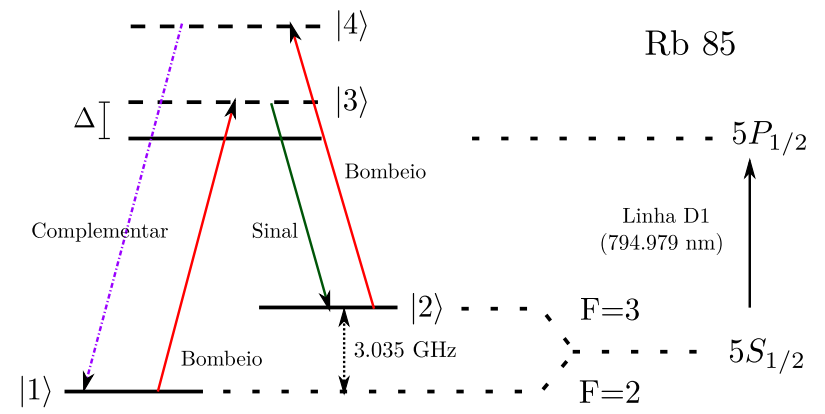

(a) Diagrama duplo- $\lambda$ da mistura de quatro ondas (4WM) na linha D1 do ${ }^{85} \mathrm{Rb}$.

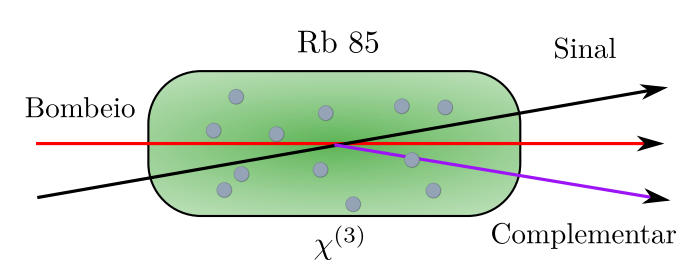

(b) Geometria. Pela conservação do momento o terceiro feixe é gerado numa outra direção.

Figura II - Representação do processo de Mistura de quatro ondas. fig. IIa nos possíveis níveis de transição e fig. IIb Representação espacial do processo dentro da célula de Rubídio. 
Devido aos altos ganhos obtidos nesses sistemas projetamos uma cavidade OPO bastante aberta, com os átomos de rubídio como meio não linear. Isto com o fim de obter uma transição suave pelo limiar de oscilação.

Na presente dissertação, foi descrita a construção e caracterização do limiar de oscilação do primeiro oscilador paramétrico ótico (OPO) com meio atômico gasoso de susceptibilidade $\chi^{(3)}$ não nula, construído no laboratório LMCAL.

No capítulo 1 realizamos uma revisão da teoria atômica do rubídio, do 4WM e à teoria clássica do OPO. No capítulo 2 apresentamos a instrumentação necessária para a obtenção do processo de $4 \mathrm{WM}$. No capítulo 3 caracterizamos o processo de $4 \mathrm{WM}$ em função de três parâmetros experimentais e obteve-se o OPO. Encontrou-se uma ótima região de frequências em torno a $\Delta=0.77 \mathrm{GHz}$ para a construção do OPO. A transição do limiar de oscilação deste OPO para diferentes dessintonias do feixe de bombeio foram abruptas. Porém, para a dessintonia $\Delta=0.38 \mathrm{GHz}$ a transição é suave. Esse é um passo importante para a obtenção de estados quânticos não gaussianos e o estudo experimental do comportamento de um OPO perto do limiar de oscilação. Por fim, são descritas as conclusões e perspectivas deste trabalho. 


\section{Parte I}

\section{Conceitos teóricos}





\section{Capítulo 1}

\section{Mistura de quatro ondas e OPO com átomos de rubídio}

Na primeira parte deste capítulo são descritas algumas características importantes que se referem aos átomos de rubídio [40,41], e como a velocidade de cada átomo gera o que é conhecido como alargamento Doppler [14]. Em seguida, o processo para obter as linhas hiperfinas de absorção, as quais são importantes no momento da estabilização e dessintonia dos laseres. Na segunda parte foi descrito como um processo não linear gerado pela não linearidade da nuvem de átomos de rubídio gera o processo base deste trabalho, a Mistura de Quatro Ondas, em base a $[5,15,20,36]$. Tudo isso a fim de introduzir os átomos de rubídio dentro de uma cavidade ótica e assim gerar o que se conhece como um Oscilador Paramétrico Ótico (OPO) [25].

\subsection{Estrutura hiperfina do ${ }^{85} R b e^{87} R b$}

Os átomos de rubídio pertencem ao grupo 1 da tabela periódica, conhecido como metais alcalinos, e seu número atômico $Z$ é 37 . A temperatura de fusão é $39,30^{\circ} \mathrm{C}$ e de ebulição é $688^{\circ} \mathrm{C}$. O rubídio foi descoberto por Robert Bunsen e Gustav Kirchhoff em 1861. Sua configuração eletrônica é $1 s^{2} 2 s^{2} 2 p^{6} 3 s^{2} 3 p^{6} 4 s^{2} 3 d^{10} 4 p^{6} 5 s^{1}$, tendo um único elétron no último nível de energia, de modo que é chamado de átomo hidrogenoide.

O rubídio tem dois isótopos naturais, o rubídio 85 com uma abundância de $72.12 \%$ e o rubídio 87 com $27.83 \%$, e possui energia de ionização de 4.17712706 (10)eV (dados retirados de $[40,41])$. Na fig. 1.1 e fig. 1.2 apresentam-se os níveis finos e hiperfinos de energia com os valores correspondentes. As transições $5^{2} S_{1 / 2} \longrightarrow 5^{2} P_{3 / 2}$ e $5^{2} S_{1 / 2} \longrightarrow 5^{2} P_{1 / 2}$, correspondem ao dubleto da estrutura fina. Usou-se a notação comum $n^{2 S+1} L_{J}$. 


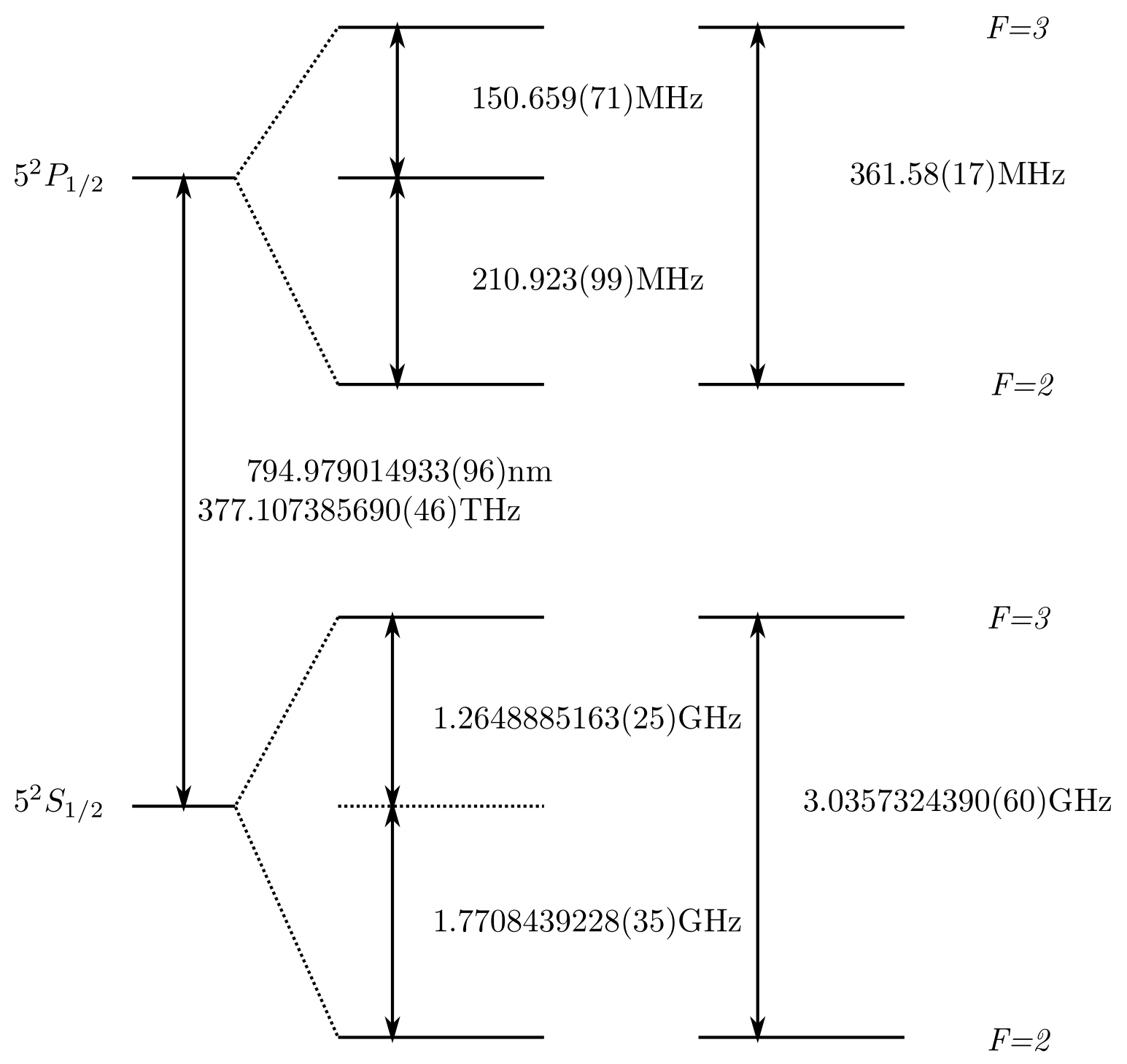

Figura 1.1 - Estrutura hiperfina de transição do ${ }^{85} \mathrm{Rb}$ na linha D1. Retirado de [41]

A estrutura fina é o resultado do acoplamento entre o momento angular $\mathbf{L}$ do elétron que encontra-se no último nível e do momento angular de spin $\mathbf{S}$, em que o momento angular total do elétron é $\mathbf{J}=\mathbf{L}+\mathbf{S}$, onde $|L-S| \leq J \leq L+S$ [2, 14]. Temos então:

- Para o estado fundamental do rubídio $85, \mathrm{~L}=0$ e $\mathrm{S}=1 / 2$, então $\mathrm{J}=1 / 2$. Em seguida para o primeiro estado excitado $\mathrm{L}=1$, então $\mathrm{J}=1 / 2$ e $\mathrm{J}=3 / 2$.

- Para o estado fundamental do rubídio $87, \mathrm{~L}=0$ e $\mathrm{S}=1 / 2$, então $\mathrm{J}=1 / 2$. Em seguida para o primeiro estado excitado $\mathrm{L}=1$, então $\mathrm{J}=1 / 2$ e $\mathrm{J}=3 / 2$. 


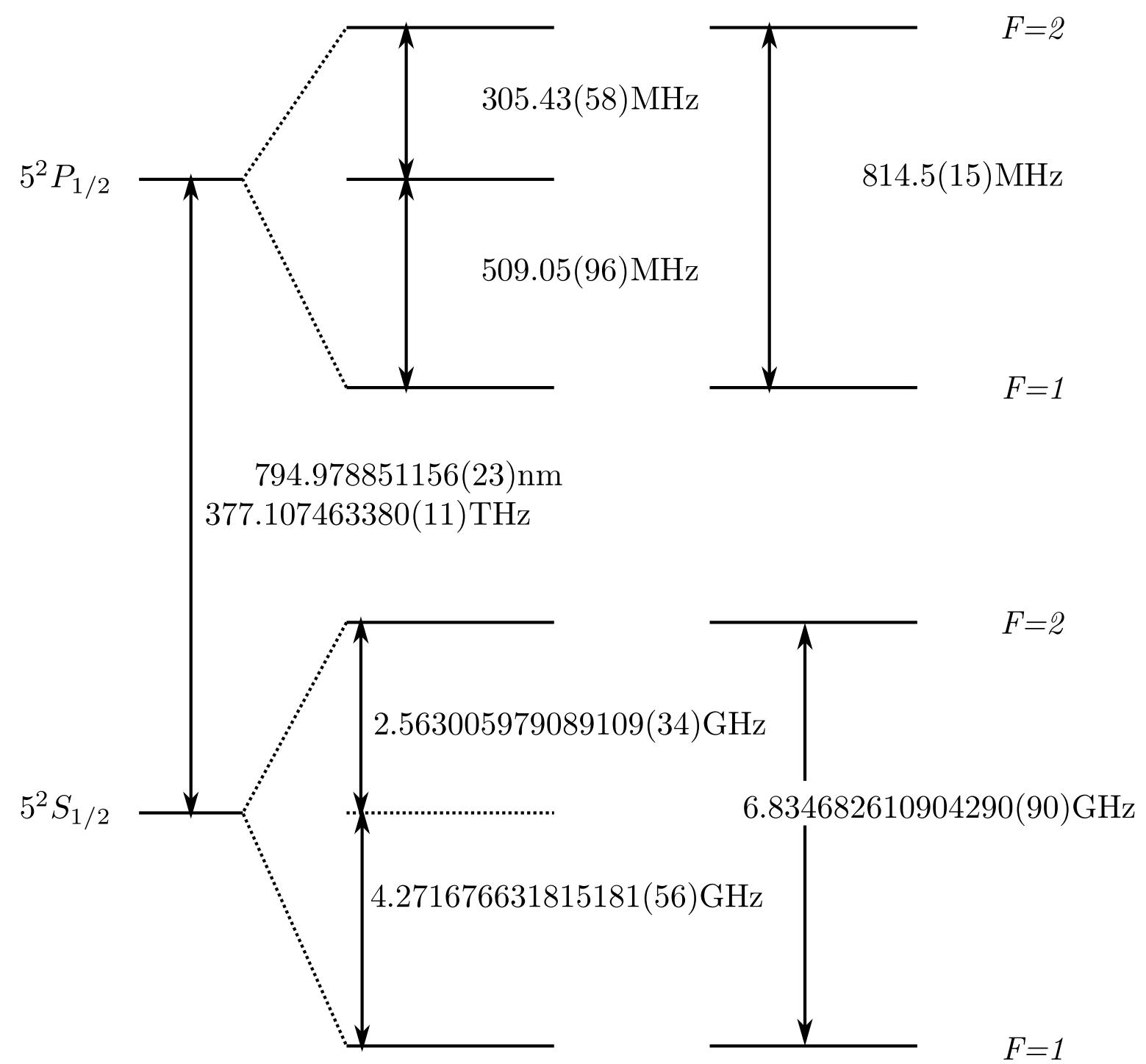

Figura 1.2 - Estrutura hiperfina de transição do ${ }^{87} R b$ na linha D1. Retirado de [40]

A estrutura hiperfina é resultado do acoplamento entre o momento angular total $\mathbf{J}$ do elétron e do momento angular total do núcleo $\mathbf{I}$, onde o momento angular total atômico é $\mathbf{F}=\mathbf{J}+\mathbf{I}$, e $|J-I| \leq F \leq J+I[2,14]$. De modo que:

- Para o estado fundamental do rubídio $85, \mathrm{~J}=1 / 2$ e $\mathrm{I}=5 / 2$, então $\mathrm{F}=2$ e $\mathrm{F}=3$. Em seguida para o estado excitado da linha $D_{2} 5^{2} P_{3 / 2} \mathrm{~F}=1,2,3,4$, e para o estado excitado da linha $D_{1} 5^{2} P_{1 / 2} \mathrm{~F}=2,3$.

- Para o estado fundamental do rubídio $87, \mathrm{~J}=1 / 2$ e $\mathrm{I}=3 / 2$, então $\mathrm{F}=1$ e $\mathrm{F}=2$. Em seguida para o estado excitado da linha $D_{2} 5^{2} P_{3 / 2} \mathrm{~F}=0,1,2,3$, e para o estado excitado da linha $D_{1} 5^{2} P_{1 / 2} \mathrm{~F}=1,2$. 


\subsubsection{Alargamento Doppler}

Neste trabalho utilizou-se gás de átomos de rubídio à temperatura ambiente ou aquecidos, dependendo do caso. Nesta seção será explicado as consequências do efeito Doppler e o modo de superar o alargamento de linha produzido, obtendo uma resolução próxima a linha natural, em base a [14].

Supondo-se que um daqueles átomos se movimenta com velocidade $v$ e um feixe de luz de frequência $\omega$ se propaga na mesma direção da velocidade do átomo. Como pode se apreciar na fig. 1.3, a relação da frequência da luz entre o sistema de referência do laboratório e o sistema de referência do átomo é $\omega_{1}$, onde $k=2 \pi / \lambda$. Para o caso em que o feixe se propaga em direção contraria, no sistema de referência do átomo a frequência da luz é $\omega_{2}$. Como consequência a componente relativa $k v$ gera o efeito Doppler.

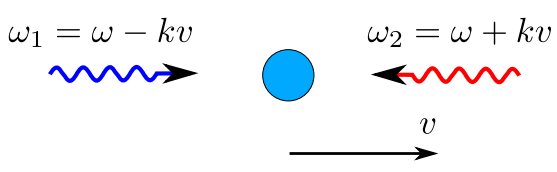

Figura 1.3 - Efeito Doppler.

Em geral a absorção em um nível de energia de um átomo tem uma largura de linha natural associada a uma função Lorentziana [37], porém podemos fazer uma simplificação a uma delta de Dirac que será explicada após. Considerando-se que um átomo absorbe radiação a uma frequência $\omega_{0}$ no seu sistema de referência, por conseguinte $\omega_{1}=\omega_{0}$ e cada átomo vai absorver radiação quando $\delta=\omega-\omega_{0}=k v$ ou

$$
\frac{\delta}{\omega_{0}}=\frac{v}{c}
$$

Como trabalhou-se com um gás quente de átomos, a fração de átomos com a velocidade entre $v$ e $v+d v$ é baseada na distribuição de Maxwell-Boltzmann:

$$
f(v) d v=\sqrt{\frac{M}{2 \pi k_{B} T}} \exp \left(-\frac{M v^{2}}{2 k_{B} T}\right) d v=\frac{1}{u \sqrt{\pi}} \exp \left(-\frac{v^{2}}{u^{2}}\right) d v
$$

onde $u=\sqrt{2 k_{B} T / M}$ é a velocidade mas provável para uma temperatura T e uma massa $\mathrm{M}$ de átomos. Relacionando a velocidade $v$ com a frequência $\omega$, fazendo uso da eq. (1.1.1), obtêm-se que a absorção tem um comportamento gaussiano:

$$
g_{D}(\omega)=\frac{c}{u \omega_{0} \sqrt{\pi}} \exp \left[-\frac{c^{2}}{u^{2}}\left(\frac{\omega-\omega_{0}}{\omega_{0}}\right)^{2}\right], \quad \int_{-\infty}^{\infty} g_{D}(\omega)=1,
$$


Este efeito é conhecido como alargamento Doppler, e faz com que as linhas de absorção hiperfinas do rubídio sejam escondidas. Este alargamento é uma função da temperatura, e como neste trabalho usou-se uma célula de rubídio previamente esquentada, a largura de linha do alargamento doppler (ao redor de $1 \mathrm{GHz}$ ) é muito maior do que a largura natural (ao redor de $6 \mathrm{MHz}$ ). As técnicas experimentais mais conhecidas para obter espectroscopia livre do alargamento Doppler são o método dos feixes cruzados, espectroscopia de absorção saturada e espectroscopia de dois fótons [14].

Neste trabalho só foi utilizada a espectroscopia de absorção saturada, a qual foi de muita importância no momento de travamento em frequência dos laseres. A teoria por trás da espectroscopia saturada é resumida da seguinte forma.
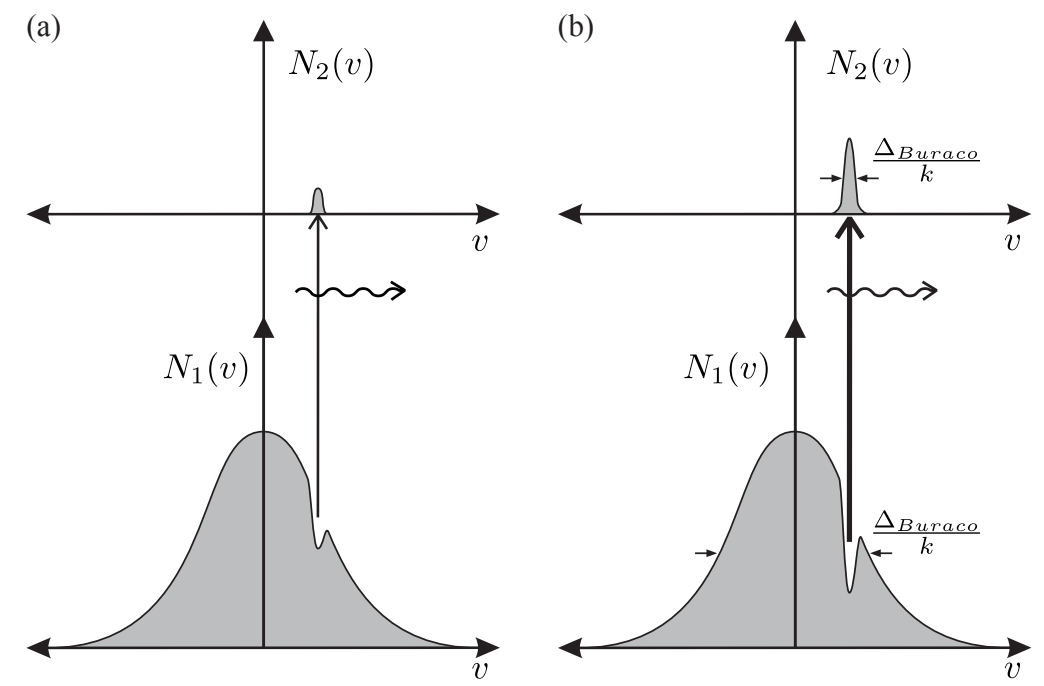

Figura 1.4 - Absorção dos átomos em função da velocidade. Na figura (a) tem-se um feixe de baixa intensidade, diferente da figura (b) onde a intensidade é maior, gerando assim um buraco maior na distribuição de velocidades dos átomos no nível fundamental. Figura retirada de [14]

Supondo um átomo de dois níveis 1 e 2, com o nível 1 sendo o estado fundamental. A densidade de número de átomos com velocidade na faixa $v$ e $v+d v$ no estado fundamental é $N_{1}(v)=N_{1} f(v)$, com $f(v)$ eq. (1.1.1) e $N$ sendo a densidade total de átomos do gás, de modo que $N=N_{1}+N_{2}$ e

$$
\int_{-\infty}^{\infty} N_{i}(v) d v=N_{i} \quad i=1,2
$$

A quantidade $N_{1}(v)-N_{2}(v)$ é afetada pela potência do laser, como pode-se observar na fig. 1.4, onde na parte da direita a potência do feixe é maior do que na esquerda, gerando assim um buraco maior na distribuição do número de átomos e levando uma maior quantidade de átomos 
para o estado exitado. O feixe interatua com os átomos que possuem uma velocidade $v=$ $\left(\omega-\omega_{0}\right) / k$. O buraco gerado pelo feixe com potência $I$ tem uma largura:

$$
\Delta \omega_{\text {Buraco }}=\Gamma\left(1+\frac{I}{I_{\text {sat }}}\right)^{1 / 2},
$$

onde $I_{\text {sat }}$ é a intensidade de saturação e $\Gamma$ é a largura natural da linha. Para o rubídio 85 e 87 na linha D1 e na transição $5^{2} S_{1 / 2} \rightarrow 5^{2} P_{1 / 2}$ temos $\Gamma=2 \pi 5.7500(56) \mathrm{MHz}$.

Divida-se o feixe em dois, um com potência alta chamado de bombeio e o outro com pôtencia baixa chamado de prova, fazendo com que eles tenham a mesma direção de propagação que na fig. 1.3. Caso o laser tenha uma frequência afastada da ressonância, $\left|\omega-\omega_{0}\right| \gg$ $\Delta \omega_{\text {Buraco, }}$, obtêm-se a fig. 1.5 da direita e da esquerda, onde o bombeio não vai afetar o feixe de prova, já que eles interagem com átomos de velocidades diferentes. Porém, no caso perto da ressonância $\omega \simeq \omega_{0}$, os dois feixes interagem com átomos que tem velocidades $v \simeq 0$, como consequência o bombeio satura muitos átomos, diminuindo a absorção do feixe de prova. Ao colocar um detector na direção do feixe de prova depois de passar pela nuvem aprecia-se um pico como na fig. 1.5. Esse jeito de obter as linhas de absorção se chama absorção saturada, e foi usada na montagem experimental.

\subsection{Polarizabilidade não linear e mistura de quatro ondas}

As propriedades óticas dos materiais mudam com a presença da luz. Considerando o momento dipolar por unidade de volume ou polarização $P(t)$, o qual no caso de óptica linear, depende linearmente do campo eléctrico aplicado da seguinte forma

$$
P(t)=\epsilon_{0} \chi^{(1)} E(t)
$$

em que a constante de proporcionalidade $\chi^{(1)}$ é conhecida como a susceptibilidade linear e $\epsilon_{0}$ é a permissividade do espaço livre. Em um caso mais geral, quando a resposta do material é não linear ao campo electromagnético aplicado, chama-se de fenômeno ótico não linear [5]. Nessa situação é preciso generalizar a eq. (1.2.1),

$$
\begin{aligned}
& P(t)=\epsilon_{0}\left[\chi^{(1)} E(t)+\chi^{(2)} E^{2}(t)+\chi^{(3)} E^{3}(t)+\cdots\right] \\
& P(t)=P^{(1)}(t)+P^{(2)}(t)+P^{(3)}(t)+\cdots,
\end{aligned}
$$

onde os termos $\chi^{(2)}$ e $\chi^{(3)}$ são conhecidos como susceptibilidades de segunda e terceira ordem, e em geral essas quantidades são tensores. Na eq. (1.2.1) e eq. (1.2.2) foram feitas as suposições 


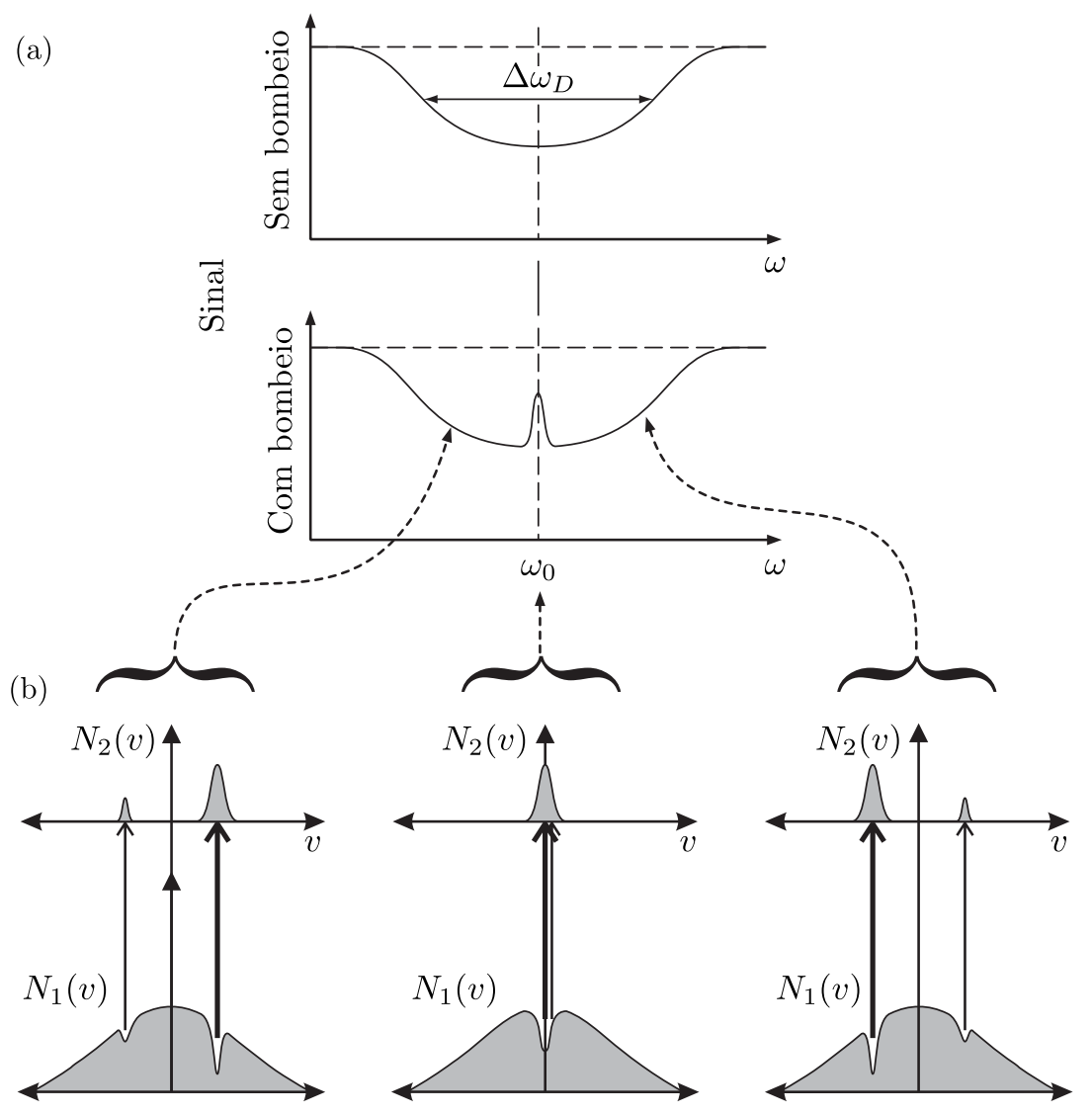

Figura 1.5 - Absorção saturada. Sinal saturado e sem saturar. Quando $v \simeq 0$, o bombeio satura a maioria dos átomos e o feixe de prova não é absorvido, gerando assim um pico no espectro. Figura retirada de [14]

de que a polarização no tempo $t$ depende instantaneamente do valor do campo, o que quer dizer que o meio é sem perdas e sem dispersão. Essas equações tem que ser generalizadas para esses condições. Processos não lineares de segunda ordem $\left(P^{(2)}(t)\right)$ só podem acontecer em cristais não centrossimétricos, em outras palavras, em cristais que não exibem simetria de inversão. Sólidos amorfos como o vidro, líquidos, alguns cristais e gases exibem simetria de inversão de modo que o termo $\chi^{(2)}$ é nulo. No caso, para este trabalho foi utilizada a nuvem de átomos de rubídio que possui o termo $\chi^{(2)}=0$ e o termo $\chi^{(3)} \neq 0$.

\subsubsection{Processos de segunda ordem $\chi^{(2)}$}

Supondo-se um campo aplicado sobre um meio não linear de segunda ordem que é representado como a soma de duas componentes $\omega_{1}$ e $\omega_{2}$

$$
E(t)=E_{1} e^{-i \omega_{1} t}+E_{2} e^{-i \omega_{2} t}+c . c
$$


onde $c . c$ é o termo complexo conjugado. Substituindo na eq. (1.2.2), obtém-se

$$
\begin{aligned}
P^{(2)}(t) & =\epsilon_{0} \chi^{(2)} E^{2}(t) \\
P^{(2)}(t) & =\epsilon_{0} \chi^{(2)}\left[E_{1}^{2} e^{-2 i \omega_{1} t}+E_{2}^{2} e^{-2 i \omega_{2} t}+2 E_{1} E_{2} e^{-i\left(\omega_{1}+\omega_{2}\right) t}+2 E_{1} E_{2}^{*} e^{-i\left(\omega_{1}-\omega_{2}\right) t}+\text { c.c }\right] \\
& +2 \epsilon_{0} \chi^{(2)}\left[E_{1} E_{1}^{*}+E_{2}^{*} E_{2}\right]
\end{aligned}
$$

Reescrevendo o resultado com a notação $P^{(2)}(t)=\Sigma_{n} P\left(\omega_{n}\right) e^{-i \omega_{n} t}$, a amplitude complexa dos vários fenômenos gerados é

$$
\begin{aligned}
P\left(2 \omega_{1}\right) & =\epsilon_{0} \chi^{(2)} E_{1}^{2}, \quad P\left(2 \omega_{2}\right)=\epsilon_{0} \chi^{(2)} E_{2}^{2}, \\
P\left(\omega_{1}+\omega_{2}\right) & =2 \epsilon_{0} \chi^{(2)} E_{1} E_{2}, P\left(\omega_{1}-\omega_{2}\right)=2 \epsilon_{0} \chi^{(2)} E_{1} E_{2}^{*}, \\
P(0) & =2 \epsilon_{0} \chi^{(2)}\left(E_{1} E_{1}^{*}+E_{2} E_{2}^{*}\right) .
\end{aligned}
$$

Os termos $P\left(2 \omega_{1}\right)$ e $P\left(2 \omega_{2}\right)$ representam a geração do segundo harmônico (fig. 1.6a), o termo $P\left(\omega_{1}+\omega_{2}\right)$ representa a geração da soma de frequência (fig. 1.6b), o termo $P\left(\omega_{1}-\omega_{2}\right)$ a geração da diferença de frequência (fig. 1.6c), e finalmente o termo $P(0)$ a retificação de frequência onde um campo eléctrico estático é criado dentro do meio não linear.

(a) Geração do segundo harmonico

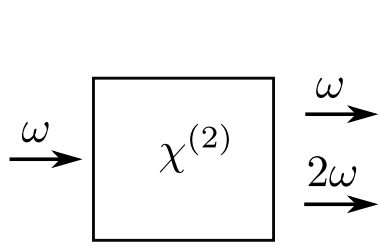

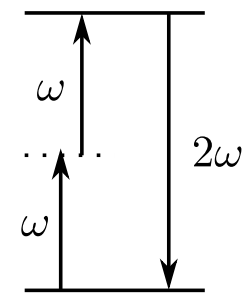

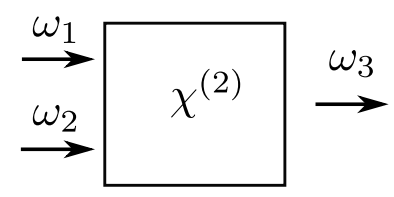

(b) Geração da soma de frequência

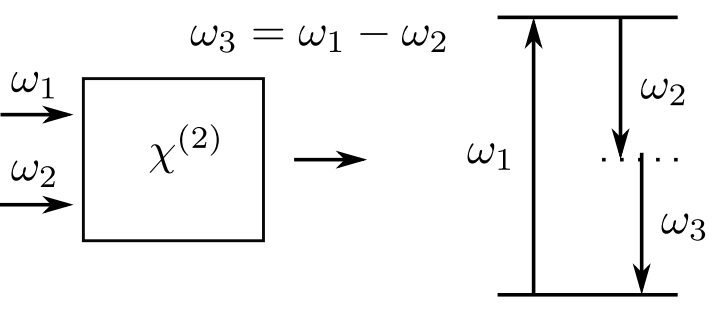

(c) Geração da diferença de frequência

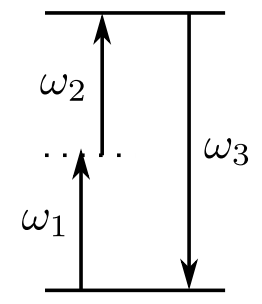

Figura 1.6 - Possíveis processos num meio não linear quadrático. Contrariamente aos processos de segundo harmônico e de soma de frequência, o processo de diferença de frequência tem um processo paramétrico de amplificação. Figuras retiradas de [5]

Como consequência esse sistema acopla três modos do campo, o qual é conhecido como mistura de três ondas e é a base para entender o oscilador paramétrico ótico OPO com 
meio $\chi^{(2)}[6,25]$. Uma aplicação do processo de soma de frequência é a produção de luz sintonizável na faixa do ultravioleta, escolhendo $\omega_{1}$ como a saída de um laser visível fixo e $\omega_{2}$ como a saída de um laser visível sintonizável. Em segundo lugar, o processo de diferença de frequência pode ser usado para gerar luz na faixa do infravermelho, com as mesmas entradas $\omega_{1}$ e $\omega_{2}$ como no exemplo anterior.

A diferença do que acontece no processo de soma de frequência, no processo de diferença de frequência, a conservação da energia diz que um fóton $\omega_{3}=\omega_{1}-\omega_{2}$ e um fóton do $\omega_{2}$ são criados, como consequência de que um fóton do feixe de entrada $\omega_{1}$ é aniquilado. Por conseguinte, o feixe com menor frequência $\omega_{2}$ é amplificado, e por essa razão o processo é chamado de Amplificação paramétrica ótica. Esse processo é de muita importância no tratamento da mistura de quatro ondas.

\subsubsection{Processos de terceira ordem $\chi^{(3)}$}

O próximo processo estudado acolhe os processos de terceira ordem. No caso de um campo aplicado consistente de três frequências diferentes

$$
E(t)=E_{1} e^{-i \omega_{1} t}+E_{2} e^{-i \omega_{2} t}+E_{3} e^{-i \omega_{3} t}+\text { c.c. }
$$

fazer o cálculo do termo $P^{(3)}(t)$ se torna mais complexo, gerando assim as possíveis combinações, a seguir

$$
\begin{array}{r}
\omega_{1}, \omega_{2}, \omega_{3}, 3 \omega_{1}, 3 \omega_{2}, 3 \omega_{3},\left(\omega_{1}+\omega_{2}+\omega_{3}\right),\left(\omega_{1}+\omega_{2}-\omega_{3}\right), \\
\left(\omega_{1}-\omega_{2}+\omega_{3}\right),\left(-\omega_{1}+\omega_{2}+\omega_{3}\right),\left(2 \omega_{1} \pm \omega_{2}\right),\left(2 \omega_{1} \pm \omega_{3}\right),\left(2 \omega_{2} \pm \omega_{1}\right), \\
\left(2 \omega_{2} \pm \omega_{3}\right),\left(2 \omega_{3} \pm \omega_{1}\right),\left(2 \omega_{3} \pm \omega_{2}\right)
\end{array}
$$

Das possíveis combinações na equação eq. (1.2.7), algumas valem a pena destacar. Os termos $\omega_{i}$ com i=1,2,3 tem uma amplitude cúbica $P\left(3 \omega_{i}\right)=\epsilon_{0} \chi^{(3)} E_{i}^{3}$, o qual corresponde a geração de terceiro harmônico. Além disso, por exemplo o termo $P\left(\omega_{1}\right)$, gera uma contribuição não linear no índice de refração em que podemos escrevê-lo como

$$
n=n_{0}+n_{2} I, \quad n_{2}=\frac{3}{2 n_{0}^{2} \epsilon_{0} c} \chi^{(3)}, \quad I=\frac{1}{2} n_{0} \epsilon_{0} c E^{2}
$$

onde $n_{0}$ é o conhecido índice linear à baixa intensidade. Como o índice de refração fica dependendo da intensidade $I$ do feixe, um processo importante para tomar em conta no experimento é o processo de auto-focalização (self-focusing) o qual pode fazer com que o meio atue como uma lente focalizando o feixe e gerando o risco de estraga-lo [15]. 


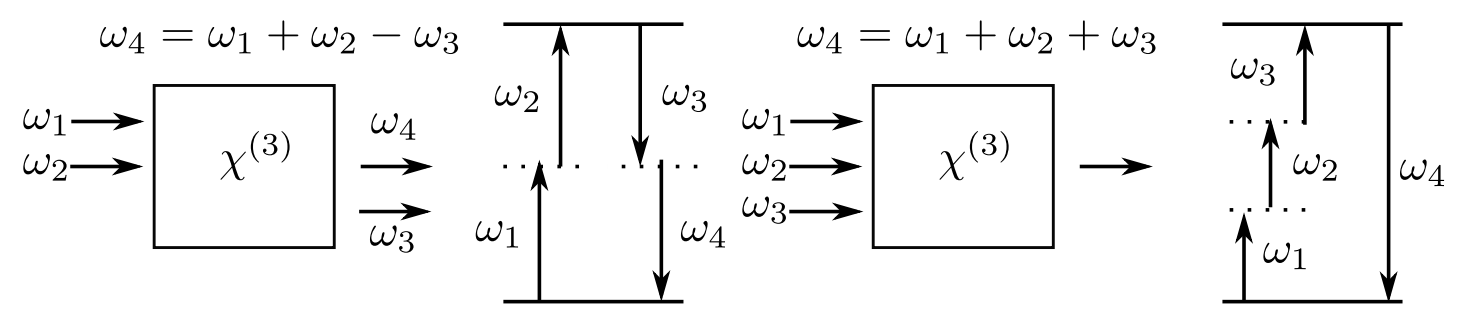

(a) Processo no qual o fóton $\omega_{3}$ é amplificado e é (b) Processo no qual os três fótons são absorvidos gerado um foton com $\omega_{4}$. e é gerado só um fóton.

Figura 1.7 - Possíveis processos num meio não linear de terceira ordem. Em fig. 1.7a tem-se um exemplo de mistura de quatro ondas. Figuras retiradas de [5]

O processo $\left(\omega_{1}+\omega_{2}+\omega_{3}\right)$ na fig. $1.7 \mathrm{~b}$ é um processo de soma de frequência análogo ao fig. 1.6b. Ao contrário, os processos $\left(\omega_{1}+\omega_{2}-\omega_{3}\right),\left(\omega_{1}+\omega_{3}-\omega_{2}\right),\left(\omega_{2}+\omega_{3}-\omega_{1}\right)$ são processos em que temos amplificação de um dos feixes. Por exemplo, na fig. 1.7a o feixe com frequência $\omega_{3}$ é amplificado e o feixe com frequência $\omega_{4}$ gerado, logo é a base da mistura de quatro ondas (Four-Wave Mixing).

\subsubsection{Espalhamento Raman}

Um processo importante para ter em conta antes de começar o estudo da mistura de quatro ondas é o espalhamento Raman [5], descoberto perlo C.V.Raman en 1928. Para poder observar o espalhamento Raman espontâneo, basta jogar um feixe de luz com frequência conhecida num meio (solido liquido ou gás) e fazer espectroscopia da luz espalhada. Na espectroscopia vão ser observados feixes com frequência dessintonizada da frequência do feixe original. Este fenômeno é usado para o cálculo de energias vibracionais de moléculas. Os feixes dessintonizados a menores frequências são chamados de componentes Stokes (fig. 1.8a), pelo contrário, aqueles dessintonizados a maiores frequências são chamados de componentes Anti-Stokes (fig. 1.8b).

Sobre a incidência de um feixe de intensidade alta é possível obter o espalhamento Raman estimulado, o qual tem uma eficiência alta, perto de $10 \%$ da energia do laser incidente é convertida a frequência de Stokes $\omega_{s}$. No processo de mistura de quatro ondas é necessário fazer a diferença dos dois possíveis canais usados. A nomenclatura dos canais Stokes e Anti-Stokes foi usada. Essa nomenclatura usada para a espectroscopia foi apropriada pela física atômica para descrever transições em meio atômicos sem envolver níveis vibracionais. 


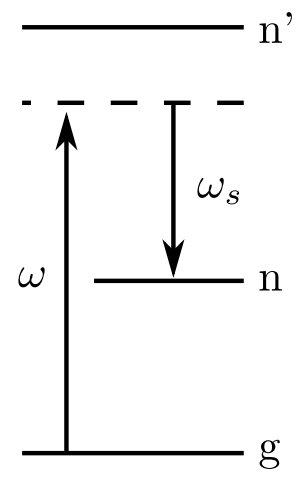

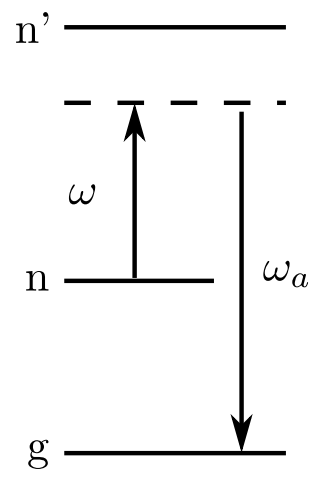

(a) Espalhamento Raman onde o feixe $\omega_{s}$ entra (b) Espalhamento Raman onde o feixe $\omega_{a}$ entra pelo canal Stokes.

Figura 1.8 - Possíveis canais no espalhamento Raman. Figuras retiradas de [5]

\subsection{Mistura de quatro ondas (4WM)}

A mistura de quatro ondas é um processo paramétrico que acontece em meios não lineares. O processo paramétrico está determinado pelo fato de que os estados inicial e final do sistema são idênticos. A população do estado fundamental só pode ser removida dele por um instante de tempo no qual reside num estado virtual. Baseados no princípio da incerteza, como consequência, a população pode residir naquele estado virtual por um tempo da ordem de $\hbar / \delta E$, onde $\delta E$ é a diferença de energia entre o estado virtual e o estado mais próximo. Contrariamente, processos que têm transferência de população de um nível a outro são chamados de processos não-paramétricos [5]. Algumas aplicações de interesse significativo do processo de 4WM são a possibilidade de geração de ondas com fase conjugada com aplicações em ótica adaptativa [36] , em que a conjugação de fase é equivalente a reversão do tempo. Além disso, o 4WM é uma fonte importante de estados de luz comprimidos ou squeezing [2, 20, 26, 36]. Em seguida, será descrito o processo de mistura de quatro ondas clássica e quanticamente, em base a $[15,20]$.

\subsubsection{Abordagem clássica do 4WM}

Um campo chamado de bombeio de potência alta $E_{3}\left(\vec{k}_{3}, \omega_{3}\right)$ com vetor de onda $\vec{k}_{3}$ e frequência $\omega_{3}$ é injetado num meio com susceptibilidade não linear $\chi^{(3)}$ e comprimento L. Além disso, um segundo campo de baixa potência em relação ao bombeio e chamado de prova, $E_{1}\left(\vec{k}_{1}, \omega_{1}\right)$, com vetor de onda $\vec{k}_{1}$ e frequência $\omega_{1}$, forma um pequeno ângulo $\theta$ com a direção de propagação do bombeio. Os dois feixes atravessam o meio, e como consequência o feixe de prova é amplificado e é gerado um terceiro feixe chamado de conjugado, $E_{2}\left(\vec{k}_{2}, \omega_{2}\right)$, com vetor 
de onda $\vec{k}_{2}$ e frequência $\omega_{2}$ (ver fig. 1.9b). Nesse sistema temos conservação de energia que pode ser descrita como

$$
2 \omega_{3}-\omega_{1}-\omega_{2}=0
$$

também conhecida como acordo de frequência. A conservação do momento

$$
2 \vec{k}_{3}-\vec{k}_{1}-\vec{k}_{2}=0
$$

que deve ser satisfeita para que haja casamento de fase. Em geral o valor de $k_{j}$ depende como $k_{j}\left(\nu_{j}\right)=\nu_{j} n\left(\nu_{j}\right) / c \operatorname{com} n\left(\nu_{j}\right)$ o incide de refração o qual em materiais dispersivos é dependente da frequência. Nesse caso $2 k_{3}-k_{1}-k_{2}=\Delta k$ é diferente de zero e é conhecido como (phase mismatch). É feita a aproximação de que $\Delta k=0$.

O nome mistura de quatro ondas tem origem no processo em que interagem dois fótons do bombeio, um fóton do feixe conjugado e um do prova, como pode se apreciar na conservação do momento na fig. 1.9c e no diagrama de energias na fig. 1.9a. Os campos são assumidos como linearmente polarizados, escrevendo cada um deles como

$$
E_{j}(z, t)=\frac{1}{2} \varepsilon_{j}(z) e^{i\left(k_{j} z-\omega_{j} t\right)}+c . c .
$$

com $\mathrm{j}=1,2,3$, e $\varepsilon_{j}$ a amplitude complexa de cada campo. Com o fim de calcular os campos ao atravessar o meio, usa-se as equações de onda no vácuo na presença de um meio com polarização [5, 19]

$$
\nabla^{2} E-\frac{1}{c^{2}} \frac{\partial^{2} E}{\partial t^{2}}=\frac{1}{\epsilon_{0} c^{2}} \frac{\partial^{2} P}{\partial t^{2}}
$$

como a direção de propagação é em $z$, a equação se reduz

$$
\frac{\partial^{2} E}{\partial z^{2}}-\frac{1}{c^{2}} \frac{\partial^{2} E}{\partial t^{2}}=\frac{1}{\epsilon_{0} c^{2}} \frac{\partial^{2} P}{\partial t^{2}},
$$

onde o campo total é a soma dos três campos

$$
E(z, t)=E_{1}(z, t)+E_{2}(z, t)+E_{3}(z, t),
$$

e a polarizabilidade é

$$
P(z, t)=\chi^{(3)} E^{3}(z, t)
$$


com $\chi^{(3)}$ a susceptibilidade do meio. Ao inserir eq. (1.3.3) e eq. (1.3.5) em eq. (1.3.4), e fazendo uso da chamada aproximação de envelope lentamente variável [36]

$$
\left|\frac{\partial^{2} \varepsilon_{i}}{\partial z^{2}}\right| \ll\left|k_{i} \frac{\partial \varepsilon_{i}}{\partial z}\right|,
$$

obtemos

$$
\sum_{j=1}^{3} i k_{j} \frac{\partial \varepsilon_{j}(z)}{\partial z} e^{i\left(k_{j} z-\omega_{j} t\right)}=\frac{1}{\epsilon_{0} c^{2}} \frac{\partial^{2} P(z, t)}{\partial t^{2}},
$$

de todos os possíveis termos gerados ao inserir eq. (1.3.3) e eq. (1.3.5) em eq. (1.3.6), só permanece o que corresponde a condição eq. (1.3.2), obtendo assim duas equações acopladas

$$
k_{1} \frac{\partial \varepsilon_{1}(z)}{\partial z} e^{i\left(k_{1} z-\omega_{1} t\right)}=\frac{i \omega_{1}^{2}}{\epsilon_{0} c^{2}} P_{1}(z, t), \quad k_{2} \frac{\partial \varepsilon_{2}(z)}{\partial z} e^{i\left(k_{2} z-\omega_{2} t\right)}=\frac{i \omega_{2}^{2}}{\epsilon_{0} c^{2}} P_{2}(z, t),
$$

onde os termos $P_{i}(z, t)$ são

$$
\begin{aligned}
& P_{1}(z, t)=\frac{3 \chi^{(3)}}{8}\left(\varepsilon_{1}^{2} \varepsilon_{1}^{*}+2 \varepsilon_{1} \varepsilon_{2} \varepsilon_{2}^{*}+2 \varepsilon_{1} \varepsilon_{3} \varepsilon_{3}^{*}+2 \varepsilon_{3} \varepsilon_{3} \varepsilon_{2}^{*}\right) e^{i\left(k_{1} z-\omega_{1} t\right)} \\
& P_{2}(z, t)=\frac{3 \chi^{(3)}}{8}\left(\varepsilon_{2}^{2} \varepsilon_{2}^{*}+2 \varepsilon_{2} \varepsilon_{1} \varepsilon_{1}^{*}+2 \varepsilon_{2} \varepsilon_{3} \varepsilon_{3}^{*}+2 \varepsilon_{3} \varepsilon_{3} \varepsilon_{1}^{*}\right) e^{i\left(k_{2} z-\omega_{2} t\right)}
\end{aligned}
$$

como o bombeio é intenso, pode-se fazer a aproximação $\left|\varepsilon_{1,2}\right|^{2} \ll\left|\varepsilon_{3}\right|^{2}$ desprezando assim os termos quadráticos do feixe de prova e do conjugado. As duas equações acopladas passam a ser

$$
k_{1} \frac{\partial \varepsilon_{1}(z)}{\partial z}=i \frac{\omega}{c}\left(\gamma \varepsilon_{1}(z)+\eta \varepsilon_{2}^{*}(z)\right), \quad k_{2} \frac{\partial \varepsilon_{2}(z)}{\partial z}=i \frac{\omega}{c}\left(\gamma \varepsilon_{2}(z)+\eta \varepsilon_{1}^{*}(z)\right)
$$

nas quais as constantes $\gamma$ e $\eta$ são definidas como

$$
\gamma=\frac{3 \chi^{(3)} \omega}{4 \epsilon_{0} c}\left|\varepsilon_{3}\right|^{2}, \quad \eta=\frac{3 \chi^{(3)} \omega}{4 \epsilon_{0} c} \varepsilon_{3}^{2}
$$

Nesse ponto, pode-se fazer a mudança de variáveis $\tilde{\varepsilon}_{j}=\varepsilon_{j} e^{-i k z}$ para simplificar as equações, e como resultado

$$
\frac{\partial \tilde{\varepsilon}_{1}}{\partial z}=i \eta \tilde{\varepsilon}_{2}^{*}, \quad \frac{\partial \tilde{\varepsilon}_{2}^{*}}{\partial z}=-i \eta \tilde{\varepsilon}_{1} .
$$

Essas equações podem ser resolvidas em função das condições de contorno. Conhecendo as amplitudes do campo de prova $\tilde{\varepsilon}_{1}(0)$ e conjugado $\tilde{\varepsilon}_{2}(0)$ no começo do meio não linear, obtêm- 
se as soluções

$$
\begin{gathered}
\tilde{\varepsilon}_{1}(z)=\cosh (|\eta| z) \tilde{\varepsilon}_{1}(0)+i \frac{\eta}{|\eta|} \sinh (|\eta| z) \tilde{\varepsilon}_{2}^{*}(0), \\
\tilde{\varepsilon}_{2}^{*}(z)=-i \frac{\eta^{*}}{|\eta|} \sinh (|\eta| z) \tilde{\varepsilon}_{1}(0)+\cosh (|\eta| z) \tilde{\varepsilon}_{2}^{*}(0),
\end{gathered}
$$

e no caso em que apenas o bombeio e o prova interagem com o meio, como na fig. 1.9b, o feixe do conjugado é nulo em $z=0, \tilde{\varepsilon}_{2}(0)=0$ e o prova $\tilde{\varepsilon}_{1}(0)=\tilde{\varepsilon}_{i n}$, a solução é

$$
\begin{aligned}
& \tilde{\varepsilon}_{1}(z)=\tilde{\varepsilon}_{i n} \cosh (|\eta| z) \\
& \tilde{\varepsilon}_{2}(z)=i \frac{\eta}{|\eta|} \tilde{\varepsilon}_{i n}^{*} \sinh (|\eta| z) .
\end{aligned}
$$

As intensidades dos campos de prova $\varepsilon_{1}$ e do conjugado $\varepsilon_{2}$ na saída do meio $(z=L)$ são

$$
\begin{aligned}
& \left|\tilde{\varepsilon}_{1}(L)\right|^{2}=\left|\tilde{\varepsilon}_{i n}\right|^{2} \cosh ^{2}(|\eta| z) \\
& \left|\tilde{\varepsilon}_{2}(L)\right|^{2}=\left|\tilde{\varepsilon}_{i n}\right|^{2} \sinh ^{2}(|\eta| z)
\end{aligned}
$$

em que podemos atribuir o parâmetro de ganho $G$ ao processo

$$
\begin{aligned}
\left|\tilde{\varepsilon}_{1}(L)\right|^{2} & =G\left|\varepsilon_{i n}\right|^{2} \\
\left|\tilde{\varepsilon}_{2}(L)\right|^{2} & =(G-1)\left|\varepsilon_{i n}\right|^{2} \\
G & =\cosh ^{2}(|\eta| L) .
\end{aligned}
$$

Concluímos que o feixe de prova é amplificado ao atravessar o meio por um fator $G$ sendo função de $\chi^{(3)}$ do meio, o campo de bombeio $E_{3}$, e do comprimento $L$ do meio. Além disso, é criado um feixe conjugado $E_{2}$ com intensidade que depende do ganho $G$ e da intensidade inicial do feixe de prova.

\subsubsection{Abordagem quântica do 4WM}

Uma abordagem fenomenológica do processo de mistura de quatro ondas na configuração duplo- $\lambda$ pode ser feita pensando em um modelo de três modos de Fock para fazer a descrição quântica dos estados dos feixes de bombeio, prova e conjugado, como feito em [15]. No processo descrito na fig. 1.9a, dois fótons do bombeio são aniquilados e são gerados um fóton do conjugado e um fóton do prova. Chamam-se aos operadores de aniquilação associados 


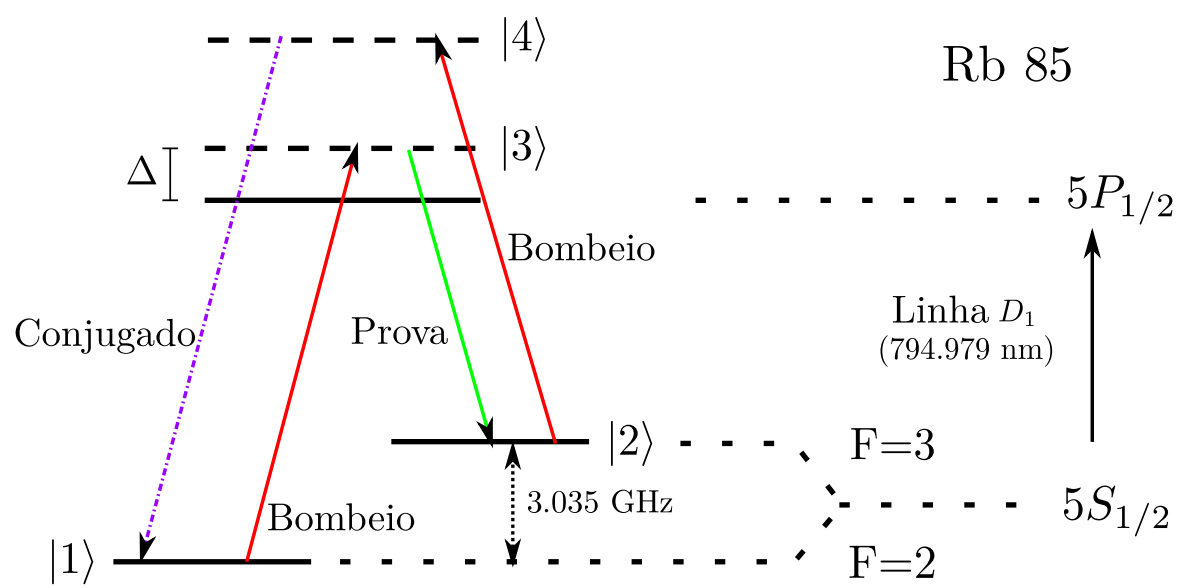

(a) Configuração duplo- $\lambda$. Dois fótons do bombeio são absorvidos, e são criados um fóton do feixe conjugado e um do prova.

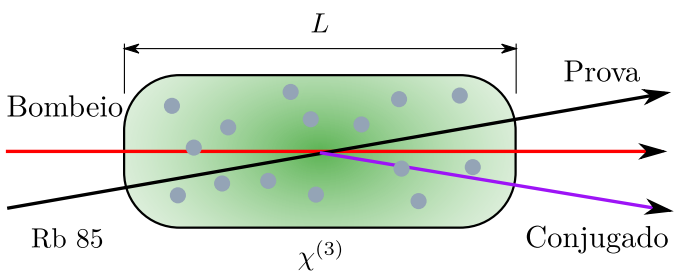

(b) Geometria para a obtenção do processo

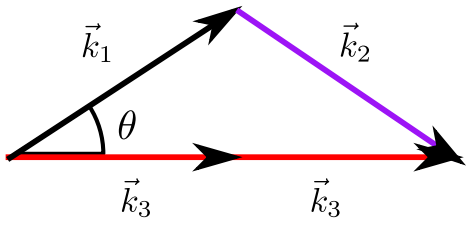

(c) Conservação do momento com $k_{1}=k_{2}$

Figura 1.9 - Mistura de Quatro Ondas.

aos três campos de $\hat{a}_{1}, \hat{a}_{2}$ e $\hat{a}_{3}$, para os campos de prova, conjugado e bombeio respectivamente, e ao parâmetro de interação de $\beta$. O hamiltoniano de interação é

$$
\hat{H}_{I}=i \hbar \beta \hat{a}_{1}^{\dagger} \hat{a}_{3} \hat{a}_{2}^{\dagger} \hat{a}_{3}+\text { h.c. }
$$

em que h.c. é o operador hermitiano conjugado. Para começar, foram feitas duas considerações, a primeira é que o bombeio é muito intenso como consequência os estados inicial e final são os mesmos, em segundo lugar, que o feixe do bombeio é um estado coerente $\left|\alpha_{3}\right\rangle$, logo após $\hat{a}_{3}\left|\alpha_{3}\right\rangle=\alpha_{3}\left|\alpha_{3}\right\rangle$. Na literatura, essa aproximação é conhecida como aproximação de bombeio não depletido [36]. Baseado nessa aproximação, substitui-se $\hat{a}_{3} \rightarrow \alpha_{3}$ no hamiltoniano, então $\alpha_{3}^{2}=\left|\alpha_{3}\right|^{2} e^{i 2 \theta} \propto I_{3} e^{i 2 \theta}$, onde dize-se que $\alpha_{3}^{2}$ é proporcional à intensidade do feixe. Fazendo uma mudança de variáveis $\xi=\beta \alpha_{3}^{2}$ obtém-se

$$
\hat{H}_{I}=i \hbar \xi \hat{a}_{1}^{\dagger} \hat{a}_{2}^{\dagger}+h . c .
$$


O operador de evolução temporal $\hat{U}(t)$ e o operador de compressão de dois modos ou two-mode squeezing operator $\hat{S}(\tau)[24,36]$, são similares

$$
\hat{U}(t)=e^{-i \hat{H}_{I} t / \hbar}=e^{-\xi\left(\hat{a}_{1} \hat{a}_{2}-\hat{a}_{2}^{\dagger} \hat{a}_{1}^{\dagger}\right)} \longleftrightarrow \hat{S}(\tau)=e^{s\left(\hat{a}_{2}^{\dagger} \hat{a}_{1}^{\dagger}-\hat{a}_{1} \hat{a}_{2}\right)}
$$

onde supõe-se que a interação no meio não linear acontece em um tempo característico $\tau$ e onde $s=\xi \tau$ é o parâmetro de compressão. Para obter a evolução temporal dos operadores de aniquilação $\hat{a}_{1}$ e $\hat{a}_{2}$, faz-se uso da representação de Heisenberg [2]

$$
\frac{d \hat{a}_{1}}{d t}=\frac{i}{\hbar}\left[\hat{H}_{I}, \hat{a}_{1}\right]=\xi \hat{a}_{2}^{\dagger} \quad \frac{d \hat{a}_{2}}{d t}=\frac{i}{\hbar}\left[\hat{H}_{I}, \hat{a}_{2}\right]=\xi \hat{a}_{1}^{\dagger}
$$

realizando o cálculo da segunda derivada, a solução das eq. (1.3.27) é

$$
\hat{a}_{1}(t)=\hat{a}_{1}(0) \cosh (\xi t)+\hat{a}_{2}^{\dagger}(0) \sinh (\xi t), \quad \hat{a}_{2}(t)=\hat{a}_{2}(0) \cosh (\xi t)+\hat{a}_{1}^{\dagger}(0) \sinh (\xi t) .
$$

Supondo que a interação acontece no tempo $\tau$ que os feixes levam para atravessarem o meio,

$$
\hat{a}_{1} \rightarrow \hat{a}_{1} \cosh (s)+\hat{a}_{2}^{\dagger} \sinh (s), \quad \hat{a}_{2} \rightarrow \hat{a}_{2} \cosh (s)+\hat{a}_{1}^{\dagger} \sinh (s) .
$$

fazendo uso da propriedade de adição do operador $\hat{S}$

$$
\hat{S}\left(s_{1}\right) \hat{S}\left(s_{2}\right)=\hat{S}\left(s_{1}+s_{2}\right)
$$

O estado inicial do feixe conjugado é vácuo, então $\left\langle\hat{N}_{\hat{a}_{2}}\right\rangle=0$. Aplicando a transformação aos operadores número, os feixes depois do processo são

$$
\begin{aligned}
&\left\langle\hat{N}_{\hat{a}_{1}}\right\rangle \rightarrow \cosh ^{2}(s)\left\langle\hat{a}_{1}^{\dagger} \hat{a}_{1}\right\rangle+\sinh ^{2}(s) \cong G\left\langle\hat{a}_{1}^{\dagger} a_{1}\right\rangle \\
&\left\langle\hat{N}_{\hat{a}_{2}}\right\rangle \rightarrow \sinh ^{2}(s)\left\langle\hat{a}_{1}^{\dagger} \hat{a}_{1}\right\rangle+\sinh ^{2}(s) \cong(G-1)\left\langle\hat{a}_{1}^{\dagger} a_{1}\right\rangle \\
&\left\langle\hat{N}_{\hat{a}_{1}}+\hat{N}_{\hat{a}_{2}}\right\rangle \cong(2 G-1)\left\langle\hat{a}_{1}^{\dagger} a_{1}\right\rangle \\
&\left\langle\hat{N}_{\hat{a}_{1}}-\hat{N}_{\hat{a}_{2}}\right\rangle \cong\left\langle\hat{a}_{1}^{\dagger} a_{1}\right\rangle
\end{aligned}
$$

onde o parâmetro $G=\cosh ^{2}(s)$ é o ganho do feixe de prova. Isto quer dizer que o feixe de prova é amplificado e o feixe do conjugado é criado, obtendo assim o mesmo resultado fenomenológico que no tratamento clássico. É possível continuar com o tratamento e demostrar que a mistura de quatro ondas gera estados comprimidos o de squeezing em base à eq. (1.3.26), eq. (1.3.33) e eq. (1.3.34), como nas referências [4,36]. Além disso já foi medido experimentalmente, como nos caso das referências [16, 20, 26]. 


\subsection{Cavidades óticas}

A seguir, será feito um estudo teórico do comportamento dos parâmetros importantes dos feixes de luz, assim como das propriedades de uma cavidade ótica [22, 28, 35, 37]. Como está descrito no desenvolvimento experimental, as cavidades óticas foram usadas para diagnosticar a luz usada, como régua e como separador de feixes com frequências distintas. Além disso e ainda mais importante, para a construção do OPO com meio atômico $\chi^{(3)}$.

\subsubsection{Feixes gaussianos}

As equações de Maxwell no espaço livre para uma onda monocromática harmônica de frequência $\omega$ tem a forma da conhecida equação de Helmholtz, seguindo as referências [19, 22], onde se mostra

$$
\left(\nabla^{2}+k^{2}\right) E(x, y, z)=0
$$

em que $E(x, y, z)$ é a amplitude complexa do campo para uma componente de polarização do vetor campo elétrico e $k=n \omega / c$, de modo que podemos escrever o campo como

$$
\frac{E(x, y, z)}{E_{0}}=\psi(x, y, z) e^{-i k z}
$$

Substituindo eq. (1.4.2) em eq. (1.4.1) e fazendo a aproximação paraxial

$$
\left|\frac{\partial^{2} \psi}{\partial z^{2}}\right| \ll 2 k\left|\frac{\partial \psi}{\partial z}\right|, \quad\left|\frac{\partial^{2} \psi}{\partial z^{2}}\right| \ll\left|\frac{\partial^{2} \psi}{\partial x^{2}}\right|,\left|\frac{\partial^{2} \psi}{\partial y^{2}}\right|,
$$

onde o primeiro termo está relacionado com a variação lenta da propagação na escala de $\lambda \mathrm{e}$ o segundo com a variação lenta na escala das componentes transversais da onda, obtemos a equação de onda paraxial

$$
\left(\frac{\partial^{2}}{\partial x^{2}}+\frac{\partial^{2}}{\partial y^{2}}-2 i k \frac{\partial}{\partial z}\right) \psi(x, y, z)=0 .
$$

Assumindo uma solução para a equação paraxial da forma

$$
\psi_{0} \propto \exp \left(-i P(z)+\frac{k r^{2}}{2 q(z)}\right)
$$


em que $\psi_{0}$ refere-se ao modo fundamental gaussiano transverso eletromagnético $T E M_{00}$, e $q(z)$ ao raio de curvatura complexo, obtém-se

$$
i P(Z)=\log \left[1-i \frac{z}{z_{R}}\right], \quad q(z)=z+i z_{R} .
$$

Por fim, a expressão do campo elétrico para o $T E M_{00}$ é

$$
\frac{E(x, y, z)}{E_{0}}=\frac{\omega_{0}}{\omega(z)} \exp \left[-\frac{r^{2}}{\omega^{2}(z)}-i \frac{k r^{2}}{2 R(z)}-i(k z-\phi(z))\right]
$$

onde cada termo representa: o comprimento de Rayleigh $z_{R}=\pi n \omega_{0}^{2} / \lambda_{0}$, a cintura do feixe gaussiano $\omega_{0}=\sqrt{2 z_{R} / k}=\sqrt{\lambda_{0} z_{R} / n \pi}$, o tamanho do feixe $\omega(z)=\omega_{0} \sqrt{1+z^{2} / z_{R}^{2}}$, o raio de curvatura $R(z)=z\left[1+z_{R}^{2} / z^{2}\right]$, e a fase de Gouy $\phi(z)=\tan ^{-1}\left(z / z_{R}\right)$.
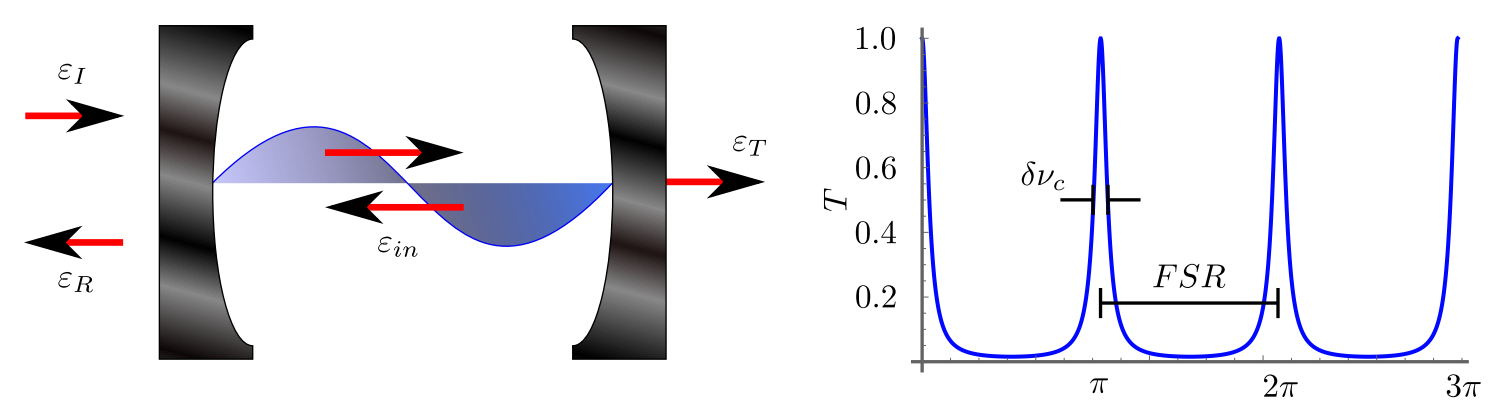

(a) Esquema geral de uma cavidade ótica. Modos (b) Transmissão da cavidade. Uma cavidade de da luz são permitidos dentro da cavidade. $F S R=\pi$ e finesse $F=50$.

Figura 1.10 - Cavidade Fabry-Perot. Um campo incidente $\varepsilon_{I}$ é refletido $\varepsilon_{R}$ e transmitido $\varepsilon_{T}$. Os espelhos tem em geral um coeficiente de transmissão e reflexão.

\subsubsection{Reflexão e transmissão numa cavidade ótica}

Um interferômetro ou cavidade Fabry-Perot é composta por dois espelhos, cada um deles com coeficientes de reflexão $R_{i}=r_{i}^{2}$ e transmissão $T_{i}=t_{i}^{2}$, respectivamente (ver fig. 1.10). Assim a intensidade da luz dentro da cavidade é uma função das propriedades óticas e geométricas dos espelhos e ao mesmo tempo das propriedades espectrais e geométricas do feixe de luz incidente. Além disso, a intensidade transmitida e a refletida é função da intensidade dentro da cavidade, por conseguinte elas são usadas como objeto de diagnóstico das fontes de luz em um experimento. Considerando o exemplo mais simples no qual a cavidade é feita por espelhos planos e o feixe incide perpendicularmente ao plano do espelho. Então

$$
\varepsilon_{I}=\varepsilon_{0} e^{i \omega t-i k z}
$$


em que $\varepsilon_{0}$ é a amplitude complexa do campo elétrico. Cada espelho tem duas fases revestidas, de modo que ele atua como espelho em qualquer uma das duas caras dependendo dos valores de $R$ e $T$. A absorção não é considerada, então a expressão da conservação da energia se transforma na relação $R_{i}+T_{i}=1$. Definiu-se a distância $L$ como aquela entre os dois espelhos, como resultado a distância $2 L$ é chamada de perímetro da cavidade. A onda incidente é refletida e transmitida parcialmente pelo primeiro espelho de modo que obtém-se

$$
\varepsilon_{t 1}=t_{1} \varepsilon_{I}, \quad \varepsilon_{r 1}=-r_{1} \varepsilon_{I}
$$

A onda transmitida ganhará uma fase $t_{1} e^{-i k L} \varepsilon_{I}$ ao percorrer o comprimento L, chegando assim ao segundo espelho e sendo parcialmente transmitido $\left(t_{2} t_{1} e^{-i k L} \varepsilon_{I}\right)$ e refletido $\left(r_{2} t_{1} e^{-i k L} \varepsilon_{I}\right)$. É claro que a parte refletida pelo segundo espelho vai percorrer mais uma vez o comprimento $\mathrm{L}$ e bater no primeiro espelho, sendo mais uma vez parcialmente refletido e ganhando uma fase $\left(r_{1} r_{2} t_{1} e^{-2 i k L} \varepsilon_{I}\right)$, e parcialmente transmitido $\left(t_{1} r_{2} t_{1} e^{-2 i k L} \varepsilon_{I}\right)$. Neste ponto pode-se reescrever

$$
r_{1} r_{2} t_{1} e^{-2 i k L} \varepsilon_{I}=r_{1} r_{2} e^{-2 i k L} \varepsilon_{t 1}=\eta \varepsilon_{t_{1}}
$$

onde o fator $\eta=r_{1} r_{2} e^{-2 i k L}$ representa o fator multiplicativo depois de uma volta pela cavidade. Agora, faz-se a soma de todas as infinitas reflexões internas

$$
\varepsilon_{i n}=\Sigma_{n=0}^{\infty} t_{1} e^{-i k L} \varepsilon_{I} \eta^{n}=\frac{t_{1} e^{-i k L}}{1-r_{1} r_{2} e^{-2 i K L}} \varepsilon_{I}
$$

em que $\varepsilon_{i n}$ é a amplitude complexa dentro da cavidade, e a amplitude transmitida é $\varepsilon_{T}=t_{2} \varepsilon_{i n}$. O coeficiente de transmissão é definido como a relação entre o campo transmitido e o refletido $T=\left|\varepsilon_{T} / \varepsilon_{I}\right|$, obtendo assim a transmissão

$$
T=\frac{1-R_{1} R_{2}-R_{1}-R_{2}}{1+R_{1} R_{2}-2 \sqrt{R_{1} R_{2}} \cos (2 k L)},
$$

e da conservação da energia

$$
R=\frac{R_{1}+R_{2}-2 \sqrt{R_{1} R_{2}} \cos (2 k L)}{1+R_{1} R_{2}-2 \sqrt{R_{1} R_{2}} \cos (2 k L)}
$$

Baseando-se nessa informação, ao colocar um detector na saída transmitida, obtém-se um espectro como na fig. $1.10 \mathrm{~b}$, onde é observada a intensidade de transmissão de uma cavidade 
Fabry-Perot. É importante definir: a Finesse da cavidade como

$$
F=\frac{F S R}{\delta \nu_{c}}
$$

o intervalo espectral livre (FSR-Free Spectral Range) $F S R=\Delta \nu_{c}=c / 2 L$ e a largura de banda $\delta \nu_{c}$ da cavidade que é a largura à meia altura dos picos de ressonância [22]. A finesse representa a amplificação do campo dentro da cavidad, o FSR o inverso do tempo que toma para um fóton percorrer a cavidade, e a largura de banda o inverso do tempo médio em que um fóton permanece dentro da cavidade [46]. Para o caso da Fabry-Perot temos

$$
F=\pi \frac{\left(R_{1} R_{2}\right)^{1 / 4}}{1-\sqrt{R_{1} R_{2}}} .
$$

\subsection{Descrição clássica do OPO}

Um meio não linear pode acoplar campos de diferentes frequências, como já foi estudado para o caso de susceptibilidade $\chi^{(2)}$ e $\chi^{(3)}$. A mistura de quatro ondas é um exemplo de acoplamento entre os campos de bombeio, prova e conjugado (fig. 1.9). Ao inserir o meio não linear no interior de uma cavidade, é possível fazer que os campos gerados oscilem, o que é conhecido como oscilador paramétrico ótico (OPO) [6, 25]. O meio amplificador, que no caso deste trabalho são os átomos de rubídio, pode levar à oscilação do OPO quando o ganho gerado pelo meio é maior do que as perdas da cavidade. Quando acontece isto o OPO gera feixes de potência média não nula, em outras palavras quando é superado o limiar de oscilação do OPO.

Um esquema geral de um OPO esta representado na fig. 1.11, em que um feixe de bombeio entra na cavidade, interage com o meio não linear e gera um feixe sinal e um complementar com frequências em geral diferentes à frequência do bombeio.

A forma básica de um OPO é a uniressonante SROPO (single resonant OPO). Neste caso a cavidade é construída para que apenas um modo fique ressonante. O bombeio pode então atravessar a cavidade e só interage com o meio não linear para gerar os feixes sinal e complementar. O feixe complementar ficaria ressonante com a cavidade. O limiar de oscilação deste SROPO não é otimizado.

Uma outra opção é no caso de dois modos ressonantes dentro da cavidade conhecido como DROPO (double resonant OPO). Os modos sinal e complementar são permitidos dentro da cavidade, fazendo que o limiar de oscilação seja reduzido. As condições de conservação de energia e ressonância dupla fazem que este tipo de OPO não apresente uma possível variação contínua na frequência de saída dos feixes, como é o caso do SROPO em que é possível variar a frequência do feixe sinal. 
Uma terceira opção é quando três modos são ressonantes, o qual é conhecido como TROPO (triple resonant OPO). A diferença dos outros dois casos, a condição de ressonância para o bombeio permite que a potência no interior da cavidade aumente, gerando assim uma redução no limiar de oscilação. Este sistema leva a efeitos como bistabilidade e inestabilidade no OPO. De fato em trabalhos do grupo, como no caso de [17, 25], foram estudadas as propriedades do TROPO com meios não lineares $\chi^{(2)}$ e $\chi^{(3)}$ respectivamente. Neste trabalho

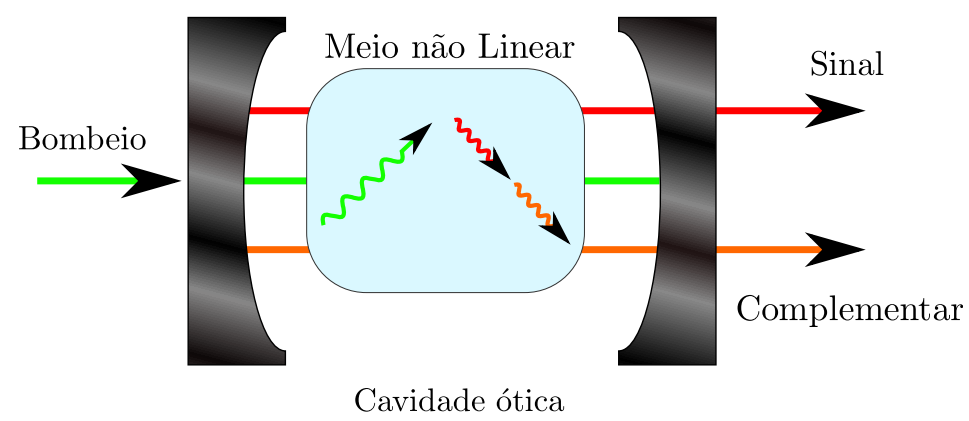

Figura 1.11 - Esquema geral de um oscilador paramétrico ótico OPO. Um meio de ganho não linear é bombeado com um laser de alta potência, gerando assim um feixe sinal e um complementar. Os átomos de rubídio vão ser usados como meio de ganho (fig. I)

construiu-se um OPO duplo-ressonante (DROPO) em que o feixe de bombeio entra na cavidade, estimula o processo de mistura de quatro ondas e é expulsado sem ressonar.

O processo de mistura de quatro ondas escolheu-se por duas razoes importantes, a primeira é que já foram medidas correlações fortes entre os feixes conjugado e prova, como explicado nos trabalhos experimentais nas referências [16, 26, 49]. A segunda razão precisa de uma explicação mais extensa.

A função de Wigner é uma função de quase-probabilidade que possibilita a representação de um estado quântico no espaço de fase, com uma discussão aprofundada em [2, $4,36,47]$. Esta função apresenta propriedades similares a uma distribuição de probabilidade, não entanto ela pode apresentar valores negativos e é por essa razão que é chamada de quasepropabilidade. Esta função facilita a caracterização e representação de estados não clássicos, e é muito usada no campo da ótica quântica para caracterizar estados da luz. Um estado é chamado de estado gaussiano quando a sua função de Wigner representa uma função gaussiana no estado de fase.

Por outro lado, o hamiltoniano é o gerador da evolução temporal e quando este é linear faz que um estado inicialmente gaussiano evolucione em um outro estado gaussiano. Acontece o mesmo para um hamiltoniano bi-linear, como é o caso da eq. (1.3.25) que representa o hamiltoniano do 4WM, com algumas aproximações feitas. Contrariamente à atuação de um hamiltoniano bi-linear, um hamiltoniano não bi-linear como é o caso da eq. (1.3.24) do 4WM 
como um caso mas geral, gera estados não gaussianos. Vale a pena repetir a eq. (1.3.24),

$$
\hat{H}_{I}=i \hbar \beta \hat{a}_{1}^{\dagger} \hat{a}_{3} \hat{a}_{2}^{\dagger} \hat{a}_{3}+\text { h.c. }
$$

O carácter não linear é gerado pelo termo quadrático $\hat{a}_{3}$ e $\hat{a}_{3}^{\dagger}$ que representa a aniquilação de dois fótons do bombeio para gerar assim um fóton do feixe conjugado e um do prova. Cada operador pode escrever-se linearizado como

$$
\hat{a}_{i}=\alpha_{i} \hat{I}+\delta \hat{a}_{i}
$$

em que $\hat{I}$ é a identidade, $\alpha_{i}$ representa o campo "clássico"e $\delta \hat{a}_{i}$ as flutuações do campo. Quando inseridos dentro de uma cavidade os átomos de rubídio, é formado o OPO. No caso do bombeio ser intenso, $\hat{a}_{3}=\alpha_{3} \hat{I}$ o campo é considerado clássico e é possível chegar na eq. (1.3.25). Esse caso corresponde a uma região muito acima do limiar de oscilação do OPO.

No outro extremo a intensidade do bombeio é baixa e menor do que o limiar de oscilação do OPO, porém ainda pode ser considerada como clássica $\hat{a}_{3}=\alpha_{3} \hat{I}$. Nesse caso o valor médio dos campos dos campos sinal e complementar é nulo, $\left\langle\hat{a}_{1,2}\right\rangle=0$. Como consequência esses dos campos só apresentam flutuações do vácuo, $\hat{a}_{i}=\delta \hat{a}_{i}$ e a eq. (1.5.1) vira

$$
\hat{H}_{I}=i \hbar \beta \alpha_{3}^{2} \delta \hat{a}_{1}^{\dagger} \delta \hat{a}_{2}^{\dagger}+\text { h.c. }
$$

O hamiltoniano ainda é bi-linear, fazendo que os campos de saída do OPO sejam estados gaussianos.

O terceiro caso é próximo ao limiar de oscilação. Nesse caso o bombeio sofre de depleção gerando assim que a intensidade média dos dois campos sinal e complementar sejam não nulos. Como o bombeio sofre depleção, não é possível considera-lo um campo clássico, então $\hat{a}_{i}=\alpha_{i} \hat{I}+\delta \hat{a}_{i}$ para os três campos não é uma aproximação valida. Para esse caso a eq. (1.5.1) não pode ser aproximado, e como consequência de ser não linear pode fazer que a saída do OPO sejam estados não gaussianos a partir de estados gaussianos.

Como conclusão e útil trabalhar perto do limiar de oscilação do OPO para poder observar produção de estados não gaussianos. Porém a transição pelo limiar de oscilação de um OPO é abrupta, dificultando a caracterização experimental. Esta transição abrupta é consequência do baixo ganho dos meios não lineares dentro da cavidade, fazendo que as cavidades sejam muito fechadas. Esse é o caso de meios $\chi^{(2)}$ em que o ganho é da ordem de $4 \%$.

Nesse ponto entra a vantagem de trabalhar com a mistura de quatro ondas em meios atômicos gerados pela susceptibilidade $\chi^{(3)}$. O ganho gerado pelo 4WM é da ordem de $400 \%$, como será estudado na parte experimental e anteriormente observado em trabalhos experimen- 
tais tais como $[15,20,26]$, de modo que possibilita a construção de cavidades óticas muito abertas e que se espera que gerará uma transição pelo limiar de oscilação suave. O objetivo desse experimento é, além de obter e caracterizar a mistura de quatro ondas, utiliza-la para poder construir um OPO $\chi^{(3)}$ com transição suave pelo limiar de oscilação.

\section{Possíveis considerações futuras}

O hamiltoniano do processo de terceira ordem $\chi^{(3)}$ pode ter uma forma bem mais complexa,

$$
\begin{array}{r}
\hat{H}_{i n t}^{(3)}=-\hbar\left[\chi_{S P M}^{(3)}\left(\hat{a}_{b}^{\dagger} \hat{a}_{b}^{\dagger} \hat{a}_{b} \hat{a}_{b}+\hat{a}_{s}^{\dagger} \hat{a}_{s}^{\dagger} \hat{a}_{s} \hat{a}_{s}+\hat{a}_{c}^{\dagger} \hat{a}_{c}^{\dagger} \hat{a}_{c} \hat{a}_{c}\right)+\right. \\
\left.\chi_{C P M}^{(3)}\left(\hat{a}_{b}^{\dagger} \hat{a}_{s}^{\dagger} \hat{a}_{b} \hat{a}_{s}+\hat{a}_{b}^{\dagger} \hat{a}_{c}^{\dagger} \hat{a}_{b} \hat{a}_{c}+\hat{a}_{s}^{\dagger} \hat{a}_{c}^{\dagger} \hat{a}_{s} \hat{a}_{c}\right)+\chi_{4 W M}^{(3)}\left(\hat{a}_{s}^{\dagger} \hat{a}_{c}^{\dagger} \hat{a}_{b} \hat{a}_{b} e^{-i \Delta k z}+\hat{a}_{b}^{\dagger} \hat{a}_{b}^{\dagger} \hat{a}_{s} \hat{a}_{c} e^{i \Delta k z}\right)\right],
\end{array}
$$

em que $\chi_{4 W M}^{(3)}, \chi_{S P M}^{(3)}$ e $\chi_{C P M}^{(3)}$ são proporcionais à susceptibilidade $\chi^{(3)}$ e com pesos desconhecidos para nosso sistema, como explicado na referência [17]. O primeiro termo em parêntesis é chamado de auto-modulação de fase (self-phase modulation), o segundo termo de modulação de fase cruzada (cross-phase modulation) e o último é o termo já conhecido de mistura de quatro ondas (4WM). Porém o termo de $4 \mathrm{WM}$ apresenta uma fase $i \Delta k z$ que vai depender do comprimento $z$ da iteração com o meio e o termo i $\Delta k$. O valor $\Delta k=2 k_{b}-k_{s}-k_{c}$ em geral é não nulo para meios dispersivos, em outras palavras para meios em que o índice de refração depende da frequência $(n=n(\omega))$.

Os dois termos de modulação de fase não afectam a intensidade dos feixes pelo fato de eles comutarem com o operador número $\hat{n}_{j}=\hat{a}_{j}^{\dagger} \hat{a}_{j}$ para o bombeio sinal e complementar $(j=b, s, c)$ respectivamente.

$\mathrm{Na}$ referência [17] foram desenvolvidas as propriedades da luz emitidas por um oscilador paramétrico ótico tipo $\chi^{(3)}$ com o hamiltoniano eq. (1.5.4), que é mais completo do que o eq. (1.3.25) ao inserir os termos de modulação de fase e de phase mismatch. É importante ter em conta esses termos como possíveis processos que possam acontecer e ou afetar o comportamento OPO para caracterizações experimentais futuras além deste trabalho. 


\section{Parte II}

\section{Desenvolvimento e resultados}





\section{Capítulo 2}

\section{Instrumentação}

O primeiro passo para conseguir a mistura de quatro ondas é escolher o sistema atômico que será utilizado, tendo em mente os possíveis laseres que possam ser montados para o comprimento de onda equivalente à diferença de frequência entre os estados hiperfinos do sistema atômico. As linhas de emissão D1 e D2 (ver fig. 1.1 e fig. 1.2), com os respectivos comprimentos de onda 795nm e 780nm para os isótopos de rubídio 85 e 87 [40, 41], são escolhidos pela sua versatilidade no momento de montar um laser com esses comprimentos de onda. Laseres de diodo que emitem nesses comprimentos de onda são baratos e o grupo tem experiência na montagem de cavidades abertas para à sintonização no comprimento desejado.

Nesse trabalho, utilizamos apenas a linha D1 do mesmo modo que em [15, 20, 26, 27 , $31,32]$, portanto precisamos construir laseres no comprimento de onda de $795 \mathrm{~nm}$. Um laser de diodo que gera baixa potência (40 mW máximo) é escolhido para ser usado como feixe de Prova. Por outro lado o laser Ti:Sapphire ou Titânio-Safira que gera uma potência máxima de 1 W, foi usado como feixe de Bombeio. Será descrita a construção e as diferentes caracterizações feitas para ter certeza que os laseres trabalham no comprimento desejado, alguns problemas e a preparação prévia para obter o processo paramétrico de mistura de quatro ondas.

\subsection{Laser de prova: Laser de diodo}

Inicialmente, dois diodos laseres da TOPTICA PHOTONICS no comprimento de onda próximo de $785 \mathrm{~nm}$ foram escolhidos. Em experiências de física atômica, diodos laseres da família GaAS, os quais emitem luz nas faixas do visível e perto do infravermelho, são de muita versatilidade no momento de fazer espectroscopia [9, 23, 29, 33]. Comumente, um diodo laser tem uma dupla hétero estrutura, com um pequeno guia de onda de comprimento $\mathrm{S}$, como na fig. 2.1. O meio ativo $A l_{x} G a_{1-x} A s$ tem um índice de refração muito maior em comparação 
ao recobrimento, possibilitando uma emissão do laser guiada. Na parte esquerda, é possível observar um espectro comum de um diodo laser obtido com uma cavidade Fabry-Perot de 13.7 GHZ de FSR. O modo principal do diodo laser é mais do que 100 vezes maior em relação ao modo mais próximo [9]. É importante dizer que o comprimento de onda dele depende também da temperatura.
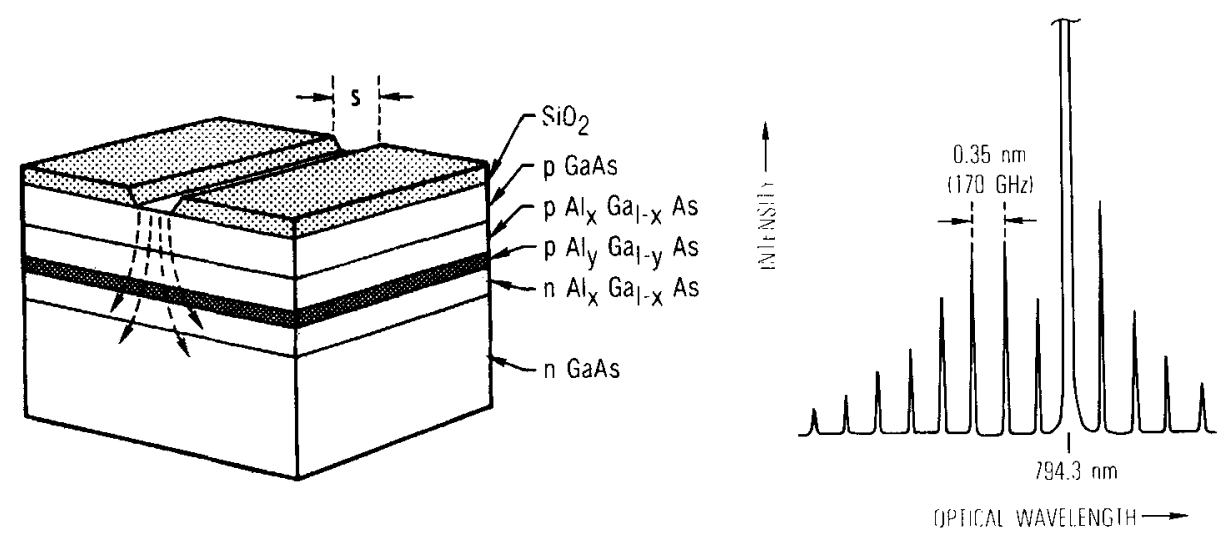

Figura 2.1 - Exemplo da estrutura de um diodo laser. Na esquerda é possível apreciar uma hétero estrutura com uma guia de onda que gera o laser. Na direita um espectro de alta resolução que mostra que o laser é praticamente monomodo. Retirado de [9]

O processo para construir um laser de diodo sintonizável que atinga o comprimento de onda $795 \mathrm{~nm}$ é o seguinte [23, 33] : O laser de diodo semicondutor escolhido, LD-0785P200-1 pode gerar uma potência máxima de $90 \mathrm{~mW}$ no comprimento de onda de $785 \mathrm{~nm}$ a uma temperatura ambiente de $25.0^{\circ} \mathrm{C}$. Ele pode trabalhar entre 780 e $790 \mathrm{~nm}$. Observa-se na fig. 2.2 a montagem do laser de diodo composta por um diodo laser da TOPTICA, que está localizado dentro de um colimador. Fazendo uso de uma rede de difração e resfriando o sistema até atingir a temperatura de $9,5^{\circ} \mathrm{C}$, o feixe de luz gerado pelo diodo é dirigido até colidir na rede de difração. A rede de difração divide espacialmente o feixe em diferentes ordens, as quais se diferenciam pelo comprimento de onda segundo a difração de Bragg [35]. Foram caracterizadas as potências da ordem $0\left(P_{0}\right)$ e ordem $-1\left(P_{-1}\right)$ geradas pela rede de difração em função da polarização de entrada do feixe de diodo. De tal forma, que para uma polarização vertical $P_{0} / P_{i}=67 \%$ e $P_{-1} / P_{i}=13 \%$ e uma polarização horizontal $P_{0} / P_{i}=8.4 \%$ e $P_{-1} / P_{i}=60 \%$, por conseguinte foi escolhida a polarização de saída vertical para não estragar o diodo por excesso de retroalimentação.

Com um parafuso micrométrico foi possível ajustar o ângulo no qual a ordem - 1 se dirige. Escolheu-se a direção contrária à aquela do feixe original (conhecida como a configuração Littrow [23]), obtendo uma retroalimentação no diodo, gerando assim um diodo laser que é sintonizável no comprimento de onda desejado de $795 \mathrm{~nm}$. O laser foi fechado e rodeado com material absorvente de umidade, prevenindo assim uma possível condensação que pudesse es- 
tragar o diodo, e deixando-o isolado das possíveis mudanças de temperatura externas. Mediante o circuito controlador de temperatura HTC-3000 da WAVELENGHT ELECTRONICS [48], diminuiu-se e estabilizou-se a temperatura para assim ultrapassar o limite estabelecido pela fábrica, de modo que a potência máxima útil diminuiu até $40 \mathrm{~mW}$. As instruções detalhadas para a construção do laser nas referências [13, 23].

\subsubsection{Laser de diodo 795 nm e cavidade Fabry-Perot}

O primeiro diagnóstico para ter certeza que o laser gera luz apenas em um comprimento de onda, independente do valor, foi a obtenção do laser monomodo. Dito de um outro modo, que o laser estava gerando luz num comprimento de onda sintonizado e que ele conseguia-se manter no mesmo por um período de tempo bastante apreciável para conseguir realizar o experimento. De modo que foi usada uma cavidade Fabry-Perot FPI 100-750 de 1 GHZ de FSR da TOPTICA PHOTONICS para observar os modos da luz gerada pelo laser (lembrando que uma cavidade desse tipo é análoga a fig. 1.10).

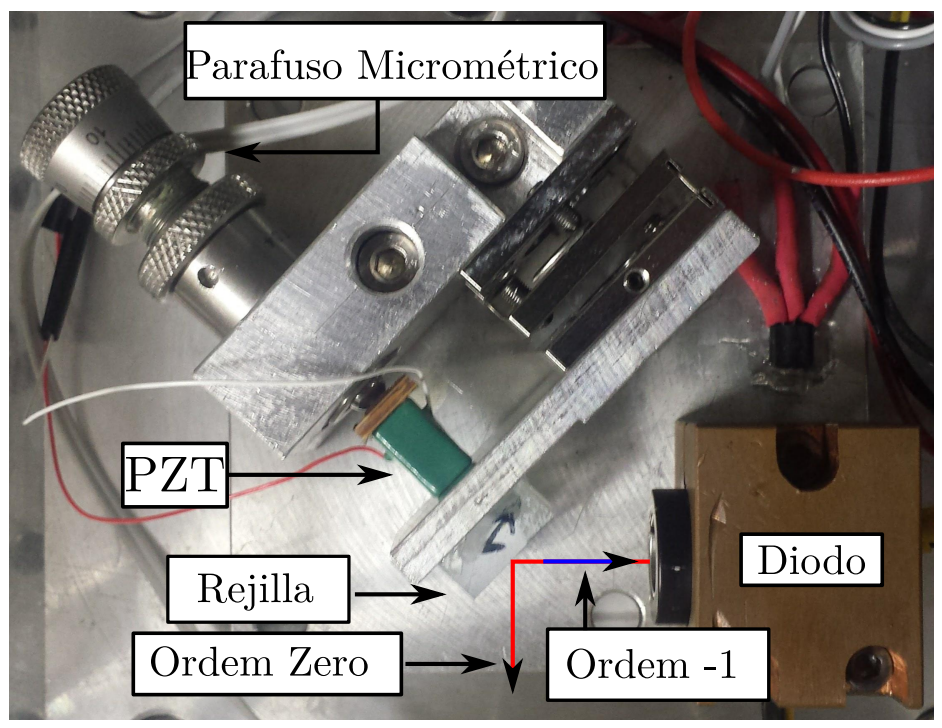

Figura 2.2 - Montagem do laser de diodo sintonizável ao redor do comprimento de onda $795 \mathrm{~nm}$. É possível distinguir o diodo, parafuso micrométrico, rede de difração e PZT. O feixe gerado de baixa potência será usado como feixe de prova (Probe).

Conforme pode ser observado na fig. 2.3 (Esquerda), aplicando uma modulação no PZT e na corrente do diodo da fig. 2.2, apenas um modo pode viver dentro da cavidade. A varredura da corrente sobre o diodo gera uma emissão estimulada e a varredura sobre o PZT gera uma retroalimentação sobre o diodo gerando assim uma emissão sintonizável. Essa cavidade tem uma Finesse de aproximadamente 400, o que representa uma perda de aproximadamente 
$1.55 \%$. A frequência de $1 \mathrm{GHz}$ será utilizada como uma referência para medições futuras.

Caso o laser não fique monomodo, não sera possível trava-lo numa das possíveis linhas de absorção hiperfinas gerando um sistema instável e pouco confiável. Além disso, no caso de ter dois ou mais modos, os resultados poderiam ter informação duplicada, gerando confusão na adquisição de dados. Por exemplo na espectroscopia de absorção saturada poderia obter-se dois picos de transição hiperfina que realmente fossem o mesmo e que estão sendo exitados por dois modos diferentes do campo.

\subsubsection{AOM e dessintonia}

O processo de mistura de quatro ondas acontece fora da ressonância atômica (ver fig. 1.9a), como consequência é preciso dessintonizar o laser em relação a uma linha hiperfina de absorção. Dividindo o feixe em dois, uma parte com potência menor em relação a outra, fazemos atravessar o feixe de baixa potência pela montagem da dessintonia (Detuning), segundo a fig. 2.4. No processo da dessintonia, é usado um Modulador Acusto-ótico (Acusto-Optic Modulator) modelo 3200-124 de $200 \mathrm{MHz}$ de frequência central da CRYSTAL TECHNOLOGY, $\mathrm{NC}$ [Inc], que trabalha na faixa de $780-850 \mathrm{~nm}$.
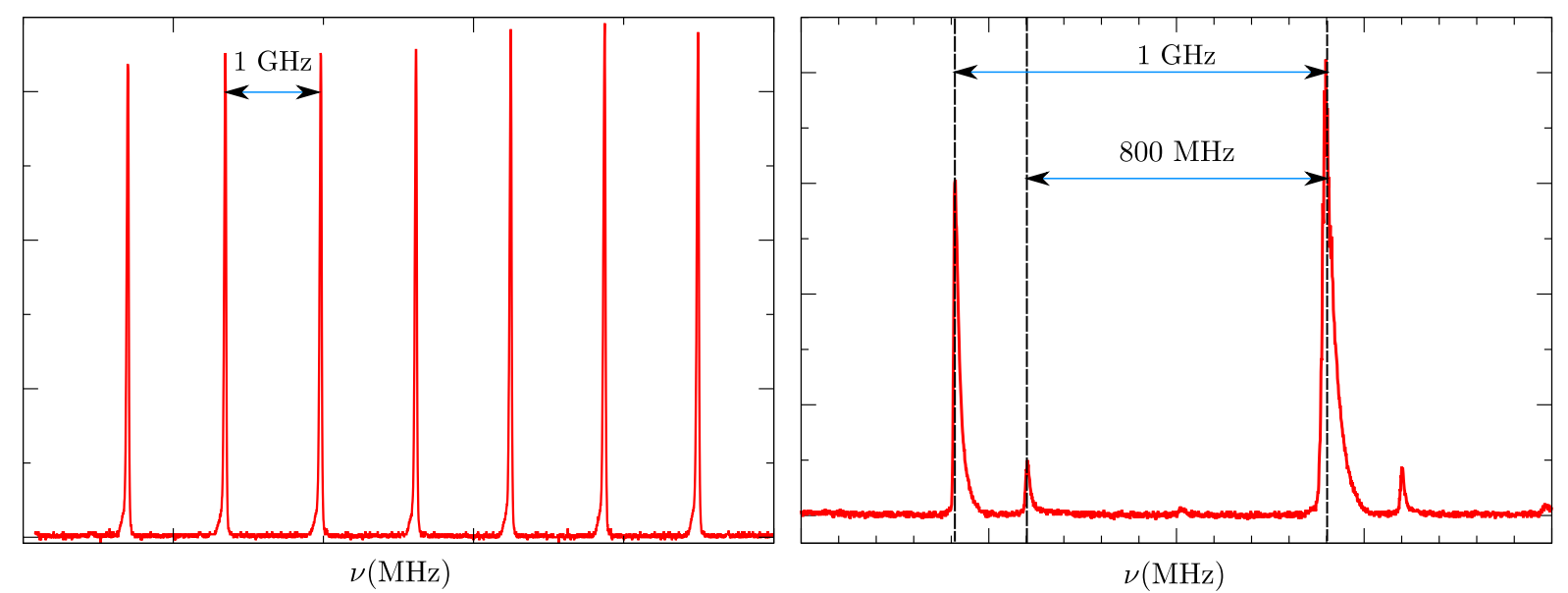

Figura 2.3 - (Esquerda) Obtenção do laser Monomodo. Apenas são consideradas as diferenças absolutas entre os picos. (Direita) Dessintonia de $800 \mathrm{Mhz}$ depois de o laser passar pelo AOM quatro vezes. O pico maior corresponde ao laser depois de passar através do AOM, e o pico menor é o laser sem modificações (direita fig. 2.4).

Um modulador acusto-ótico é um aparelho constituído por um cristal, geralmente de quartzo de dióxido de telúrio $\left(\mathrm{TeO}_{2}\right)$, o qual é submetido a um sinal periódico de alta frequência. Esse sinal de alta frequência vai produzir uma frente de onda aproximadamente plana o qual modifica o índice de refração do cristal periodicamente, gerando assim um médio periódico, de 
modo que o AOM trabalha baseado na difração de Bragg [35]. Ao atravessar o AOM, o feixe difrata em diferentes ordens as quais vão ter uma adição ou subtração na frequência relativa ao laser principal.

Neste experimento foi usado um AOM de $200 \mathrm{MHz}$ de frequência, gerando assim ordens com frequência igual a $\omega=\omega_{I} \pm n 200 \mathrm{MHz}$, onde $n$ corresponde a ordem de difração com os possíveis valores $n=0,1,2 \ldots$ e $\omega_{I}$ a frequência inicial do laser seja qual for, porém ao redor de 780nm. A vantagem do AOM é que ele além de produzir diferentes ordens, aquelas ordens de difração são separadas espacialmente, de tal forma que é possível só escolher uma das ordens, cobrindo o caminho das outras ${ }^{1}$. Dentro dos parâmetros escolhidos em [15, 26], a frequência de dessintonia em relação a uma linha de absorção hiperfina foi aproximadamente $1 \mathrm{GHz}$. Pela ausência física de um AOM dessas características, foi usado um esquema experimental de quatro passagens.

Em primeiro lugar, na fig. 2.4 o feixe vai pelo caminho 1 e com uma polarização horizontal consegue passar através do cubo polarizador divisor de feixe (PBS-Polarizer Beam Splitter), continuando pelo caminho 2. Ao chegar ao AOM, são gerados a ordem $0,-1,-2 \ldots$ etc. Escolhendo a ordem -1 que está a uma frequência relativa de -200 MHz, o feixe atravessa uma placa de quarto de onda (QWP-Quarter Wave Plate) incide contra o espelho e volta pelo mesmo caminho passando mais uma vez pela placa de onda. Como o feixe atravessou duas vezes a placa de quarto de onda, ela vai mudar a polarização do feixe de luz em 90 graus, deixando o feixe com polarização vertical. Percorrendo pela segunda vez o AOM e escolhendo mais uma vez a ordem -1 dos feixes difratados, o feixe é dessintonizado uma quantidade de -200 $\mathrm{MHz}$, somando assim um total de $-400 \mathrm{MHz}$. Como o feixe vem com polarização vertical, percorrendo o caminho 3 chega até o PBS, logo após bate contra o segundo espelho e volta pelo caminho 4. Nesse momento repete-se todo o processo de passagem dupla pelo AOM e mudança da polarização do feixe, o qual percorre até o caminho 5 e 6 . Sintetizando, o feixe atravessou 4 vezes o AOM gerando assim uma dessintonia de $-800 \mathrm{MHz}$ em relação ao feixe que nunca passou pelo AOM. Esta é uma ótima ideia de como gerar dessintonia maior do que o aparelho consegue apenas com uma passagem.

Porém tem-se um problema. O feixe que volta pelo caminho 6 tem a mesma polarização que o feixe original que vem na direção 1 . Não se pode permitir que qualquer feixe volte no mesmo caminho até regressar ao laser de diodo. No caso disso acontecer, o laser pode desestabilizar, fazendo que ele pule de modo ou até estragando o diodo. Além disso, não haveria maneira de confirmar se a dessintonia foi feita corretamente. Conforme essa possível situação, faz-se uso de um Isolador ótico (OI-Optical Isolator). Um isolador ótico, é um aparelho ótico que permite que um feixe com uma certa polarização atravesse só em uma direção de propagação,

\footnotetext{
${ }^{1}$ A diferença do EOM que gera também ordens de difração que vão na mesma direção de propagação [35].
} 
de modo que se por acaso o feixe voltar pelo mesmo caminho, o OI não deixaria ele voltar até o laser. O OI trabalha com dois cubos PBS e um rotador de Faraday, os quais servem em conjunto como discriminadores de polarização.

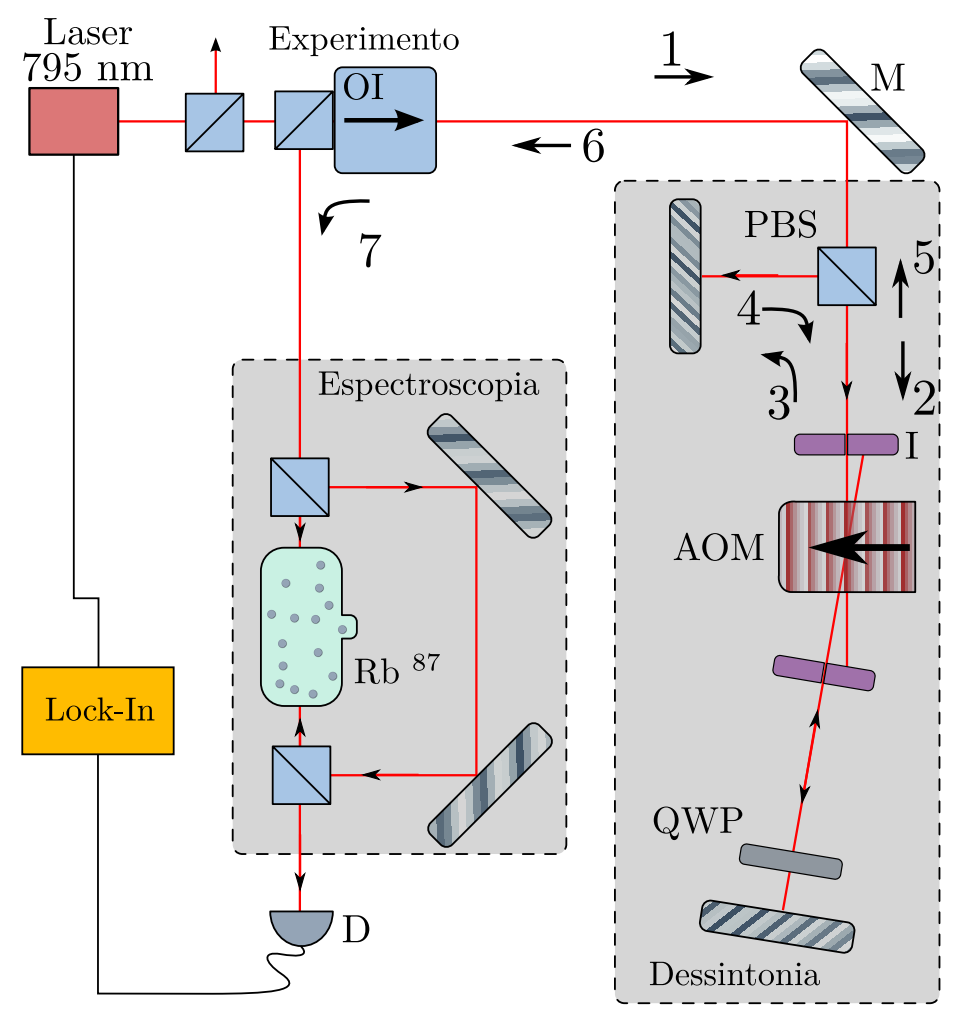

Figura 2.4 - Configuração experimental Dessintonia e espectroscopia. QWP: Lamina $\lambda / 4$ (Quarter Wave Plate), OI: Isolador Ótico (Optical Isolator), PBS: Cubo Polarizador (Polarization Beam Splitter), M:Espelho (Mirror), I: Iris, D:Detector, $\mathrm{Rb}^{87}$ : Célula de Rubídio 85 e 87, AOM: Modulador acusto-ótico de 200 Mhz (Acusto-optical modulator)

Aquele feixe que volta com a mesma polarização vai ser jogado fora por um dos dois cubos, mudando assim sua direção. Na fig. 2.4, após o feixe ser dessintonizado e percorrer o caminho 6 com polarização horizontal, ele chega até o IO, e como ele tem a mesma polarização do que o feixe inicial, o IO vai mudar a sua polarização de horizontal para vertical, jogando assim o feixe para o caminho 7. Fazendo uso mais uma vez da cavidade de referência Fabry Perot de 1 GHZ, obtém-se na fig. 2.3 (Direita) um espectro onde os picos maiores representam o feixe depois da dessintonização e os picos menores com o feixe original para fazer a comparação. Por conseguinte, o feixe foi dessintonizado $-800 \mathrm{MHz}$ em relação ao feixe original.

\subsubsection{Espectroscopia de absorção saturada}

Por meio da cavidade Fabry-Perot consegue-se deixar o laser monomodo e ter certeza que ele produzirá apenas uma frequência, logo após fazendo uso do AOM e da cavidade Fabry- 
Perot e jogando com a polarização do feixe, dessintonizou-se o laser $-800 \mathrm{MHz}$ em relação ao laser que não atravessou a processo de dessintonia. Se for tomado como referência o feixe que foi dessintonizado, o feixe que será dirigido para o processo de mistura de quatro ondas estará a $+800 \mathrm{MHz}$. Agora é necessário ter certeza de duas coisas. Em primeiro lugar, que o laser esteja no comprimento de onda desejado, o qual corresponde as proximidades de $795 \mathrm{~nm}$, em seguida, que esse comprimento de onda fique constante durante um tempo apreciável. Os átomos de rubídio, além do meio para produzir a mistura de quatro ondas, são uma ótima forma de ter certeza que o laser está nas proximidades de 795nm (ou 780nm no caso da linha D2).

Nas fig. 1.1 e fig. 1.2, nota-se que pela estrutura hiperfina dos átomos, fazer uma espectroscopia de absorção saturada [14] [23] é uma boa ideia para dar uma estimativa do comprimento de onda gerado pelo laser e em seguida trava-lo no comprimento de onda dado por alguma das possíveis transições hiperfinas.

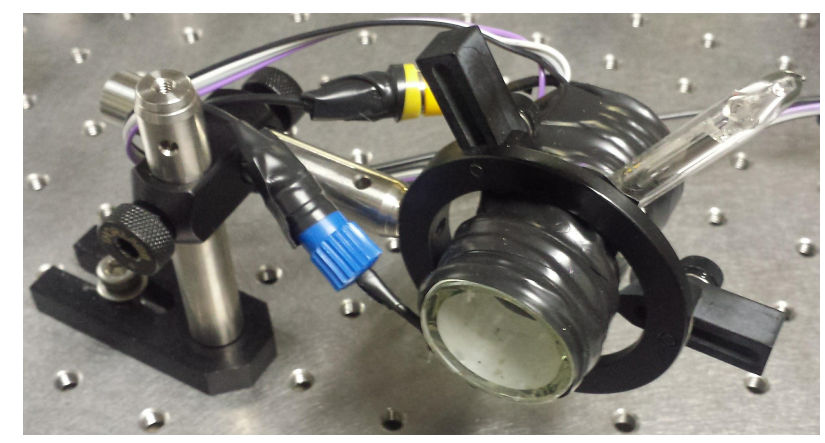

Figura 2.5 - Célula de Rubídio. Célula preenchida com isótopos de Rb 85 e 87 . A célula é aquecida fazendo passar uma corrente por um fio resistivo. Diferentes células foram usadas nas espectroscopias, na montagem da mistura de quatro ondas (4WM) e dentro da cavidade OPO.

Inicialmente, faz-se uso de uma célula preenchida com isótopos de rubídio 85 e 87, que foi aquecida fazendo passar uma corrente por um fio resistivo que envolve a célula, como na fig. 2.5. Na fig. 2.4, tem-se o esquema de absorção saturada, no qual o feixe que vem na direção 7 bate no PBS. O PBS deixa passar en torno de $10 \%$ da potência, e os $90 \%$ restantes serão desviados em direção contra propagante. O $90 \%$ da potência saturam os átomos, conseguindo assim que no detector seja possível distinguir o espectro saturado do rubídio 85 e 87 na linha D1 com as linhas hiperfinas de absorção. O espectro está ilustrado na fig. 2.6.

Pode-se perceber no espectro todas as possíveis transições hiperfinas partindo dos níveis hiperfinos $5 S_{1 / 2(F=1)}$ e $5 S_{1 / 2(F=2)}$ para o Rubídio 87 , e dos $5 S_{1 / 2(F=2)}$ e $5 S_{1 / 2(F=3)}$ para o Rubídio 85. Além disso, nota-se os picos de crossover. Com a cavidade de $1 \mathrm{GHZ}$ foi possível obter a escala do gráfico. 


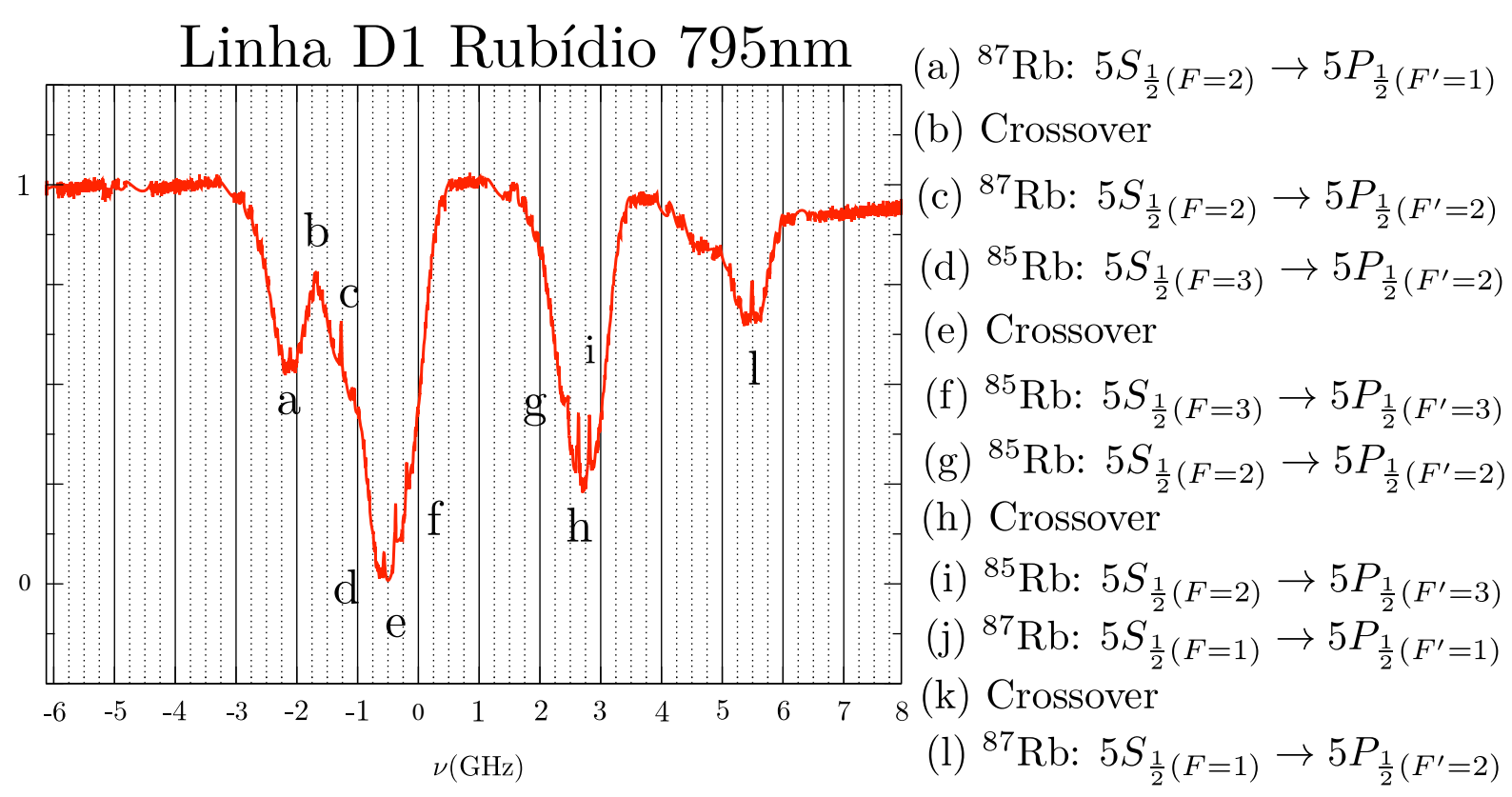

Figura 2.6 - Espectroscopia de absorção saturada para o Rubídio 85 e 87 na linha D1. O laser será travado em um dos picos de absorção fazendo uso de um sistema de Dither e Lock-In para medições futuras (esquerda fig. 2.4). São representados os diferentes picos de absorção que correspondem aos possíveis níveis de energia permitidos, que foram obtidos usando a cavidade de referência de $1 \mathrm{GHz}$ de FSR. Comparação feita com os valores na literatura (fig. 1.1 e fig. 1.2)

\subsection{Laser de bombeio: Laser titânio-safira}

O laser Ti:Sapphire ou Titânio-Safira gera uma alta potência da ordem de $1 \mathrm{~W}$ e foi escolhido para ser usado como feixe de bombeio. Porém, um segundo laser de diodo de características semelhantes ao já descrito foi montado com objetivo de usa-o com um outro laser amplificador, o SDL8630.

\subsubsection{Primeira tentativa: SDL8630 e laser de diodo}

Como primeira tentativa, o laser SDL8630 [39] ao ser bombeado por um laser de baixa potência, pode gerar em torno de $250 \mathrm{~mW}$ de potência. A razão pela qual ocorre esta amplificação é por que é bombeado eletricamente por uma corrente DC. O SDL8630 é formado por um pequeno chip semicondutor que ao ser bombeado externamente gera um feixe com o mesmo comprimento de onda desse bombeio e amplificado. Na referência [26] usou-se uma potência do bombeio de $350 \mathrm{~mW}$ e como o laser de diodo gera máximo $40 \mathrm{~mW}$ não pode ser usado como feixe de bombeio. Porém ao usar o laser de bombeio para bombear o SDL ele vai funcionar como amplificador.

$\mathrm{Na}$ fig. 2.7 tem-se um teste simples de comportamento do feixe de saída do SDL8630 em função do comprimento de onda do feixe de bombeio externo o qual se deseja amplifi- 
car. Quando o SDL foi bombeado com um laser de diodo (fig. 2.2) no comprimento de onda próximo de 780nm, foi possível observar através da curva vermelha que a amplificação nesse comprimento de onda foi muito boa. No entanto quando o mesmo SDL foi bombeado com o laser de diodo no comprimento de onda perto de $795 \mathrm{~nm}$, comprimento de onda utilizado nesse trabalho, a potência de amplificação que o SDL gerou caiu bastante, como pode se apreciar na curva de cor preto.

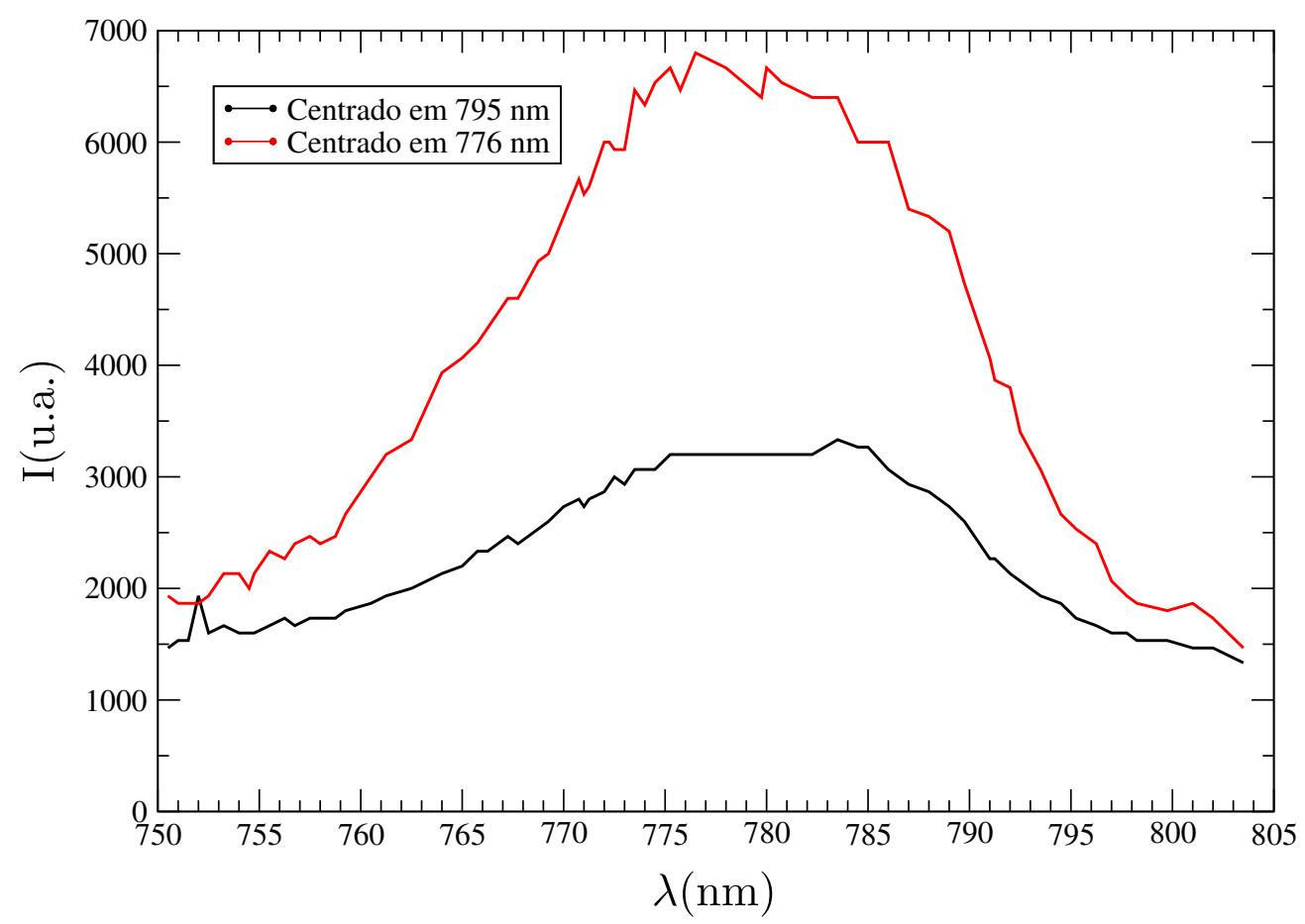

Figura 2.7 - Potência de amplificação do SDL8630 em função do comprimento de onda de entrada. O laser SDL8630 pode gerar até $250 \mathrm{~mW}$ de potência de saída no comprimento $776 \mathrm{~nm}$, no entanto no comprimento de $795 \mathrm{~nm}$, a amplificação caiu bastante. O laser foi bombeado com um laser de diodo fig. 2.2. O laser usado foi um laser Ti-Sapphire (fig. 2.8).O espectro é largo porque usou-se o medidor de comprimento de onda OCEANOPTICS.

Concluiu-se que o chip dentro do SDL trabalha muito bem como amplificador em torno do comprimento de onda $780 \mathrm{~nm}$ (linha D2 do Rubídio), mas para o comprimento de onda de 795 nm (linha D1) não. Por fim, escolheu-se um laser Ti:Sapphire como bombeio.

\subsubsection{Laser titânio-safira $795 \mathrm{~nm}$}

Um laser Ti:Sapphire é um laser sintonizável que emite luz vermelha e próxima ao infravermelho, na faixa de $650 \mathrm{~nm}$ até $1100 \mathrm{~nm}$. O nome Ti:Sapphire refere-se ao meio de ganho que encontra-se dentro de uma cavidade do tipo esquematizado na fig. 2.8. O meio de ganho é um cristal de safira $\left(\mathrm{Al}_{2} \mathrm{O}_{3}\right)$ dopado com íons de titânio [21]. A cavidade é bombeada com o laser Coherent Verdi-18 no comprimento $532 \mathrm{~nm}$ com aproximadamente $8 \mathrm{~W}$ de potência, e na 
saída é gerada luz no comprimento $795 \mathrm{~nm}$ com $1 \mathrm{~W}$.

A cavidade esta composta, além do cristal Ti:Sapphire (ou titânio safira), pelos seguintes elementos que servem para controlar a frequência da luz gerada e asseguram que o sentido do feixe seja único:

- Dois espelhos esféricos, altamente refletores no comprimento de interesse (infravermelho) sendo um deles usado como porta de entrada do laser de bombeio Verdi-18 que gera luz com 532nm de comprimento de onda. Os espelhos são esféricos para conseguir fazer o acordo de modo dentro da cavidade e que seja estável.

- Dois espelhos planos, um dois quais é usado como porta de saída do laser gerado no comprimento desejado e o outro está colado a um PZT que irá oscilar mediante a aplicação de um sinal AC externo.

- Um filtro birrefringente (Filtro de Lyot) feito por um material anisotrópico, o qual se define como um material cujas qualidades como elasticidade, condutividade, velocidade de propagação da luz variam dependendo da direção espacial. Essa anisotropia gera a birrefringência ou dupla refração, fazendo assim que um feixe incidente seja desdobrado em dois raios linearmente polarizados $[10,35]$. O filtro permite sintonizar a frequência do laser com uma precisão de milésimo de nanômetro.

- Um etalon, o qual é usado para fazer um pré-travamento do laser no comprimento de onda desejado. Ele é uma lâmina de vidro delgada que funciona como uma Fabry-Perot, e pela sua largura tem um FSR da ordem de GHz. O filtro de Lyot não é suficiente para garantir que o laser trabalhe monomodo, o que o etalon enxerga.

- Um diodo ótico, que é responsável pela propagação do feixe em apenas uma direção.

Para ter certeza que o comprimento de saída da cavidade é o desejado, faz-se uso mais uma vez dos átomos de rubídio. Fazendo um pre-travamento no etalon e aplicando um sinal no PZT, gera-se o espectro de absorção saturada do Rubídio 85 e 87 (ver fig. 2.6), e fazendo uso de um sistema de travamento, deixa-se o laser no comprimento de onda desejado. Para maior informação do laser Titânio-Safira ver as referências[10, 21]

\subsection{Fibra ótica e ruídos não desejados}

Uma alternativa para fazer com que o experimento fique mais estável no sentido mecânico da montagem e o possível desalinhamento do caminho do feixe por erro humano é fazer 


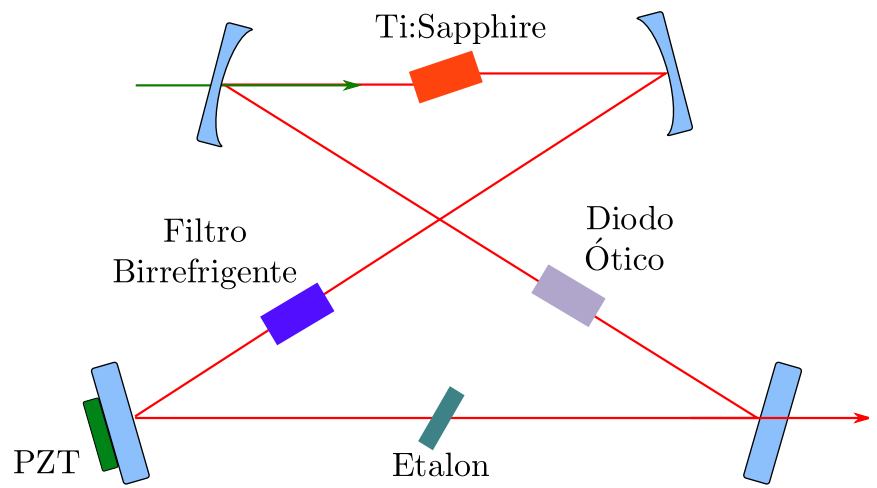

Figura 2.8 - Esquema de uma cavidade ótica tipo borboleta sintonizável. Dentro da cavidade está o cristal Ti:Sapphire. Laser usado como Bombeio (Pump)

uso da fibra ótica. Além disso, o laser titânio-safira está em uma outra sala, de modo que o uso da fibra ótica era indispensável. A fibra ótica é uma guia de onda que trabalha baseada na reflação interna total [35]. Um esquema bastante simples para fazer um bom acoplamento do feixe de luz com a fibra ótica é observado na fig. 2.9, em que temos um colimador de fibra conectado a uma das duas pontas da fibra ótica e uma série de parafusos micrométricos nos eixos X, Y e Z.

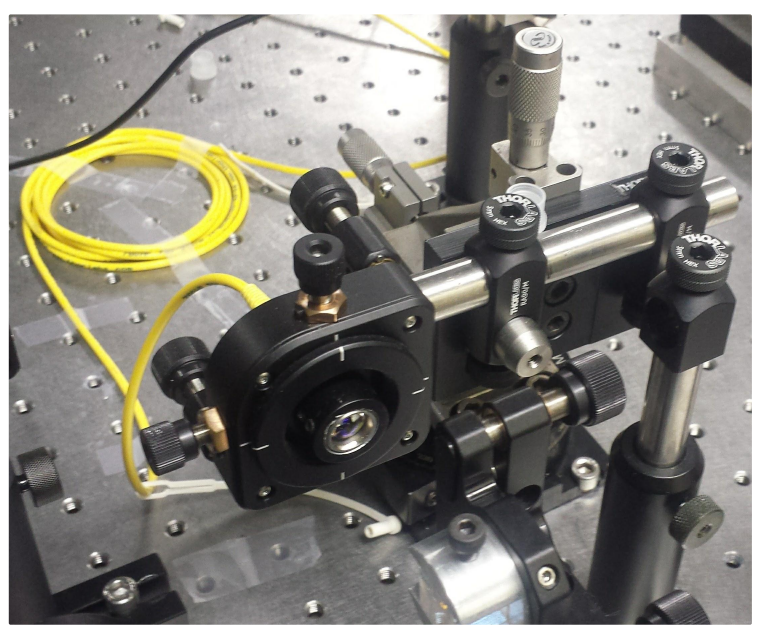

Figura 2.9 - Acoplamento da fibra ótica. Acoplamento ar-fibra. O uso da fibra ótica tem a vantagem de deixar o feixe colimado, gaussiano e com uma cintura menor. Também deixa o caminho ótico independente do caminho anterior, o que permite uma maior estabilidade na montagem.

O perfil de propagação do feixe que vai sair do outro lado da fibra ótica, é sempre o mesmo independentemente do perfil do feixe antes de ser acoplado na fibra. Isso facilita bastante a construção das cavidades que serão usadas depois e a caracterização dos fenômenos estudados. Depois de o feixe gerado pelo laser de diodo ser acoplado a fibra ótica, o feixe de saída foi levado para a espectroscopia de absorção saturada. Nesse ponto foi observado um problema. 


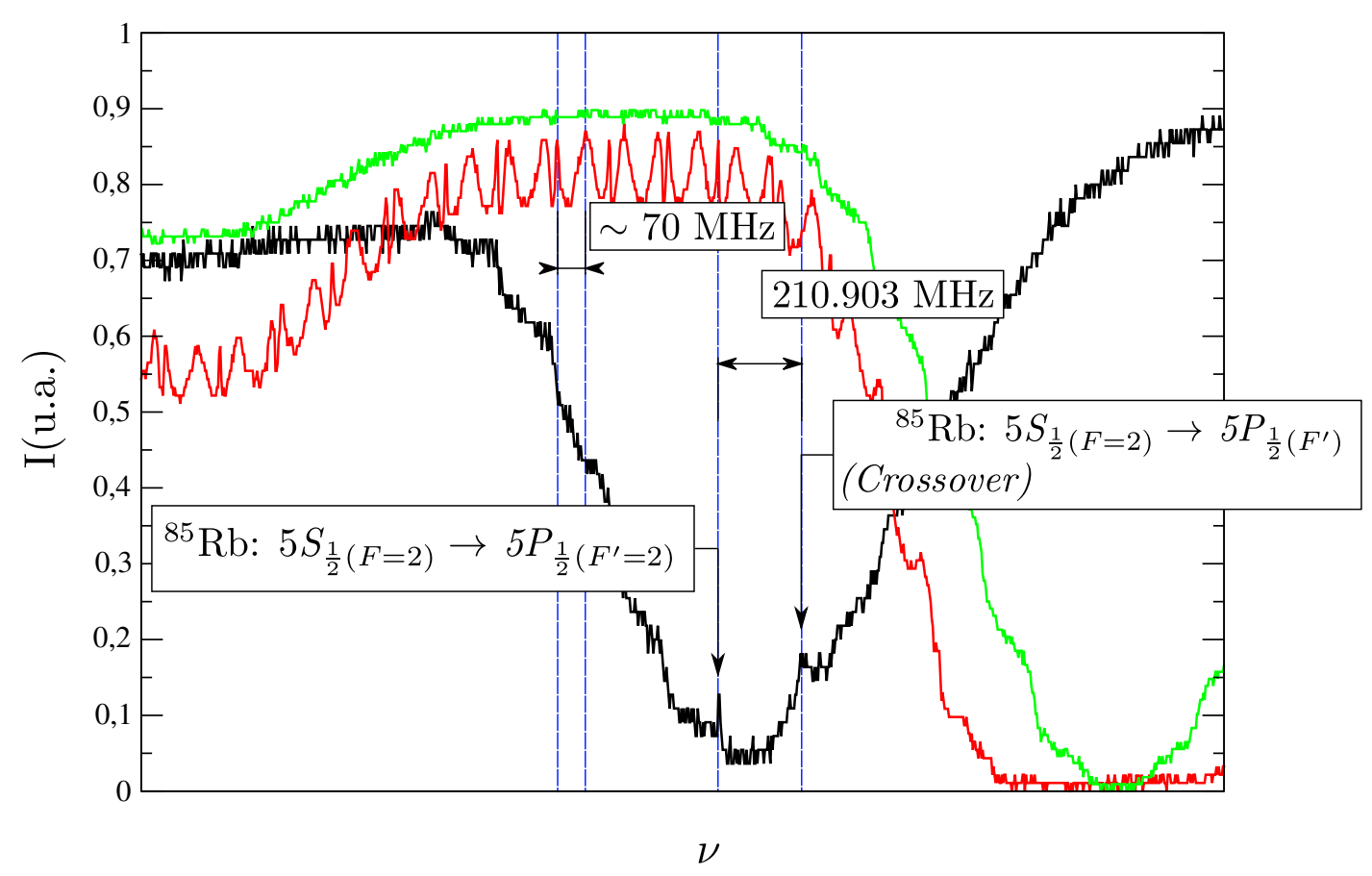

Figura 2.10 - Ruido gerado pela Fibra ótica. Espectro de referência do Rb 85 ao redor da transição $F=2 \rightarrow F^{\prime}$ (Preto). Espectro deslocado $800 \mathrm{Mhz}$ de um feixe que passou pela fibra ótica sem polir, em que é possível distinguir um ruido com $\sim 70 \mathrm{MHz}$ gerado pelas pontas da fibra (Vermelha). Espectro do mesmo feixe onde as pontas da fibra foram polidas gerando um pequeno ângulo entre elas, e assim resolvendo o problema (Verde).

Na fig. 2.10 em cor preto temos uma parte do espectro de absorção saturada do isótopo de Rubídio 85, centrado na linha de absorção hiperfina $5 S_{1 / 2(F=2)} \rightarrow 5 S_{1 / 2\left(F^{\prime}=2\right)}$, e afastado dele a +210 MHz o crossover da mesma transição (fig. 1.1). Esse espectro foi obtido com o feixe sem atravessar a fibra ótica. Pegando uma parte daquele feixe e acoplando-o na fibra ótica, levando-o até a absorção saturada, foi obtido o espectro vermelho. É claro que os dois espectros teriam que ser iguais, no entanto, é evidente que o espectro vermelho tem uma oscilação que não apresenta o espectro de cor preto.

Uma característica das fibras óticas é o ângulo no qual as pontas estão em relação ao feixe de saída. A fibra que havia sido escolhida tinha os dois extremos paralelos, o que fazia com que a fibra trabalhasse como se fosse uma cavidade Fabry-Perot, em outras palavras, as duas pontas trabalhavam como espelhos do tipo mostrado na fig. 1.10a, gerando assim uma cavidade ótica. Essa oscilação não deixava diferenciar os picos de absorção, não deixaria fazer o travamento do laser e o processo de mistura de quatro ondas. O problema foi resolvido introduzindo um pequeno ângulo e polindo uma das pontas [42]. 


\section{Capítulo 3}

\section{Resultados e discussão}

Neste capítulo descrevemos os três resultados experimentais deste trabalho. Em primeiro lugar a obtenção da Mistura de Quatro Ondas em átomos de rubídio 85 e 87. Em segundo lugar a caracterização do processo paramétrico em função da dessintonia do bombeio, potência do bombeio e temperatura de célula de rubídio. Em base a aquela caracterização foi possível achar regiões de frequências do bombeio ótimas de trabalho, e entender que a amplificação e absorção do feixe de prova tanto como a intensidade do feixe de prova são ajustáveis dependendo desses parâmetros. Finalizando, a construção e caracterização do Oscilador Paramétrico Ótico OPO com meio $\chi^{(3)}$. Para isso construímos uma cavidade linear com perdas variáveis, que somado com o fato de ter um meio com ganho ajustável gera um OPO com transição suave pelo limiar de oscilação.

\subsection{Obtenção da mistura de quatro ondas}

O primeiro resultado experimental foi a obtenção do processo paramétrico de Mistura de Quatro Ondas. Estudou-se dois exemplos com dessintonia do bombeio $\Delta$ diferente. Logo após, foram estudados os efeitos gerados no processo ao mudar os parâmetros da dessintonia do bombeio, a potência do bombeio e a temperatura da célula de rubídio. Os dados do 4WM foram colhidos em colaboração com o estudante de mestrado Harold Rojas e para um analises mais extenso é possível ver na sua dissertação na referência [34].

O esquema experimental foi baseado no [26] correspondente ao mostrado na fig. 3.1. Um feixe de bombeio intenso gerado pelo laser Titânio-Safira e com polarização vertical atravessa a célula de rubídio. Em segundo lugar, um feixe de intensidade menor chamado de prova gerado pelo laser de diodo e com polarização horizontal inside na célula, formando um pequeno ângulo $\theta$ com o feixe de bombeio. Como consequência da presença de dois cubos polarizadores 
(PBS), o feixe de bombeio interage com os átomos e é discriminado pela sua polarização vertical. Após do segundo cubo PBS, foram colocados dois fotodetetores PDA36A/THORLABS de Silício [43]. A célula de rubídio foi previamente esquentada. A temperatura da célula foi $T=83.8^{0} \mathrm{C}$ nos exemplos 1 e 2 como mostrado na tab. 3.1.

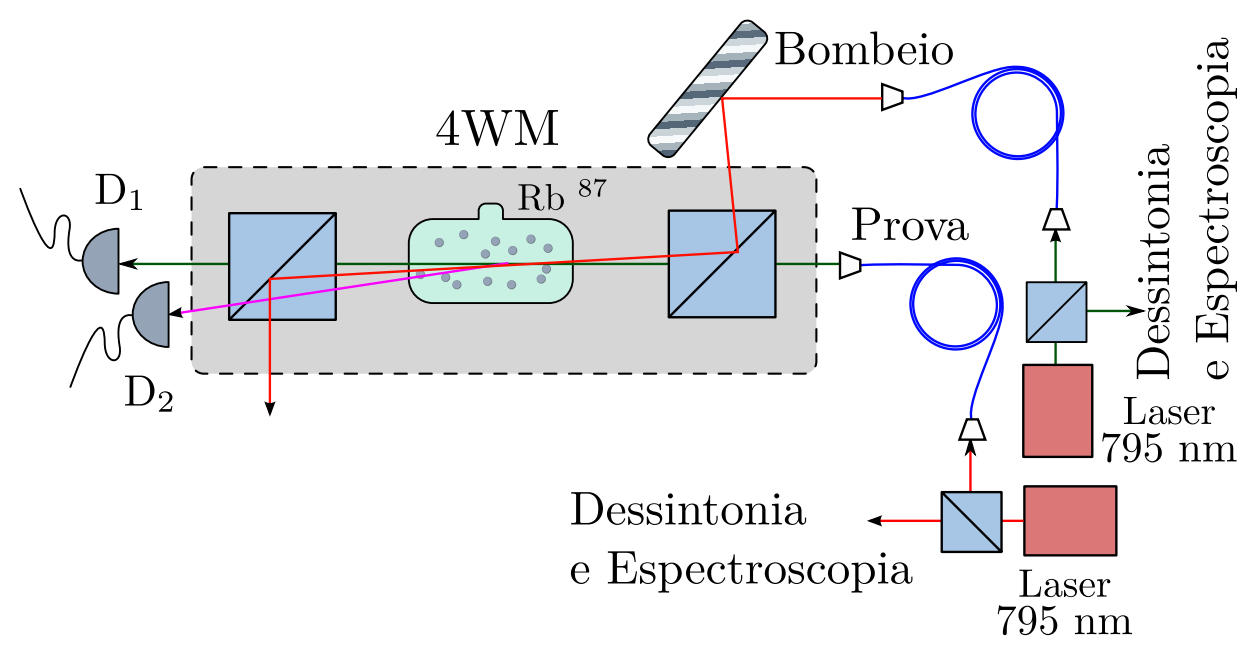

Figura 3.1 - Montagem para obtenção da Mistura de Quatro Ondas (4WM). Mediante a incidência de dois feixes laser que se cruzam em um pequeno ângulo e atravessam a célula de Rb é possível obter o processo de mistura de quatro ondas. $\mathrm{O}$ primeiro feixe verticalmente polarizado e com potência alta, se chama de bombeio (Pump). $\mathrm{O}$ segundo feixe horizontalmente polarizado e com potência baixa, se chama de prova (Probe). Os detedores $D_{1} \mathrm{e}$ $D_{2}$ vão detetar o sinal do prova e do conjugado, respectivamente.

Dentro da cavidade do Titânio-Safira na fig. 2.8 manipulou-se o filtro de Lyot e o etalon com o fim de sintonizar o feixe gerado no comprimento ao redor de $795 \mathrm{~nm}$. Diferentes frequências são atingidas ao variar o ângulo do etalon. O ajuste fino no comprimento de onda foi fixado com uma tensão constante sobre o PZT. Uma parte da luz gerada foi dirigida até o medidor de comprimento de onda BRISTOL INSTRUMENTS 671, com uma precisão de $10^{-4} \mathrm{~nm}[7,8]$.

Em segundo lugar, sintonizou-se o comprimento de onda gerado pelo laser de diodo com o PZT que está dentro da cavidade da fig. 2.2. Sobre o PZT aplicou-se uma tensão AC com o fim de fazer uma varredura periódica, gerando assim o espectro de absorção saturada de referência (fig. 2.6) e o espectro de transmissão da cavidade Fabry-Perot de $1 \mathrm{GHz}$ de FSR (fig. 2.3). Com o PZT atingiu-se uma varredura de $\sim 14 \mathrm{GHz}$ na frequência. Esses dois espectros foram usados como escala. Em resumo a frequência do feixe de prova está sendo variada, porém a frequência do feixe de bombeio está fixa para cada medição feita.

Na fig. 3.3 observam-se diferentes fenômenos paramétricos de mistura de quatro ondas, que irão ser explicados com maior detalhe. A fig. 3.3a representa os espectros obtidos com o detetor $D_{1}$ que mede apenas a intensidade da luz que vem do feixe de prova. Numa sequência temporal paralela, a fig. $3.3 \mathrm{~b}$ representa os dados obtidos com o detector $D_{2}$, o qual só mede 


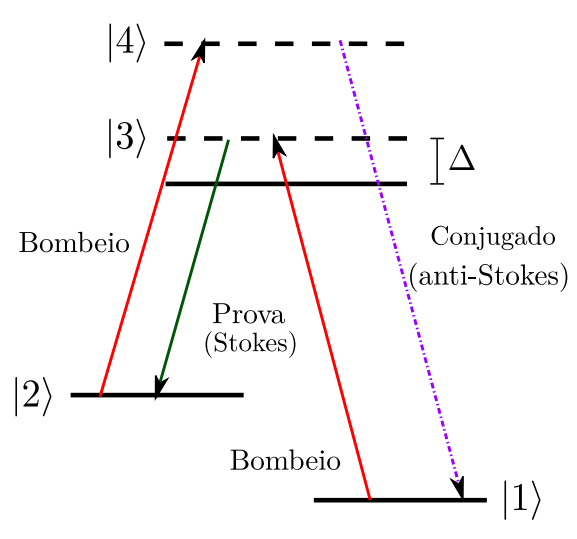

(a) Canal Stokes para o feixe de prova.

$\mathrm{Rb} 85$

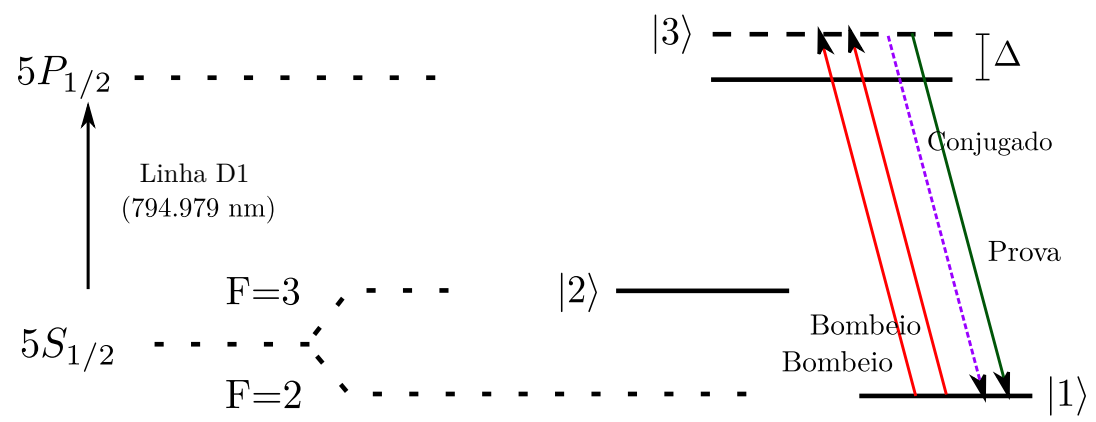

(c) Sintonia do feixe de prova e bombeio

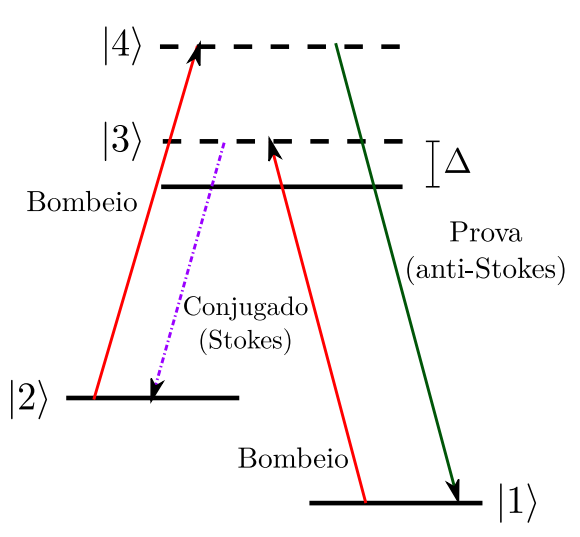

(b) Canal AntiStokes para o feixe de prova.

$|4\rangle$

$1\rangle$

(1)

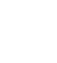

Figura 3.2 - Mistura de Quatro Ondas (4WM) para os canais Stokes, AntiStokes, e na sintonia. O feixe de prova (probe) pode estar dessintonizado em relação ao bombeio $\pm 3 G H z$. Se ele estiver dessintonizado $-3 \mathrm{GHz}$, dizemos que ele está no canal Stokes, contrariamente, se estiver dessintonizado $+3 \mathrm{GHz}$, dizemos que ele está no canal Anti-Stokes. O terceiro caso é quando o prova está sintonizado com o bombeio.

a geração do feixe conjugado. Fica claro então que nenhum dos dois detectores enxerga o feixe de bombeio. Além disso, como consequência da separação espacial dos dois feixes, o feixe conjugado não é detectado pelo primeiro detector e o prova não é detectado pelo segundo detector.

Um parâmetro importante no processo é a frequência do bombeio $\omega_{\text {bombeio }}$. Na fig. $3.4 \mathrm{a}$ observa-se um espectro de referencia de absorção saturada (vermelho) dessintonizado $+800 \mathrm{MHz}$ sendo o mesmo do que na fig. 2.6. Utilizou-se sempre para poder obter o valor da dessintonia do bombeio $\Delta$ em relação a um dos picos de absorção. O valor $\Delta$ é conhecido como valor de dessintonia de um fóton. Escolheu-se como $\Delta=\omega_{\text {bombeio }}-\omega_{0}$ em relação a frequência do pico do crossover $\omega_{0}$ da transição ${ }^{85} \mathrm{Rb}: 5 S_{1 / 2}(F=2) \rightarrow 5 P_{1 / 2}\left(F^{\prime}=2\right.$ co 3$)$. O pico dessa transição é a letra $h$ na fig. 2.6, e corresponde ao valor $\lambda_{0}=794,975345 \mathrm{~nm}$.

$\mathrm{O}$ espectro que foi detectado pelo detector $D_{1}$ é o espectro sem saturação, de cor 
verde na fig. 3.3a. Como consequência da ausência de um feixe de bombeio com varredura na frequência, não se observam os picos das transições hiperfinas. Esse espectro foi renormalizado para poder obter os valores de ganho ou de absorção segundo o caso. A linha azul representa a frequência na qual a transição do crossover ${ }^{85} \mathrm{Rb}: 5 S_{1 / 2}(F=2) \rightarrow 5 P_{1 / 2}\left(F^{\prime}=2\right.$ co 3$)$ deveria estar. Observa-se um espectro parecido a aquele da absorção saturada, porém temos novos picos de absorção e de amplificação, que serão explicados.

É importante dizer que com o aumento da temperatura da célula de rubídio, o alargamento doppler aumenta, o que pode-se observar ao comparar os vales de absorção do espectro vermelho com o espectro verde na fig. 3.3a. A largura de banda gerada pelo alargamento doppler em eq. (1.1.3) depende da temperatura da amostra [14]. Essa largura de banda ou FWHM (Full width at half maximum), segundo eq. (1.1.3) é

$$
\frac{\Delta \omega_{D}}{\omega_{0}}=2 \sqrt{\ln 2} \frac{u}{c} \cong 1.7 \frac{u}{c}
$$

com $\omega_{0}$ a frequência de absorção do átomo no seu próprio sistema de referencia e a velocidade $u=\sqrt{2 k_{B} T / M}$. Na sua vez $k_{B}$ a constante de Boltzmann, $T$ a temperatura e $\mathrm{M}$ a massa.

Repare-se em fig. 3.3a na faixa $\nu \in[-3,5 ;-1,0] \mathrm{GHz}$ que além da largura aumentar consideravelmente na figura verde em comparação à vermelha, a absorção é máxima. Os dois vales que pertencem as transições ${ }^{87} \mathrm{Rb}: 5 S_{1 / 2}(F=2) \rightarrow 5 P_{1 / 2}\left(F^{\prime}\right)$ e ${ }^{85} \mathrm{Rb}: 5 S_{1 / 2}(F=3) \rightarrow$ $5 P_{1 / 2}\left(F^{\prime}\right)$ ficaram indistinguíveis um do outro.

\subsubsection{Exemplo 1: Mistura de quatro ondas com dessintonia do bombeio de $\Delta=1.5 G H z$}

No instante de tempo $t_{1}$ na fig. 3.3a o feixe de prova presenta uma frequência em relação ao bombeio de $\omega_{\text {prova }}=\omega_{\text {bombeio }}-3 G H z$. Nesse caso o feixe de prova entrará na configuração duplo- $\lambda$ pelo canal Stokes, como representado na fig. 3.2a. O canal é chamado assim pela similitude que existe com o espalhamento Raman induzido na fig. 1.8a. A configuração duplo- $\lambda$ fecha-se ao ser gerado um feixe do conjugado com uma frequência $\omega_{\text {conjugado }}=$ $\omega_{\text {bombeio }}+3 G H z$. O feixe conjugado é gerado no mesmo instante de tempo $t_{1}$ e detetado na fig. 3.3b. O feixe do prova foi amplificado em aproximadamente $200 \%$, além disso foi gerado o feixe conjugado. Essa é a mistura de quatro ondas na configuração Stokes para o feixe de prova.

Como consequência da diferença em frequência dos níveis hiperfinos $5^{2} S_{1 / 2}(F=2)$ e $5^{2} S_{1 / 2}(F=3)(3.0357 G H z$ para o rubídio 85 na fig. 1.1$)$, concluiu-se que o processo paramétrico no instante $t_{1}$ em fig. 3.3 aconteceu nesse isótopo, e não no rubídio 87 . Perto do 
instante $t_{1}$ observou-se uma absorção logo após da amplificação. É importante aclarar que a absorção aconteceu em um nível virtual.

Continuando com o transcurso do tempo, no instante de tempo $t_{2}$ o feixe de prova em fig. 3.3a é amplificado ao chegar na sintonia com o feixe de bombeio. A amplificação é mínima, no entanto é útil no momento de conhecer a frequência do feixe do bombeio. No segundo detector fig. 3.3b não foi possível observar a geração do conjugado.

Após disso, no instante de tempo $t_{3}$ o feixe de prova entra pelo canal Anti-Stokes fig. 3.2b. Nesse canal, chamado assim pela analogia com fig. 1.8b, o feixe de prova está dessintonizado em relação ao bombeio $+3 G H z$, então a relação $\omega_{\text {prova }}=\omega_{\text {bombeio }}+3 G H z$ cumpre-se. Foi observada uma amplificação próxima a 300\%. Fechando o processo paramétrico, é gerado o feixe do conjugado pelo canal Stokes com uma frequência $\omega_{\text {prova }}=\omega_{\text {conjugado }}-3 G H z$ no mesmo instante $t_{3}$. Essa é a mistura de quatro ondas na configuração AntiStokes para o feixe de prova no rubídio 85.

Pela mesma razão do que no processo no tempo $t_{1}$, foi possível comprovar que a mistura acontece no isótopo 85 e não no 87 . Até agora foram observados dos processos de mistura de quatro ondas no instante $t_{1}$ e $t_{3}$ respetivamente com a diferença no canal de entrada para o feixe de prova. Ademas reparou-se uma absorção fora da absorção natural do rubídio.

A célula de rubídio também tem uma concentração do isótopo de rubídio 87. No instante $t_{1}^{\prime}$ anterior a $t_{1}$, observa-se uma absorção em fig. 3.3a. A diferença de frequência dos níveis hiperfinos $5^{2} S_{1 / 2}(F=1)$ e $5^{2} S_{1 / 2}(F=2)$ para o rubídio 87 é $6.84 G H z$. Consequentemente a absorção está relacionada com o rubídio 87 . Por outro lado no segundo detector não se observou nenhum efeito no mesmo instante de tempo. 


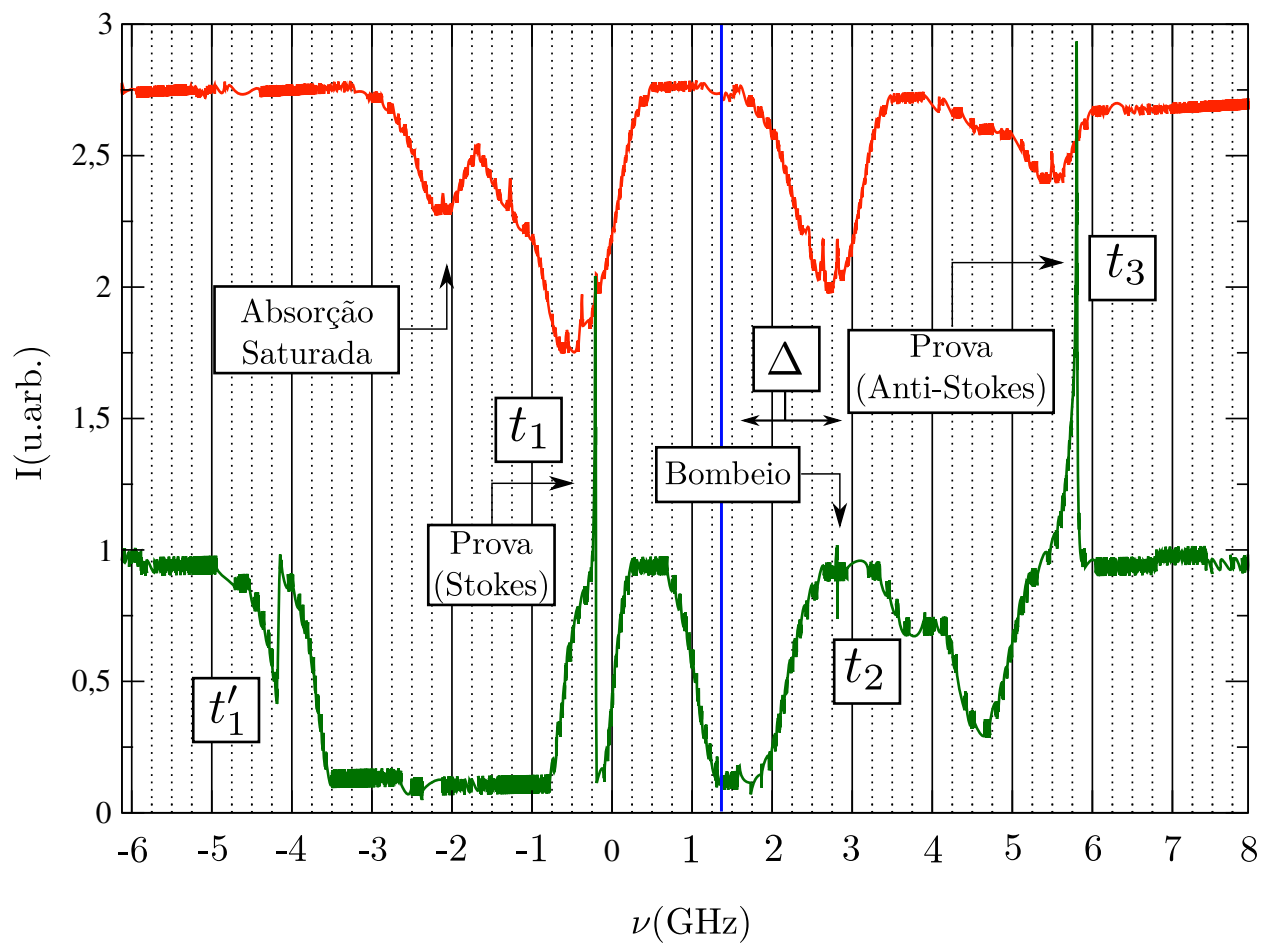

(a) Sinal do detector $D_{1}$ (Embaixo-Verde) Absorção não saturada do feixe de prova depois que os feixes de prova e bombeio atravessam a célula de $\mathrm{Rb}$ (fig. 3.1). Observou-se a amplificação do feixe de prova nos canais Stokes e Anti-Stokes. (Acima-Vermelho) Espectro de absorção saturada do Rb na linha D1.

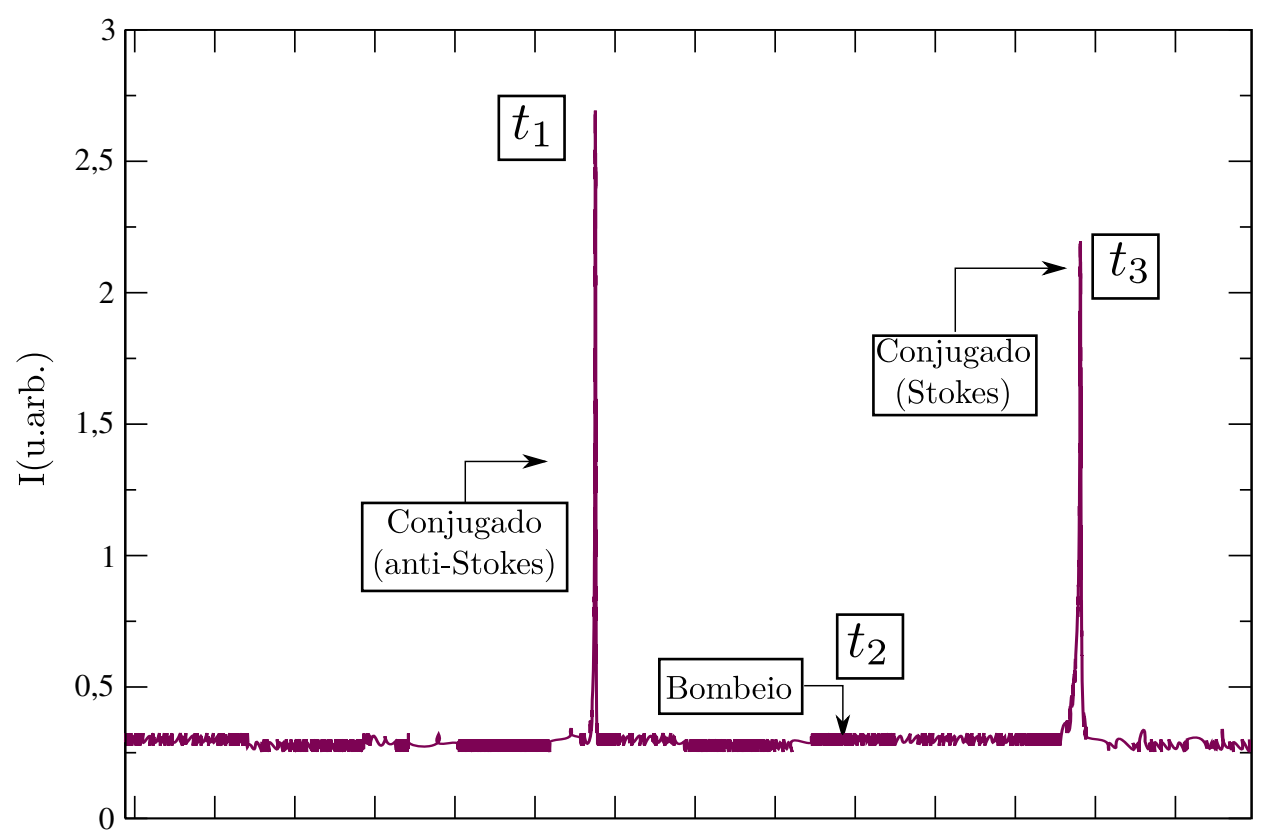

\section{$t$}

(b) Sinal do detector $D_{2}$. (fig. 3.1) Geração do feixe conjugado nos canais Anti-Stokes y Stokes.

Figura 3.3 - Obtenção do fenômeno de Mistura de Quatro Ondas (Exemplo 1). nos tempos respetivos $t_{1}$ e $t_{3}$, onde $t_{1}<t_{2}<t_{3}$. Foi reproduzido o mesmo resultado que no experimento do P.Lett [12] O bombeio está dessintonizado $\Delta=1,5 \mathrm{GHz}$. 


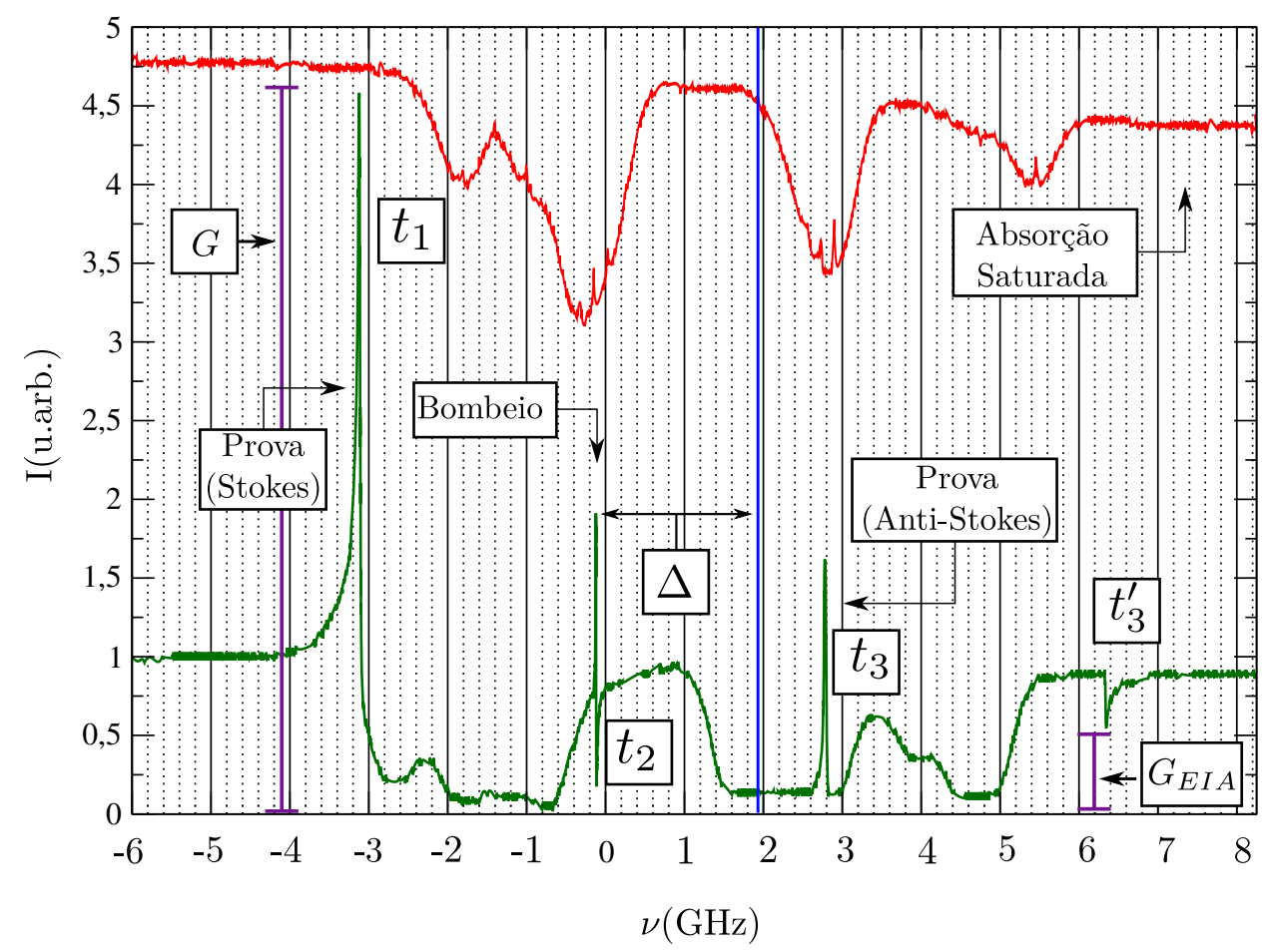

(a) Sinal do detector Det $_{1}$. (Embaixo-Verde) Absorção não saturada depois que os feixes de prova e bombeio atravessam a célula de $\mathrm{Rb}$ (fig. 3.1). Observou-se a amplificação do feixe de prova nos canais Stokes e AntiStokes, e na sintonia. (Acima-Vermelho) Espectro de absorção saturada do rubídio na linha D1. $t_{1}<t_{2}<t_{3}$.

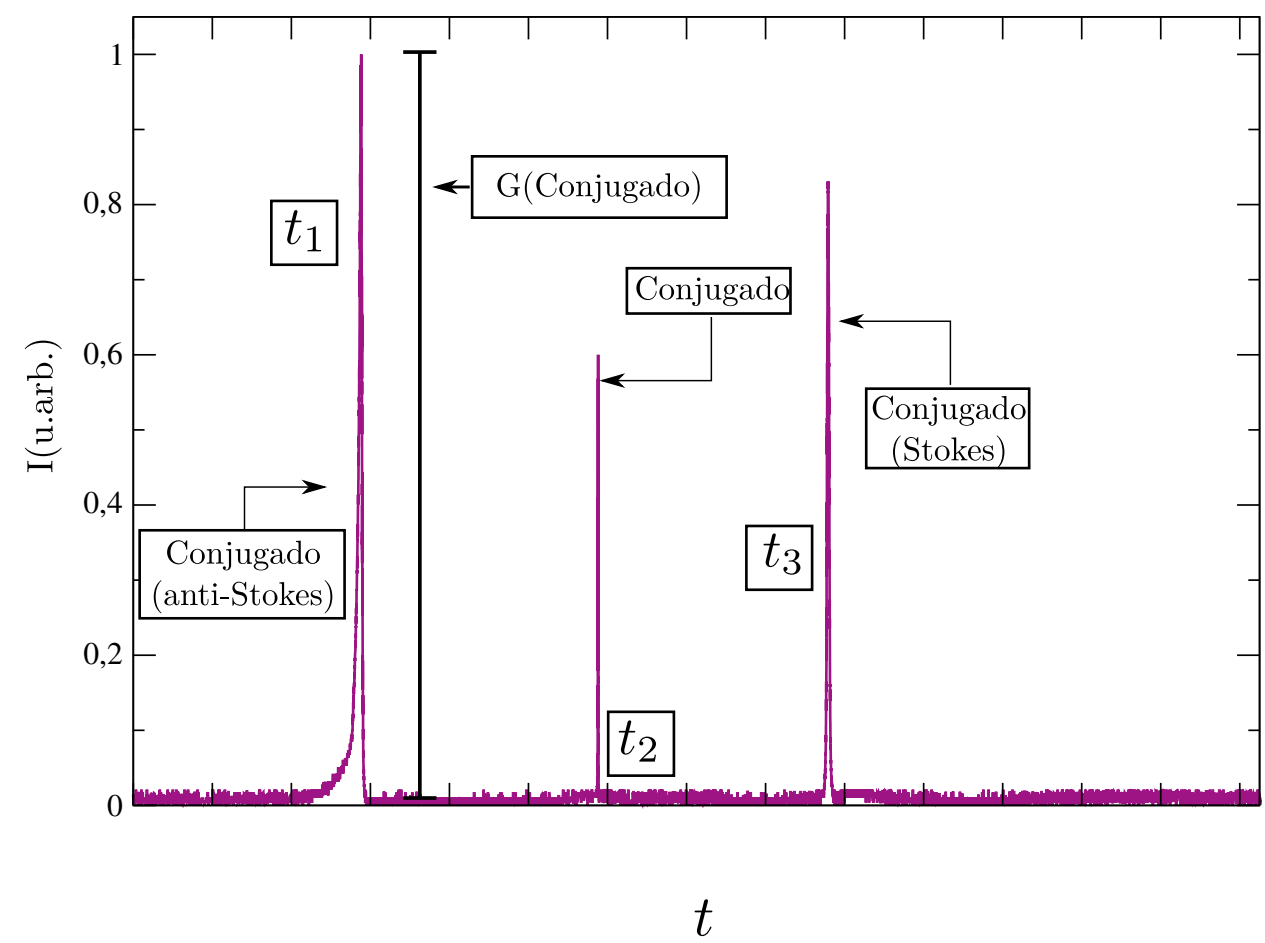

(b) Sinal do detector Det $_{2}$. Geração do feixe conjugado nos canais Anti-Stokes, Stokes e na sintonia.

Figura 3.4 - Obtenção do fenômeno de Mistura de Quatro Ondas (Exemplo 2). O bombeio está dessintonizado $\Delta=-2 \mathrm{GHz}$. Geração do conjugado na sintonia $t_{2}$, como na fig. 3.2b. 


\subsubsection{Exemplo 2: Mistura de quatro ondas com dessintonia do bombeio de}

$$
\Delta=-2.0 G \mathrm{~Hz}
$$

Nesse caso a dessintonia do bombeio mudou-se para o valor $\Delta=-2 G H z$. Os instantes do tempo $t_{i}$ nesse novo exemplo não correspondem aos $t_{i}$ do exemplo 1 , para todos os valores de $i=1,2,3$.

No instante de tempo $t_{1}$ apreciou-se na fig. 3.4a o ganho gerado pela mistura de quatro ondas com o feixe de prova no canal de entrada Stokes. O ganho é aproximadamente de $450 \%$. Contrariamente ao que acontece na fig. 3.3a no canal Stokes para o prova, não se observou uma absorção nas proximidades da amplificação em $t_{1}$. O processo é fechado ao ser gerado o conjugado pelo canal Anti-Stokes fig. 3.4b. Como os feixes do prova e conjugado são gerados a uma frequência de $-3 G H z$ e $+3 G H z$ respetivamente em relação ao bombeio, o processo aconteceu no isótopo 85.

No instante de tempo $t_{2}$ reparou-se um processo que não foi observado no exemplo 1. Nesse caso o feixe de prova está sintonizado com o feixe de bombeio. Na fig. 3.4a o feixe de prova é amplificado até um $200 \%$ e próximo a ele, tem uma absorção. Entretanto em fig. 3.4b o feixe do conjugado detetou-se com uma amplificação apreciável. Essa é a mistura de quatro ondas degenerada, na qual o bombeio, prova e conjugado tem a mesma frequência, como representado em fig. 3.2c. Mesmo eles tendo a mesma frequência, a sua direção de propagação espacial é diferente. Além disso, pelo fato de os feixes estarem em ressonância não é justificável dizer que o processo aconteceu em algum dos isótopos por separado. Pela abundancia de $72.12 \%$ do rubídio 85 e $27.83 \%$ do rubídio 87 , é razoável expressar que o processo aconteceu nessa mesma proporção e ao mesmo tempo nos dois tipos de átomos. O pico representa a soma dos dois processos em alguma proporção desconhecida.

No instante de tempo $t_{3}$ reparou-se a absorção e amplificação simultânea do prova entrando pelo canal Anti-Stokes em fig. 3.4a. Gerou-se o conjugado em fig. 3.4b. O processo é a mistura de quatro ondas com o feixe de prova Anti-Stokes para o rubídio 85.

No instante de tempo $t_{3}^{\prime}$ em fig. 3.4a constatou-se um processo não observado até agora. Notou-se uma absorção análoga a aquela do exemplo 1 no instante de tempo $t_{1}$ para esse caso. Uma diferença importante entre os vales é a direção de abertura da absorção. No caso do exemplo 1, ao se aproximar ao tempo $t_{1}^{\prime}$ a luz começa a ser absorvida até ter uma transição forte a uma minuscula amplificação fig. 3.3a. Por oposição em fig. 3.4a, ao se aproximar no $t_{3}^{\prime}$ primeiro aconteceu uma amplificação pequena logo após uma transição forte a uma absorção. Esse pico fica a uma frequência de $+6.8 \mathrm{GHz}$, pelo que está relacionado com o rubídio 87. Não é possível afirmar que é mistura de quatro ondas, por que não se observou a geração do conjugado. 


\subsubsection{Caracterização da mistura de quatro ondas em função de diferentes parâmetros experimentais}

O conjunto de processos de Mistura de Quatro Ondas e absorção antes descritos nos exemplos 1 e 2 serão estudados detalhadamente. Os parâmetros modificados para o estudo são: Dessintonia do bombeio $\Delta$, intensidade do bombeio $I_{B}$ e temperatura da célula $T_{R b}$. Cada parâmetro calculou-se e/ou mediu-se da seguente forma:

- Dessintonia do bombeio $\Delta$. Definiu-se como $\Delta=\omega_{\text {bombeio }}-\omega_{0}$ em que $\omega_{0}$ corresponde a frequência da transição do pico do crossover ${ }^{85} \mathrm{Rb}: 5 S_{1 / 2}(F=2) \rightarrow 5 P_{1 / 2}\left(F^{\prime}=2\right.$ co 3$)$. O pico dessa transição é a letra $h$ na fig. 2.6, e corresponde ao valor $\lambda_{0}=794,975345 \mathrm{~nm}$. Segundo a tab. 3.1 variou-se na faixa $\Delta \in[-7 ; 6] G H z$.

- Intensidade do campo de bombeio e do campo de prova. Calculou-se mediante a equação

$$
I=\frac{P}{\pi \omega^{2}}
$$

no qual a potência $P$ mediu-se com o sensor S121C de Silício da THORLABS [44], e a cintura $\omega$ (ver sec. 1.4) com o BEAMPROFILE da THORLABS. Os raios das cinturas dos dois feixes foram mantidas constantes no percurso do experimento. Os valores foram $R_{B}=(326 \pm 38) \mu m$ para o bombeio e $R_{P}=(187 \pm 38) \mu m$ para o prova.

- Temperatura da célula de rubídio. Utilizou-se uma célula com abundancia natural dos isótopos 85 e 87. Ela foi esquentada mediante uma corrente que atravessa um fio resistor (ver fig. 2.5). Mediu-se a temperatura com um circuito integrado LM35 e um termopar.

- Ângulo $\theta$ formado entre o feixe de bombeio e o de prova. Permaneceu constante com um valor de $\theta \approx 0.08^{0}$.

O comprimento da célula de rubídio foi $L_{c}=(78.05 \pm 0.05) \mathrm{mm}$. Todas as medidas de comprimento de onda foram feitas com o BRISTOL INSTRUMENTS 671 [7, 8]. 


\subsubsection{Coeficientes de absorção e amplificação}

Prévio ao análise dos dados experimentais, é importante definir os coeficientes de amplificação paramétrica e de absorção. Todos os dados obtidos foram normalizados em relação ao começo e final da varredura. Esses pontos são tais que não existe absorção dos isótopos de rubídio. Os eixos da frequência em todos os espectros obtidos foram deslocados até a transição $h$ na fig. 2.6, correspondente ao valor $\lambda_{0}=794,975345 \mathrm{~nm}$.

Posteriormente à normalização definimos o coeficiente de amplificação $G$ e o coeficiente de absorção $G_{E I A}$ como:

$$
\begin{gathered}
G=\frac{\text { Valor máximo do pico da intensidade do campo amplificado }}{\text { Valor da intensidade do campo sem amplificar }} \\
G_{E I A}=\frac{\text { Valor mínimo do vale de intensidade do campo absorvido }}{\text { Valor da intensidade do campo sem absorção }}
\end{gathered}
$$

\begin{tabular}{c|c|c|c|c|c|c}
\hline $\mathrm{P}_{a}$ & $\begin{array}{c}\Delta \\
( \pm 0,05 \mathrm{GHz})\end{array}$ & $\begin{array}{c}I_{\mathrm{B}}[ \pm 5 \%] \\
\left(\mathrm{W} / \mathrm{cm}^{2}\right)\end{array}$ & $\begin{array}{c}I_{\mathrm{Pr}}[ \pm 5 \%] \\
\left(\mathrm{W} / \mathrm{cm}^{2}\right)\end{array}$ & $\begin{array}{c}T_{\mathrm{Rb}} \\
\left({ }^{\circ} \mathrm{C}\right)\end{array}$ & $\begin{array}{c}\approx \theta \\
\left( \pm 0.01^{o}\right)\end{array}$ & $\begin{array}{c}T_{\mathrm{Lab}} \\
\left({ }^{o} \mathrm{C}\right)\end{array}$ \\
\hline$\Delta$ & $\Delta \in[-7 ; 6]$ & 33,6 & 0,12 & $83,8 \pm 0,4$ & 0,12 & $22,9 \pm 0,1$ \\
\hline & 0,78 & & & & \\
$I_{\mathrm{B}}$ & 0,92 & $I_{\mathrm{B}} \in[4,7 ; 28,0]$ & 0,05 & $78,6 \pm 0,5$ & 0,08 & $22,5 \pm 0.1$ \\
& 1,08 & & & & & \\
\hline$I_{\mathrm{Pr}}$ & 1,19 & 30,0 & $I_{\mathrm{Pr}} \in[0,02 ; 0,42]$ & $78,2 \pm 0,4$ & 0,08 & $22,5 \pm 0,1$ \\
\hline \multirow{2}{*}{$T_{\mathrm{Rb}}$} & 1,11 & 29,7 & 0,17 & $T_{\mathrm{Rb}} \in[54 ; 110]$ & 0,08 & $22,8 \pm 0,2$ \\
\hline
\end{tabular}

Tabela 3.1 - Parâmetros usados na caracterização. O parâmetro de controle é alterado deixando os demais fixos. $\Delta$ dessintonia do feixe de bombeio. $I_{\mathrm{B}}$ intensidade do campo de bombeio. $I_{\mathrm{Pr}}$ intensidade do campo de prova. $T_{\mathrm{Rb}}$ temperatura da célula de rubídio. $\theta$ ângulo entre os feixes de prova e bombeio. $T_{\mathrm{Lab}}$ temperatura do laboratório. Cinturas dos feixes de bombeio e prova na região de interação $R_{\mathrm{B}}=(326 \pm 38) \mu \mathrm{m}$ e $R_{\mathrm{Pr}}=(187 \pm 38) \mu \mathrm{m}$.

Note-se no exemplo fig. 3.4a e fig. 3.4b. O coeficiente $G$ mede a amplificação nos possíveis casos de canais Stokes e Anti-Stokes para o prova e Anti-Stokes e Stokes para o conjugado. Repare-se que ao falar do processo de mistura de quatro ondas pelo canal Stokes do prova, o feixe conjugado tem que passar pelo canal Anti-Stokes fig. 3.2a. Acontece o mesmo ao falar da mistura de quatro ondas pelo canal Anti-Stokes do prova deixando como única opção que o conjugado seja gerado no canal Stokes fig. 3.2b. 


\subsubsection{Ganho em função da dessintonia do bombeio}

Estudou-se o ganho $G$ e $G_{E I A}$ em função da dessintonia do bombeio $\Delta$. A faixa de dessintonias foi $\Delta \in[-7,0 ; 6,0]$ segunda a tab. 3.1. Ela foi gerada com uma amostra de setenta dados, cada um deles do tipo dos exemplos fig. 3.3 e fig. 3.4. Separou-se a informação de cada espectro em duas figuras, fig. 3.5a e fig. 3.5b para o rubídio 85 e 87 respectivamente. Logo após cada figura foi dividida em duas possíveis configurações de entrada para o feixe de prova, o canal Stokes fig. 3.2a e o canal Anti-Stokes fig. 3.2b para o feixe de prova.

\section{Rubídio 85: Prova no canal Stokes}

Dependendo de cada valor $\Delta$ em fig. 3.5a, o feixe de prova Stokes encontra-se a $\omega_{\text {prova }}=\Delta-3 G H z$, como no instante $t_{1}$ em fig. 3.3a. Em segundo lugar o feixe conjugado estará na mesma figura intitulada de Stokes com $\omega_{\text {conjugado }}=\Delta+3 G H z$ como no instante $t_{1}$ em fig. 3.3b. Fica claro então que para um valor $\Delta$, o valor da frequência do conjugado e do prova encontram-se dessintonizados, mesmo aparecendo no mesmo valor de frequência $\Delta$. $\mathrm{O}$ valor de absorção encontra-se na mesma frequência do prova $\omega_{\text {prova }}=\Delta-3 G H z$, como no instante $t_{1}$ em fig. 3.3a.

Repara-se que nas faixas $\Delta \leq-2 \mathrm{GHz}$ e $\Delta \in[0.5 ; 2] \mathrm{GHz}$ de fig. 3.5a existe amplificação do prova no canal Stokes (preto). Os máximos são em $\Delta \approx-3.34 ;-2.44 ; 1.01$. A absorção logo após da amplificação existe para $\Delta \geq-4$ (vermelho). Não é possível ter um valor de comparação para o feixe conjugado, sendo as suas unidades de intensidade arbitraria. A geração do conjugado Anti-Stokes (azul) percebeu-se em quase toda a região e os máximos estão nos mesmos máximos do prova Stokes.

\section{Rubídio 85: Prova no canal anti-Stokes}

Dependendo de cada valor $\Delta$ em fig. 3.5a, o feixe de prova Anti-Stokes encontra-se a $\omega_{\text {prova }}=\Delta+3 G H z$ (preto), como no instante $t_{3}$ em fig. 3.3a. Em seguida o feixe conjugado estará na mesma figura intitulada de Anti-Stokes com $\omega_{\text {conjugado }}=\Delta-3 G H z$ como no instante $t_{3}$ em fig. $3.3 b$ (Azul). $\mathrm{O}$ valor de absorção encontra-se na mesma frequência do prova $\omega_{\text {prova }}=$ $\Delta+3 G H z$, como no instante $t_{3}$ em fig. 3.3a (vermelho).

O campo de prova Anti-Stokes apresenta amplificação aproximadamente em um $70 \%$ da região de estudo. Os máximos estão em $\Delta \approx-3.63 ;-2.01 ;-0.78 ; 0,77 \mathrm{GHz}$. O campo conjugado Stokes apresenta seus máximos de intensidade nas mesmas dessintonias. O valor da absorção é nulo para $\Delta>0.4 \mathrm{GHz}$. Essa região é de muito interesse por que a amplificação do prova e a intensidade do conjugado são muito altas e a absorção nula. Nessa mesma região no 
caso anterior Stokes, a amplificação do prova e intensidade do conjugado são altas no entanto a absorção é diferente do zero.

\section{Rubídio 87: Prova no canal Stokes}

Dependendo de cada valor $\Delta$ em fig. 3.5b, o feixe de prova Stokes encontra-se a $\omega_{\text {prova }}=\Delta-6.8 G H z$ (preto), como no instante $t_{1}^{\prime}$ em fig. 3.4a. Logo após o feixe conjugado estará na mesma figura intitulada de Stokes com $\omega_{\text {conjugado }}=\Delta+6.8 G H z$ (azul). $\mathrm{O}$ valor de absorção encontra-se na mesma frequência do prova $\omega_{\text {prova }}=\Delta-6.8 G H z$ (vermelho), como no instante $t_{1}^{\prime}$ em fig. 3.4a. Note-se que pela varredura de aproximadamente $14 \mathrm{Ghz}$ como nos exemplos fig. 3.3 e fig. 3.4, o feixe de prova no canal Stokes só foi estudado na região $\Delta>-1.5 \mathrm{GHz}$.

Praticamente a amplificação do feixe de prova Stokes no existe na região de estudo. O feixe tem amplificação ao entrar no vale das transições do rubídio $855 S_{1 / 2}(F=2) \rightarrow$ $5 P_{1 / 2}\left(F^{\prime}\right)$ e do rubídio $875 S_{1 / 2}(F=1) \rightarrow 5 P_{1 / 2}\left(F^{\prime}\right)$. No entanto essa amplificação nunca consegue ser maior do que 1 , pela absorção natural da largura doppler do rubídio. Verificou-se a geração do feixe conjugado Anti-Stokes com intensidades baixas em comparação ao caso do rubídio 85 . A absorção é máxima na região $\Delta \in[1.5 ; 4.5]$. Só na região $\Delta \in[-1.5 ; 0.5]$ a absorção é baixa e a amplificação é a máxima atingida nesta configuração.

\section{Rubídio 87: Prova no canal anti-Stokes}

Dependendo de cada valor $\Delta$ em fig. 3.5b, o feixe de prova Anti-Stokes encontra-se a $\omega_{\text {prova }}=\Delta+6.8 G H z$ (preto), como no instante $t_{3}^{\prime}$ em fig. 3.3a. Em segundo lugar o feixe conjugado estará na mesma figura intitulada de Anti-Stokes com $\omega_{\text {conjugado }}=\Delta+6.8 \mathrm{GHz}$ (azul). O valor de absorção encontra-se na mesma frequência do prova $\omega_{\text {prova }}=\Delta-6.8 \mathrm{GHz}$ (vermelho), como no instante $t_{3}^{\prime} \mathrm{em} \mathrm{fig.} \mathrm{3.3a.} \mathrm{Note-se} \mathrm{que} \mathrm{pela} \mathrm{varredura} \mathrm{de} \mathrm{aproximadamente}$ $14 \mathrm{Ghz}$ como nos exemplos fig. 3.3 e fig. 3.4, o feixe de prova no canal Anti-Stokes só foi estudado na região $\Delta<0 \mathrm{GHz}$.

Como no caso anterior, a amplificação do feixe de prova pelo canal Anti-Stokes é baixa. A amplificação é mínima em $\Delta=-4 \mathrm{GHz}$. Na faixa $\Delta \in[-3 ; 0]$, tem um valor perto de 1 . Por outro lado a absorção do feixe de prova é maior na faixa $\Delta \in[-5 ;-3]$. A mistura de quatro ondas não é um processo apreciável no rubídio 87 nas condições estudadas. 


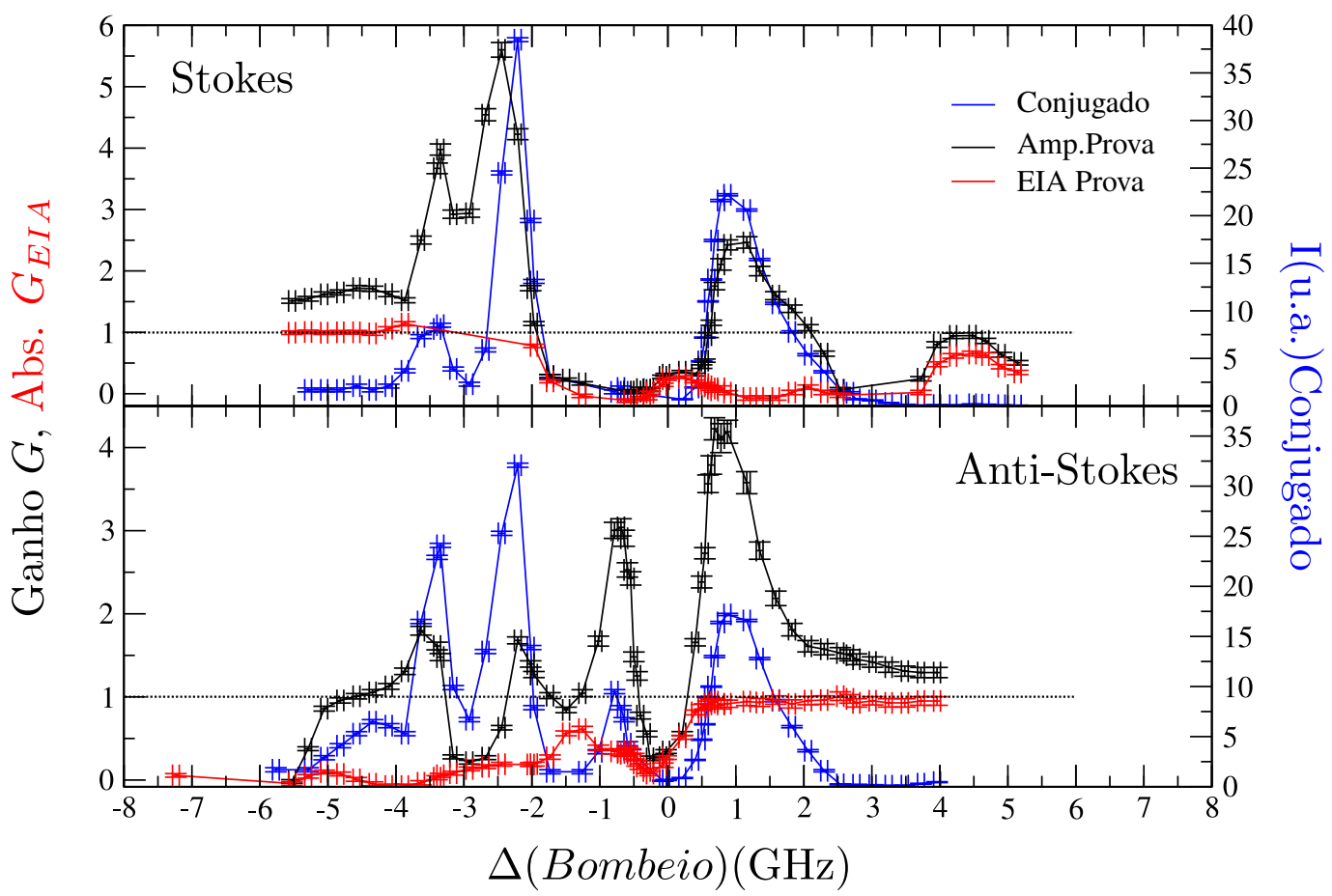

(a) Os feixes de prova e conjugado estão a uma frequência $\Delta \pm 3 \mathrm{GHz}$ dependendo do canal de entrada, para o rubídio 85 .

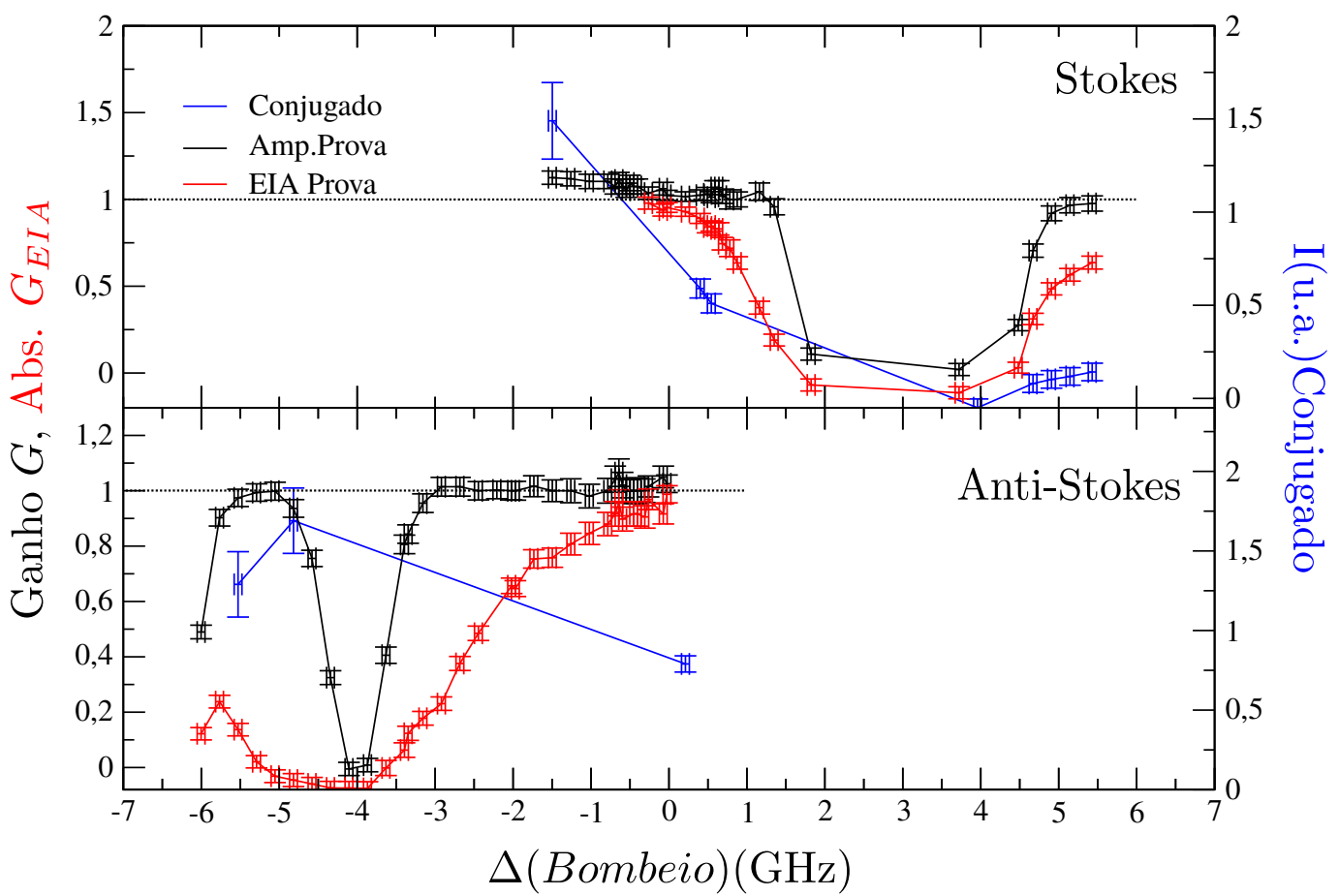

(b) Os feixes de prova e conjugado estão a uma frequência $\Delta \pm 6.8 \mathrm{GHz}$ dependendo do canal de entrada, para o rubídio 87.

Figura 3.5 - Ganhos dos feixes de prova e conjugado em função da dessintonia $\Delta$ do bombeio. Ganhos para os diferentes canais possíveis de entrada para o rubídio 85 fig. $3.5 \mathrm{a}$ e rubídio 87 fig. 3.5b. A escala de intensidade do conjugado é diferente e sempre fica no lado direito. 


\subsubsection{Ganho em função da potência de bombeio}

A segunda caracterização foi feita em função da intensidade do feixe de bombeio. Segundo a tab. 3.1 a intensidade foi varrida na faixa $I_{B} \in[4,7 ; 28,0] \mathrm{W} / \mathrm{cm}^{2}$. Na fig. 3.5a com o prova no canal Anti-Stokes, esses valores não tem absorção como já foi estudado. Além disso o ganho do feixe de prova Anti-Stokes é da ordem de $4 \mathrm{em} \Delta=0.77 \mathrm{GHz}$. Escolheu-se estudar valores perto desse máximo. Estudou-se o sistema para quatro dessintonias do bombeio $\Delta=0,78 ; 0,92 ; 1,08 ; 1,19 \mathrm{GHz}$. Todas as figuras apresentam uma curva para ajudar aos olhos.

\section{Amplificação prova e absorção}

Em todas as figuras fig. 3.6b, fig. 3.7b, fig. 3.8b, fig. 3.9b estudou-se os processos nos dois isótopos. Notou-se que a amplificação do feixe de prova, mesmo entrando pelo canal Stokes ou Anti-Stokes, sempre teve um comportamento monotonamente crescente ao aumentar a intensidade do bombeio. De forma idêntica, a absorção para os dois isótopos sempre aumento. O melhor valor de amplificação do prova reparou-se no canal de entrada Anti-Stokes para o isótopo 85, com uma intensidade de $I_{B}=28 \mathrm{~W} / \mathrm{cm}^{2}$. O canal Anti-Stokes para o prova sempre tem uma maior eficiência do que o Stokes, no ${ }^{85} \mathrm{Rb}$. A dessintonia $\Delta=0.78 \mathrm{GHz}$ fig. $3.6 \mathrm{~b}$ tem a maior amplificação do prova Anti-Stokes e absorção em comparação com as outras três dessintonias fig. 3.7b,fig. 3.8b, fig. 3.9b. Por outro lado os processos no rubídio 87 não apresentam sinal de uma mudança apreciável. A absorção aumenta porém, a amplificação do prova não foi estudada. Um fato a mais para demostrar que o processo de mistura de quatro ondas no rubídio 87 na linha D1 nas condições estudadas não é o fenômeno predominante.

\section{Intensidade conjugado}

Em todas as figuras fig. 3.6a, fig. 3.7a, fig. 3.8a, fig. 3.9a estudou-se só os processos no rubídio 85. A intensidade do feixe conjugado em qualquer canal de entrada sempre teve um comportamento monotonamente crescente ao aumentar a intensidade do bombeio. Quando o conjugado é gerado no canal Stokes (o feixe de prova no Anti-Stokes, pela notação nos exemplos fig. 3.5) a intensidade sempre foi maior do que sendo gerado no canal Anti-Stokes. Atingiuse o maior ponto com a máxima intensidade sob estudo, $I_{B}=28 \mathrm{~W} / \mathrm{cm}^{2}$. O valor do máximo para as quatro frequências foi próximo a $0.55(u . a)$. Conclui-se que a intensidade do bombeio sempre aumenta a intensidade de geração do conjugado, na faixa de estudo, resultado que é correspondente com a teoria em eq. (1.3.21) e eq. (1.3.31). 


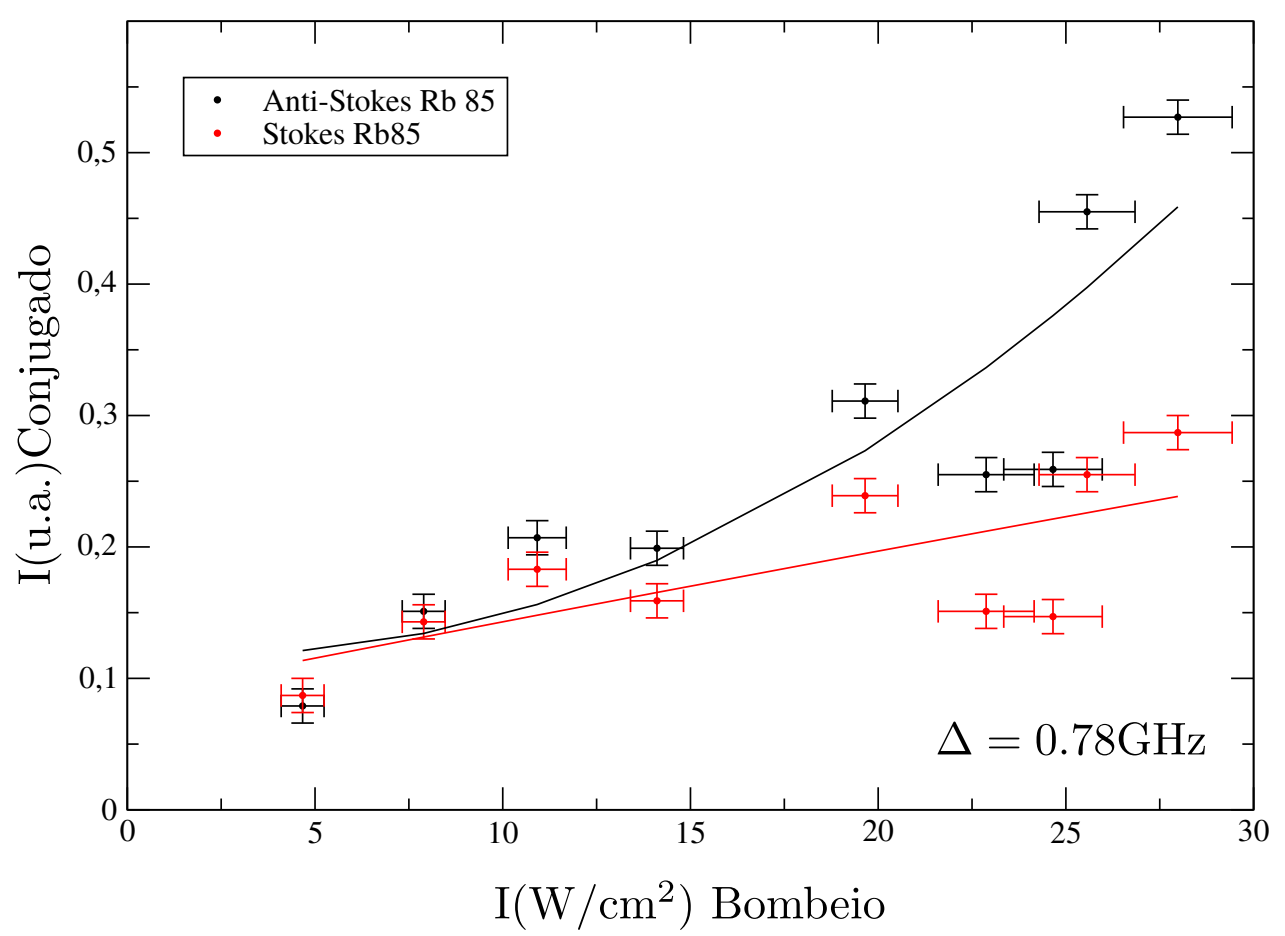

(a) Intensidade do feixe Conjugado para os canais de entrada Anti-Stokes e Stokes para o rubídio 85.

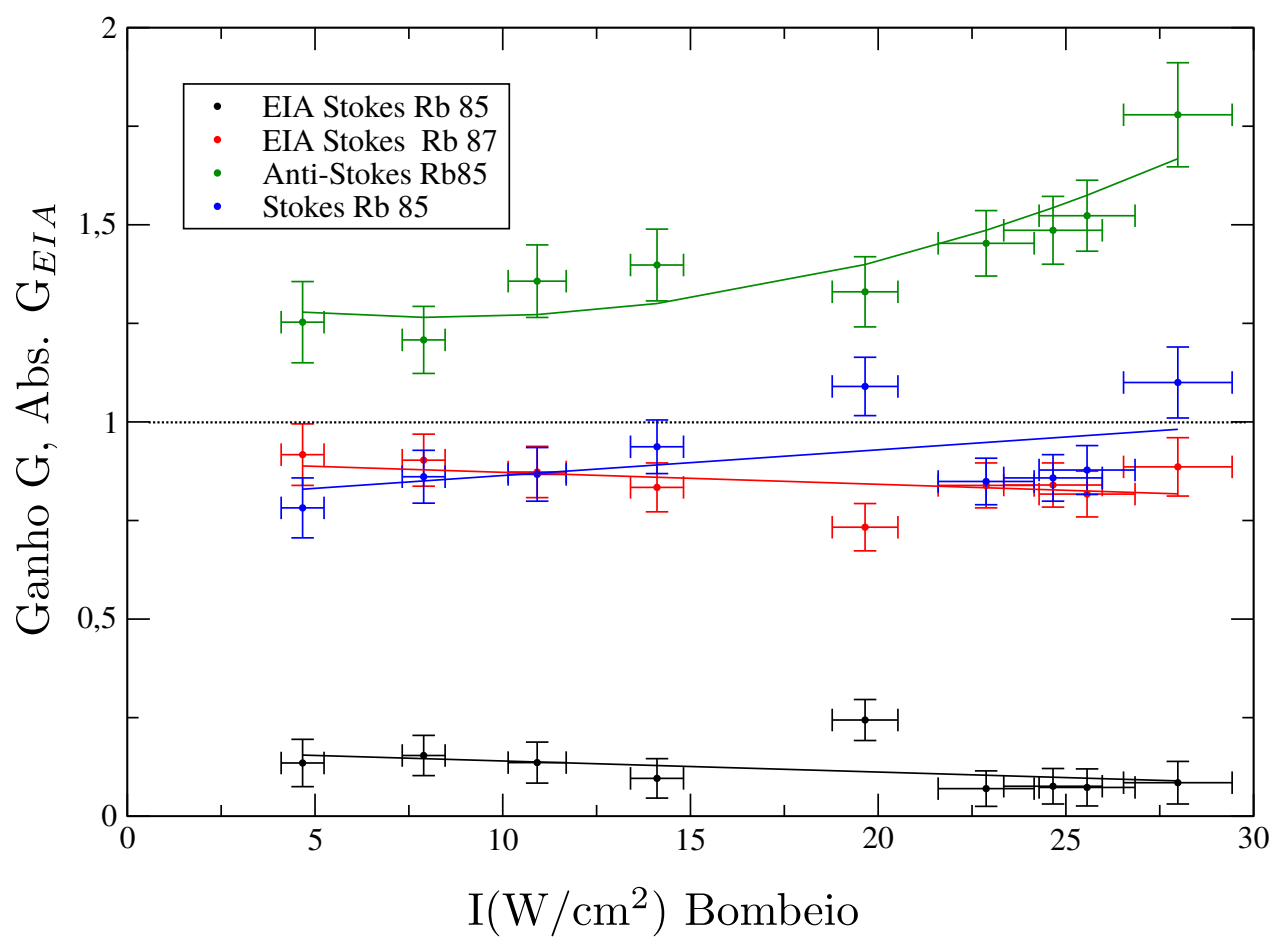

(b) Ganho do feixe de prova, para os canais Stokes e Anti-Stokes, e para a absorção, para o rubídio 85 e 87.

Figura 3.6 - Ganho dos feixes conjugado e prova em função da Intensidade do bombeio. Ganhos para una dessintonia de $\Delta=0.78 \mathrm{GHz}$ do bombeio. 


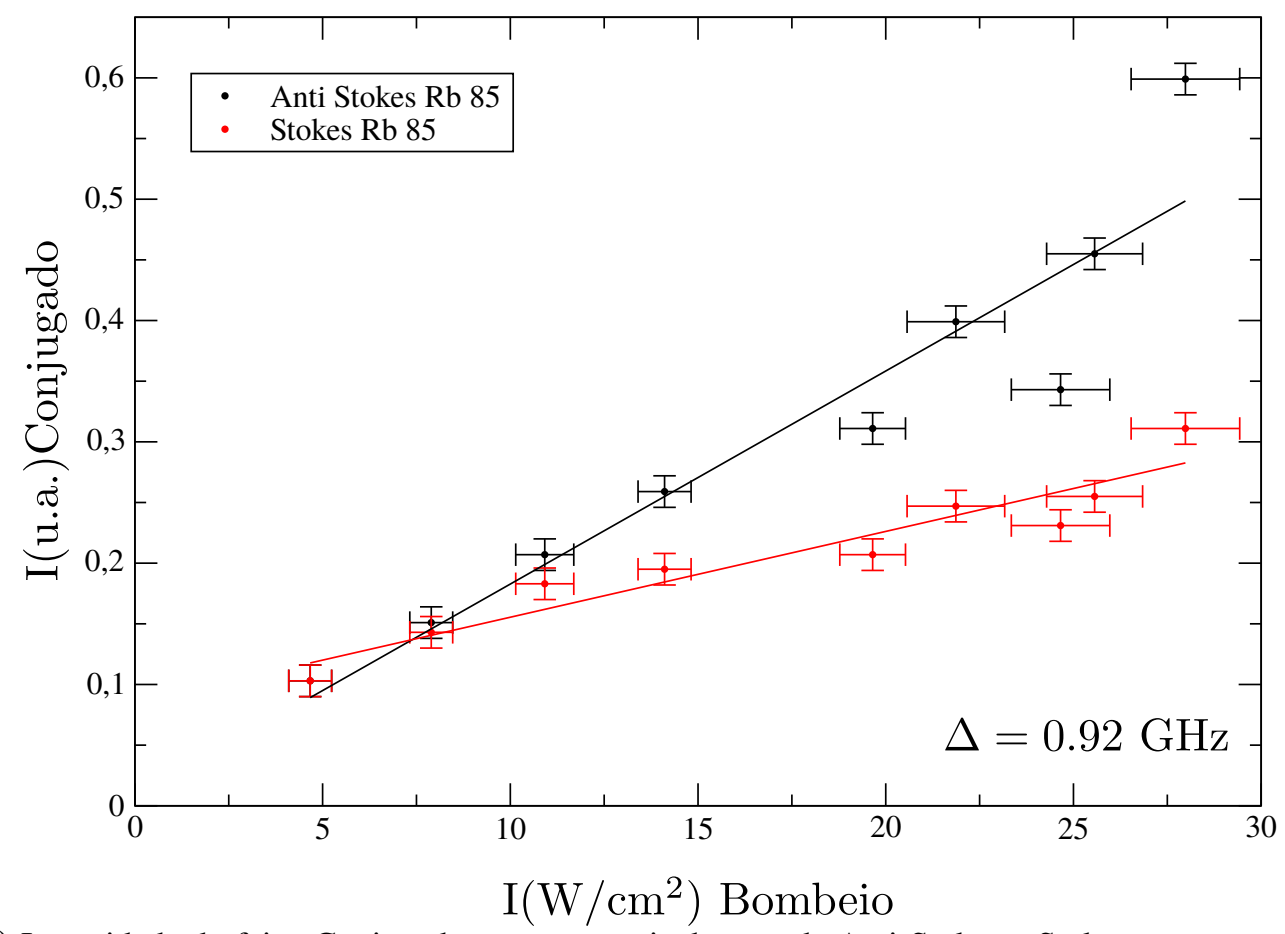

(a) Intensidade do feixe Conjugado para os canais de entrada Anti-Stokes e Stokes para o rubídio 85 .

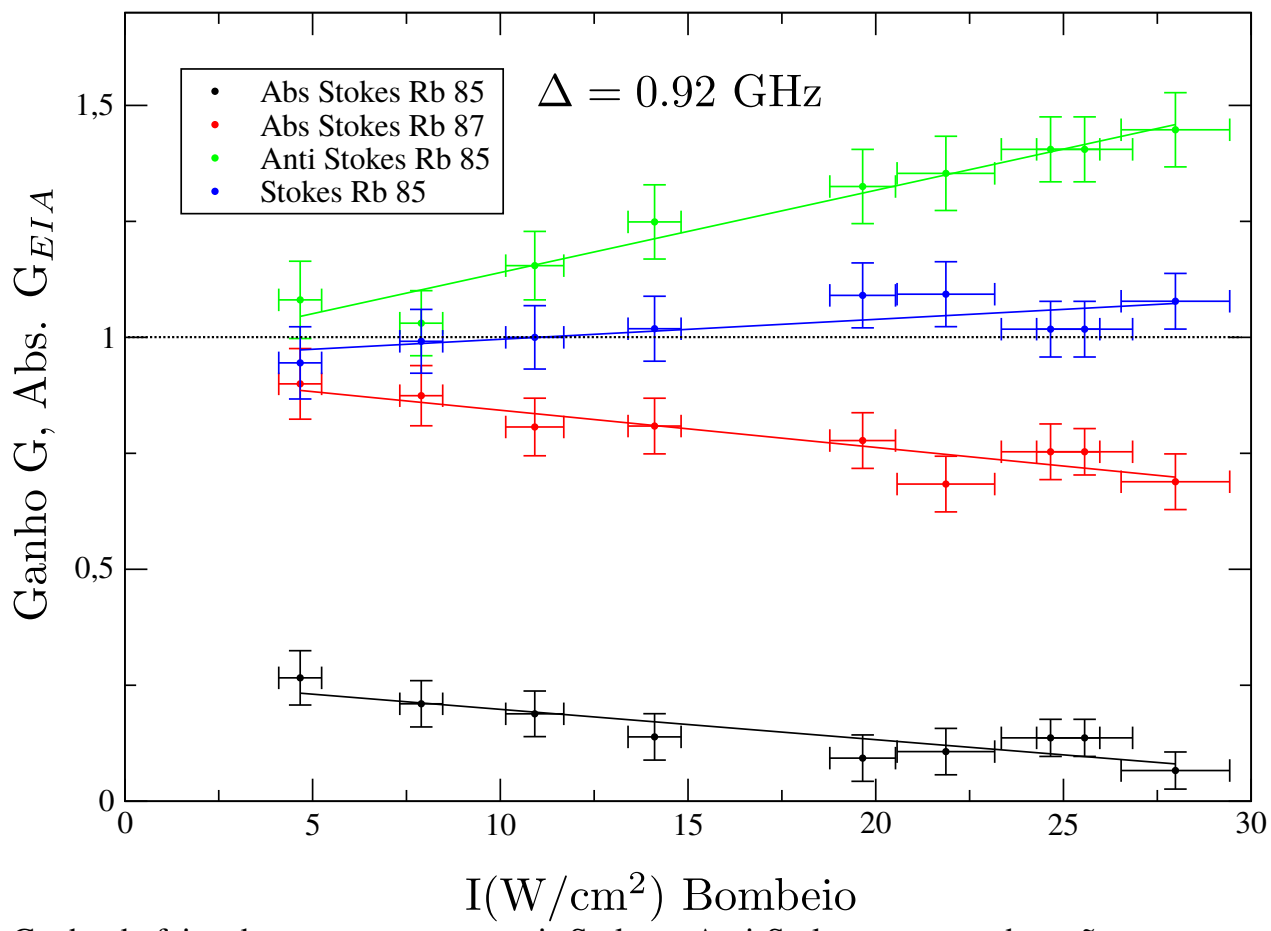

(b) Ganho do feixe de prova, para os canais Stokes e Anti-Stokes, e para a absorção, para o rubídio 85 e 87.

Figura 3.7 - Ganho dos feixes conjugado e prova em função da Intensidade do bombeio. Ganhos para una dessintonia de $\Delta=0.92 \mathrm{GHz}$ do bombeio. 


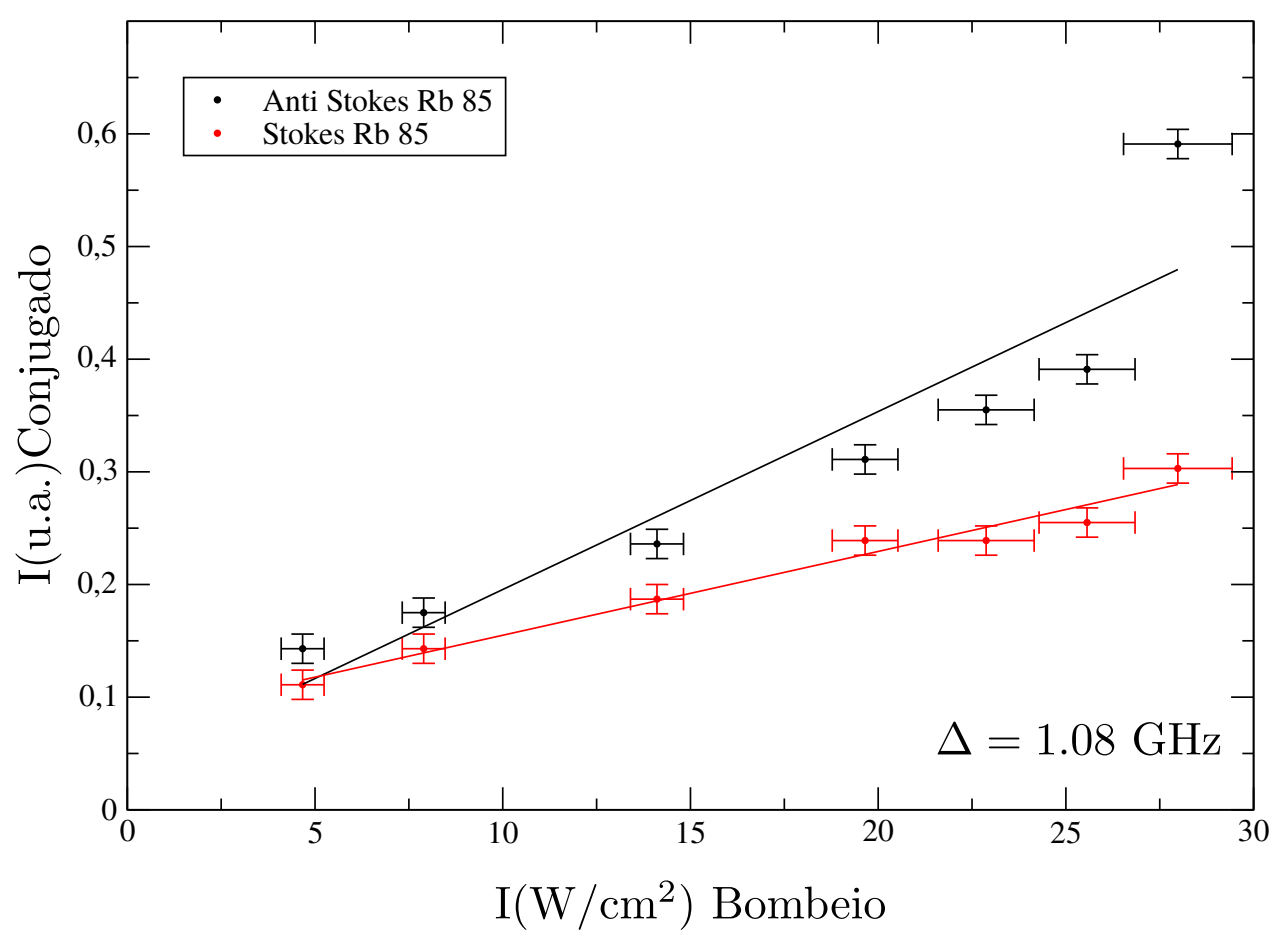

(a) Intensidade do feixe Conjugado para os canais de entrada Anti-Stokes e Stokes para o rubídio 85.

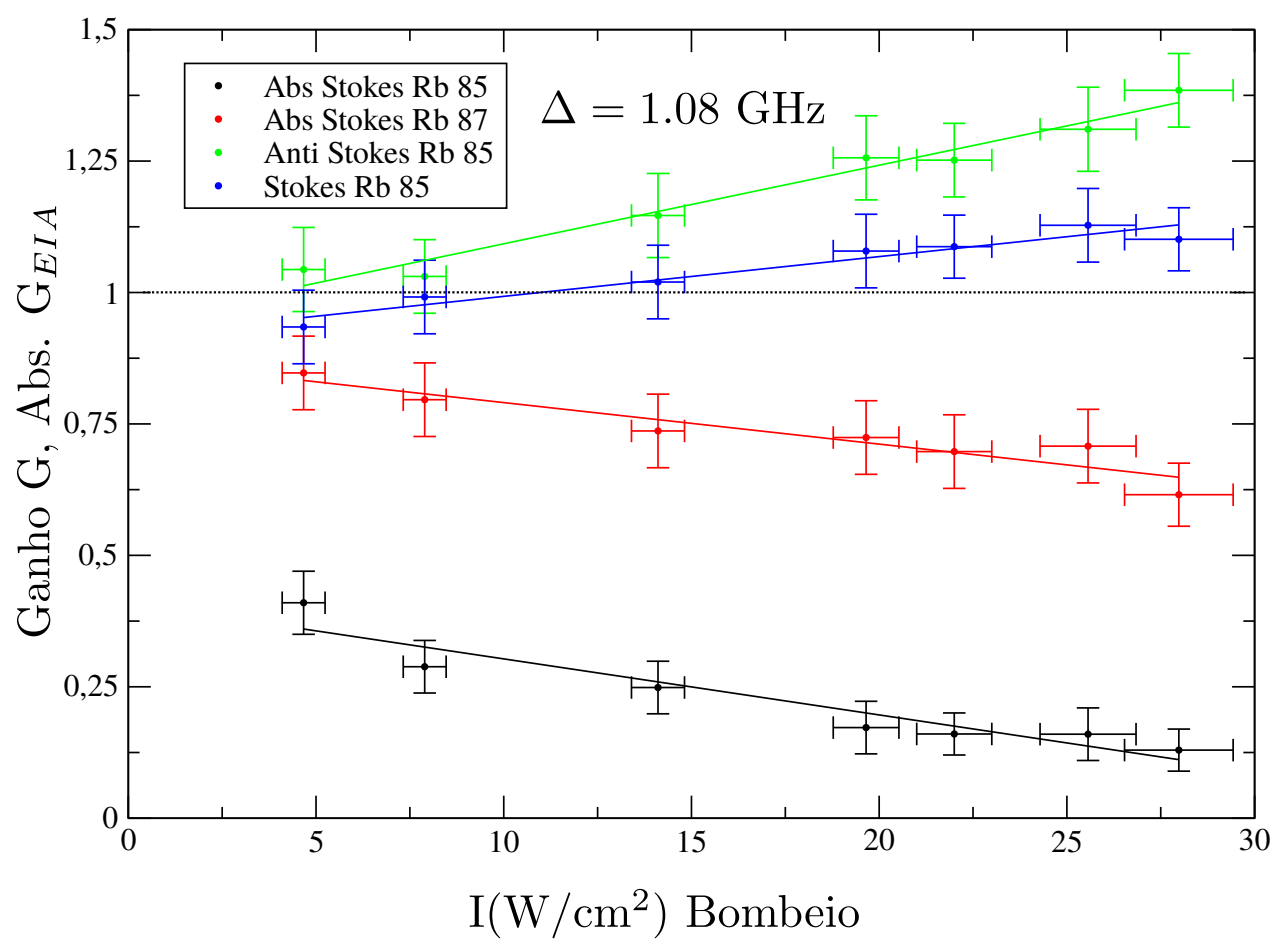

(b) Ganho do feixe de prova, para os canais Stokes e Anti-Stokes, e para a absorção, para o rubídio 85 e 87 .

Figura 3.8 - Ganho dos feixes conjugado e prova em função da Intensidade do bombeio. Ganhos para una dessintonia de $\Delta=1.08 \mathrm{GHz}$ do bombeio. 


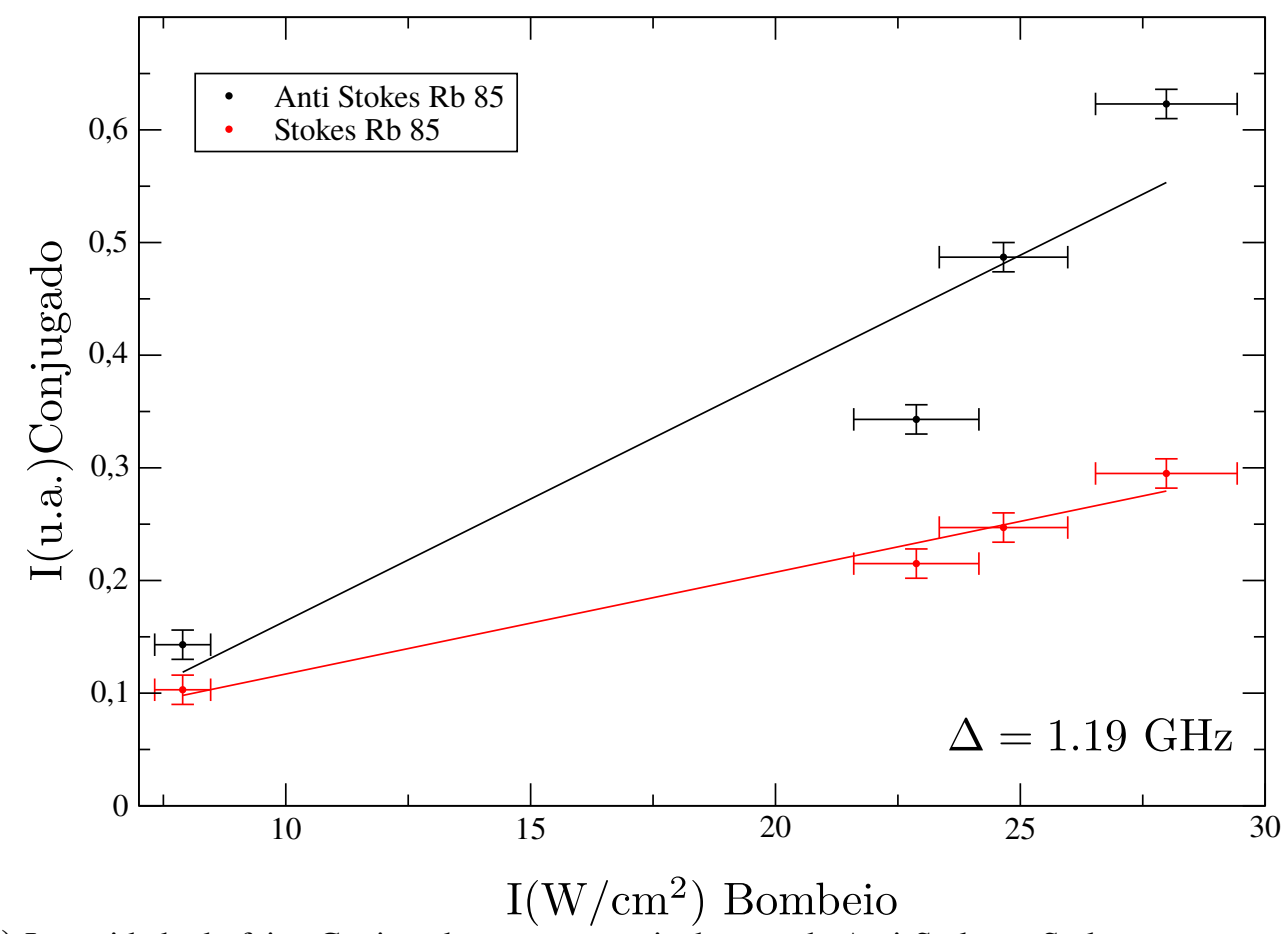

(a) Intensidade do feixe Conjugado para os canais de entrada Anti-Stokes e Stokes para o rubídio 85 .

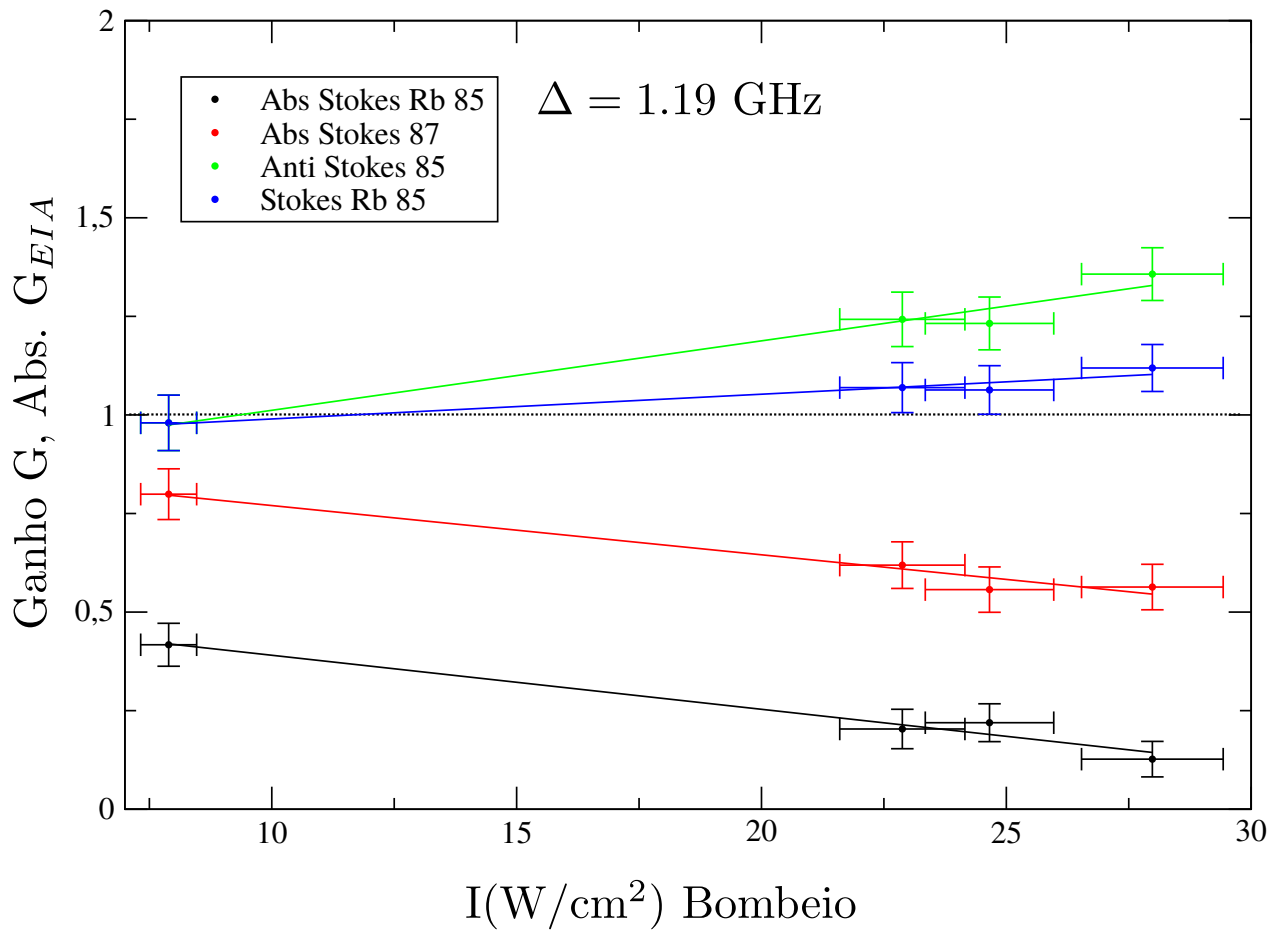

(b) Ganho do feixe de prova, para os canais Stokes e Anti-Stokes, e para a absorção, para o rubídio 85 e 87.

Figura 3.9 - Ganho dos feixes conjugado e prova em função da Intensidade do bombeio. Ganhos para una dessintonia de $\Delta=1.19 \mathrm{GHz}$ do bombeio. 


\subsubsection{Ganho em função da temperatura da célula}

A terceira e última caracterização foi feita em função da temperatura da célula de rubídio. Segundo a tab. 3.1 foram estudadas duas intensidades de bombeio diferentes $I_{B}=$ $[29.7 ; 42.3] \mathrm{W} / \mathrm{cm}^{2}$. A dessintonia do bombeio foi $\Delta=1.11 \mathrm{GHz}$. Estudou-se apenas o comportamento do feixe de prova nos canais Stokes e Anti-Stokes, mesmo assim a absorção para os dois isótopos. O feixe conjugado não foi tratado.

Como explicado em fig. 2.5, um fio resistor metálico envolve a célula de rubídio. A potência dissipada é $P=I V$, com $I$ a corrente que atravessa o fio e $V$ a diferença de tensão aplicada. Consequentemente aumentou-se a potência em cada caso e aguardou-se até a temperatura chegar num valor constante. A densidade atômica esta diretamente relacionada com a temperatura [15].

Para uma intensidade de $I_{B}=29.7 \mathrm{~W} / \mathrm{cm}^{2}$, um circuito integrado LM35 usou-se para medir a temperatura, como mostrado em fig. 3.10a. No eixo $\mathrm{X}$ representou-se a temperatura medida em grãos centigrados e a potência entregue pelo resistor.

Para uma intensidade de $I_{B}=42.3 \mathrm{~W} / \mathrm{cm}^{2}$, além do LM35 usou-se um termopar para medir a temperatura, como mostrado em fig. 3.10b. As medidas do termopar foram sistematicamente maiores em comparação as obtidas com o LM35. Escolheu-se a medida do termopar por ser um instrumento com maior acurácia.

Nos dois casos aumentando a temperatura gerou-se um aumento no ganho da amplifica ção Stokes e Anti-Stokes para o rubídio 85. O ganho no canal Anti-Stokes do prova sempre foi maior do que no Stokes. Em segundo lugar, a absorção também presentou um incremento ao aumento da temperatura. A absorção do rubídio 87 sempre foi menor do que o 85 .

A largura de banda Doppler depende da temperatura, como explicado em sec. 3.1. Ao aumentar a temperatura, a absorção gerada pelas proximidades a qualquer umas das transições dos dois isótopos descritas em fig. 2.6 aumenta. Como no caso da fig. 3.10b para valores próximos de $90^{\circ} \mathrm{C}$ no qual a absorção é máxima.

Como nos casos anteriormente descritos do ganho paramétrico em função da dessintonia e potência do bombeio, o rubídio 87 apresenta um incremento na absorção e o processo de mistura de quatro ondas não é predominante.

Uma conclusão importante é a seguente: é possível atingir valores de amplificação comparáveis aumentando a temperatura da célula e diminuindo a intensidade do feixe. No entanto pela dependência funcional da largura doppler com a temperatura, a absorção também aumenta. Precisa-se fazer uma melhor caracterização da dependência em função de uma faixa maior de temperatura. 


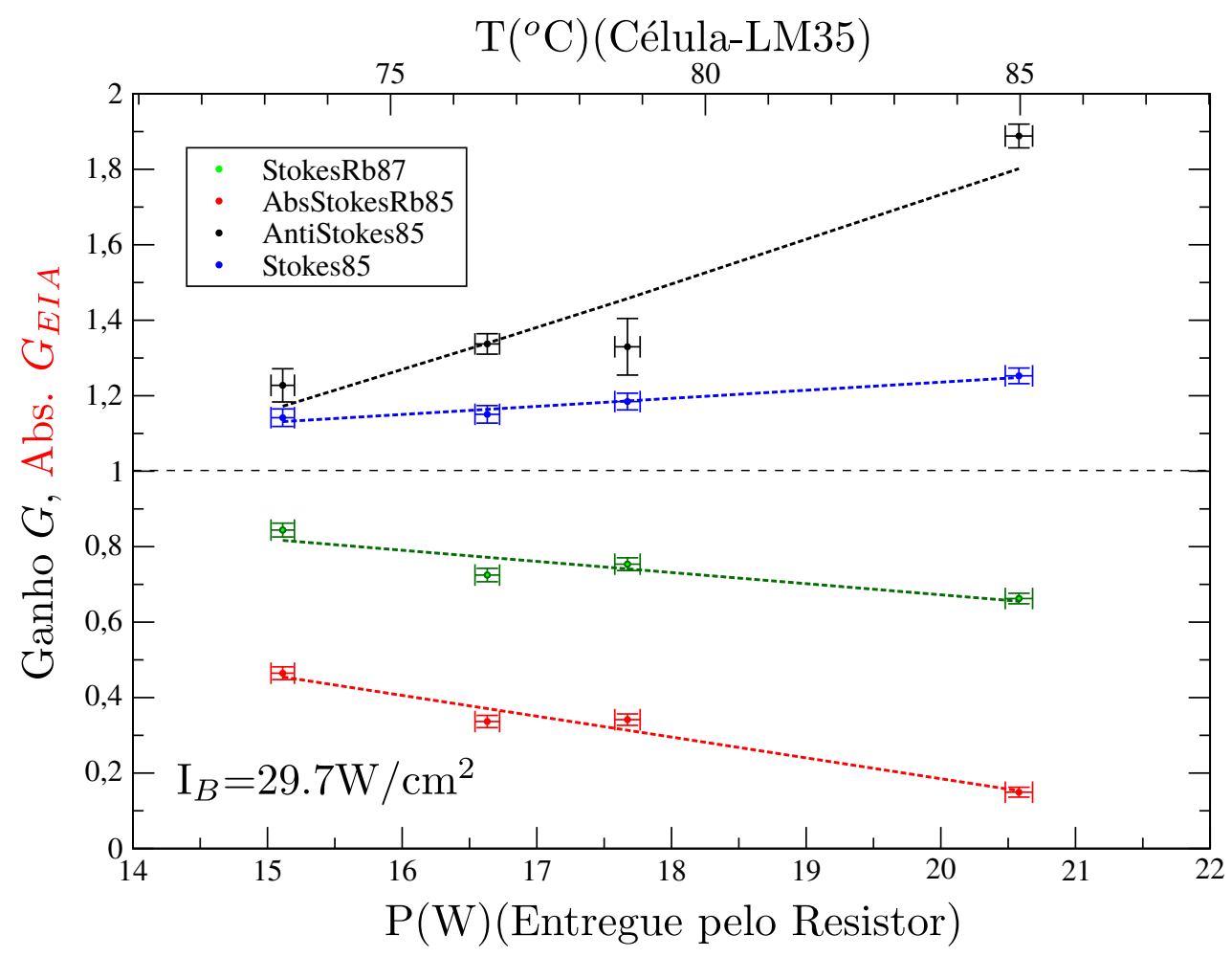

(a) Dependência para uma potência de $88 \mathrm{~mW}$ do bombeio.

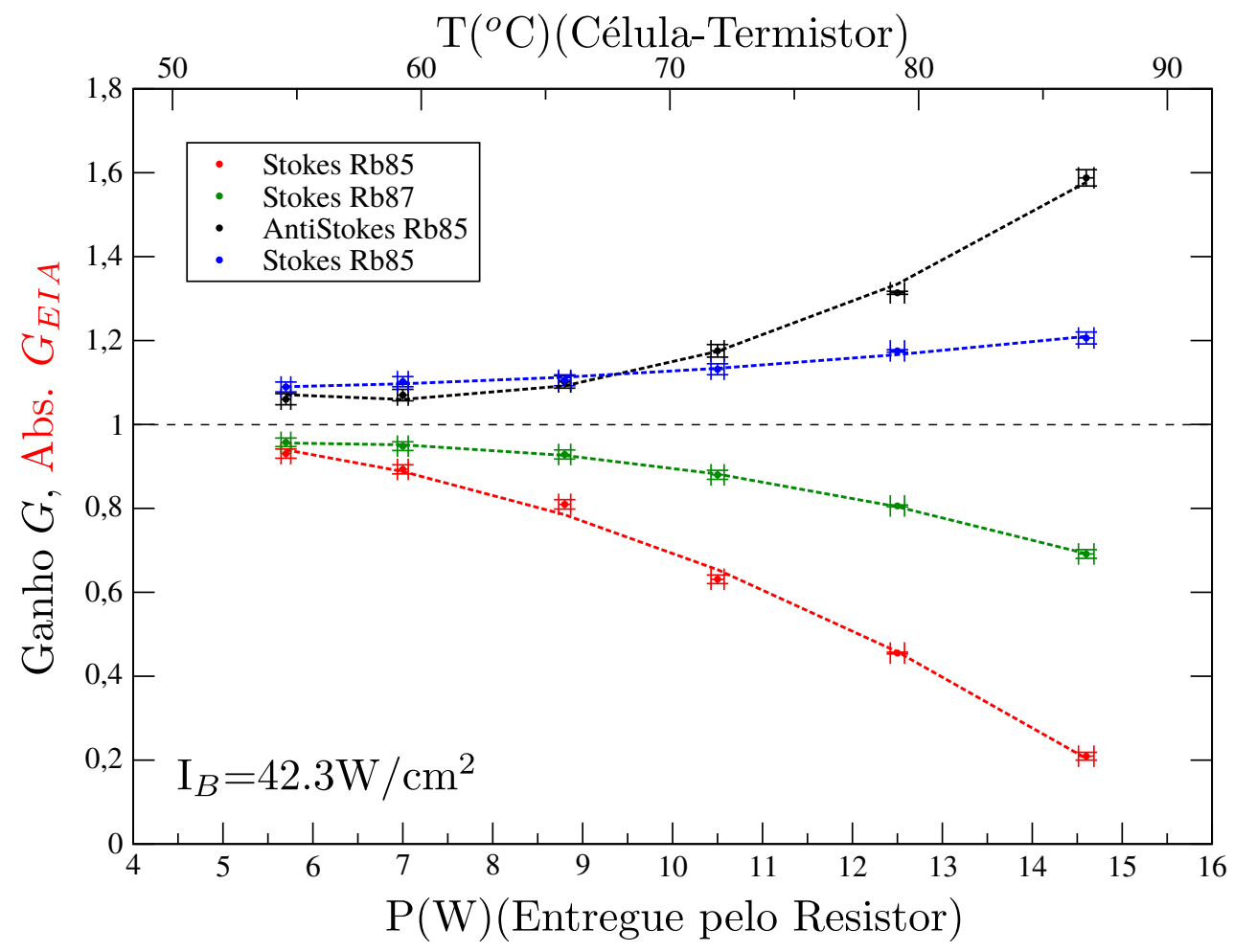

(b) Dependência para uma potência de $126 \mathrm{~mW}$ do bombeio.

Figura 3.10 - Ganhos do feixe de prova em função da potência entregue pelo resistor (Temperatura). Ganhos para duas intensidades de bombeio diferentes. 


\subsection{Cavidade OPO $\chi^{(3)}$}

A mistura de quatro ondas é um processo paramétrico em que o feixe de prova é amplificado e é gerado um feixe conjugado, como foi demostrado nos resultados experimentais e explicado no calculo teórico. Através de um feixe de bombeio intenso e um feixe semente chamado de prova interagindo com os átomos de rubídio foi possível obter o processo. Além disso, o processo foi predominante no isótopo 85. Esse processo é uma boa escolha para a construção de um Oscilador Paramétrico Ótico no qual o meio de ganho são os átomos de rubídio. Estudou-se que é possível controlar o ganho do feixe de prova, a intensidade da geração do conjugado e a absorção em função de distintos parâmetros. Além disso o ganho é muito alta em comparação a processos não lineares tipo $\chi^{(2)}$.

A montagem final do experimento está representada na fig. 3.11. Como primeiro passo utilizou-se uma montagem da mistura de quatro ondas análoga à fig. 3.1. Na parte intitulada 4WM, o feixe de bombeio é inserido com polarização vertical sendo discriminado pelo segundo cubo PBS, de modo que ele não vai ser detectado. Ao mesmo tempo o feixe de prova atravessa a célula e é detectado. O detector mediu espectros do tipo fig. 3.3a ou fig. 3.4a dependendo da dessintonia $\Delta$ do bombeio. Este esquema usou-se para ter certeza de qual era o regime de mistura de quatro ondas estudado, já que não é possível observar o processo dentro da cavidade OPO. Ele é uma referência para as medições com a transmissão do OPO.

Em seguida a figura intitulada OPO representa os elementos da cavidade. A cavidade OPO está composta por: dois cubos polarizadores divisores de feixe PBS, uma lâmina de quarto de onda QWP, dois espelhos curvos de alta refletância, um PZT e a célula de rubídio com abundancia natural dos dois tipos de isótopos estáveis.

A ideia principal por trás de como trabalha a cavidade é a seguente. Um feixe com polarização vertical incide no primeiro cubo dentro da cavidade. O cubo refletirá o feixe no sentido do primeiro espelho, atravessando assim a célula de rubídio. Logo após o feixe bate contra o espelho, sendo refletido no sentido oposto e atravessando a célula por segunda vez. Como ele mantém a mesma polarização o cubo de incidência atua como discriminador levando o feixe para fora da cavidade. Então o feixe de bombeio usou-se só para gerar o processo porém não deveria ficar dentro da cavidade.

Quando o feixe atravessou a célula por primeira e segunda vez, nos dois casos foram gerados os dois feixes que fecham o diagrama duplo- $\lambda$ fig. 3.2, gerando assim a mistura de quatro ondas. Esses dois feixes, em principio com polarização horizontal não serão discriminados pelo primeiro cubo, atravessando assim os dois cubos PBS e chegando até a lamina de quarto de onda QWP. 


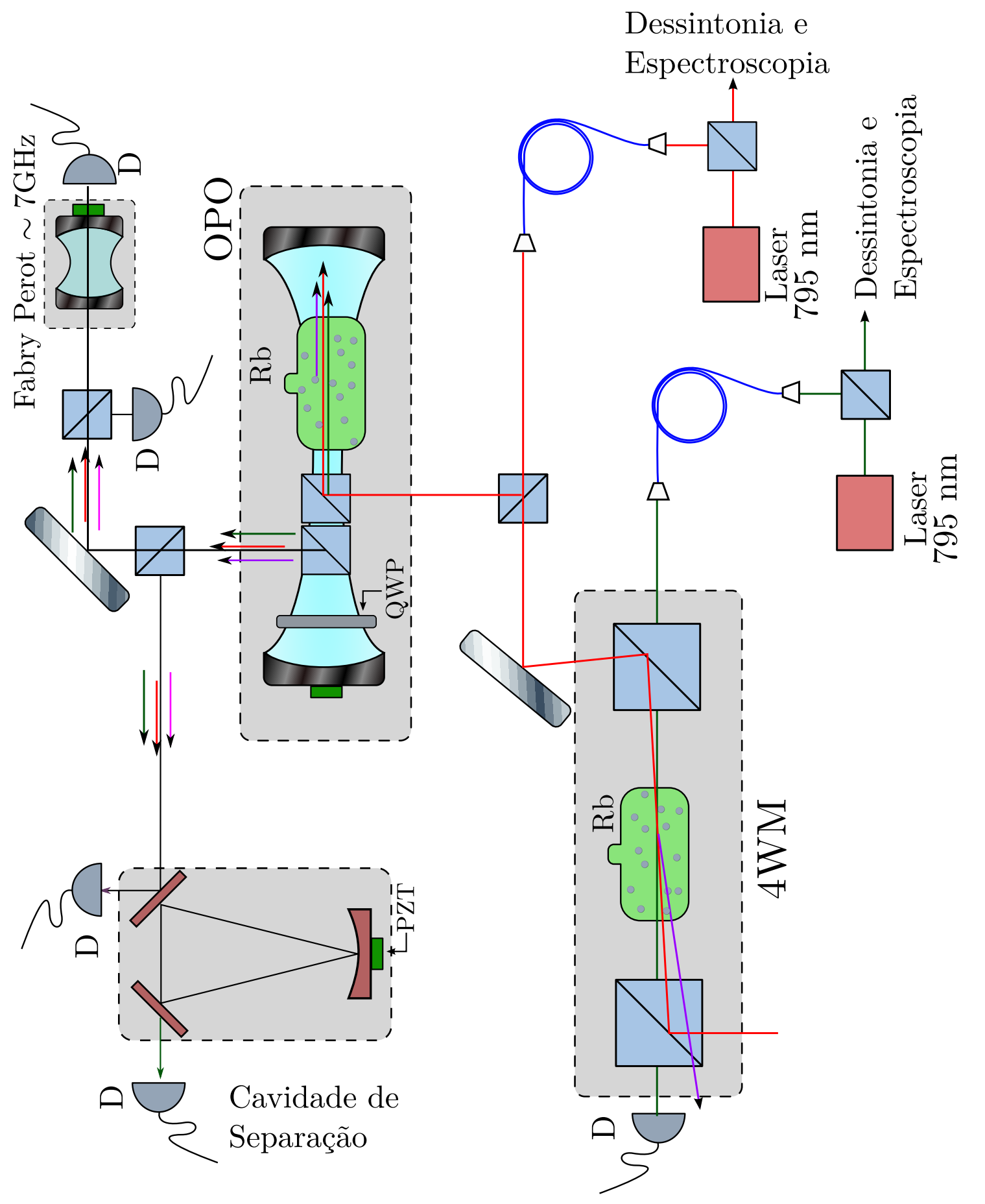

Figura 3.11 - Montagem do OPO com uma célula de Rb dentro de uma cavidade. O OPO é bombeado só com um feixe de alta potência. Fora da cavidade é usada uma montagem para obter a mistura de quatro ondas (4WM) como referência (ver fig. 1.9) com os dois feixes. Depois do OPO, o feixe de bombeio e os dois feixes gêmeos gerados saem na mesma direção de propagação. São necessárias uma cavidade Fabry-Perot para ter certeza da oscilação do OPO e cavidades de separação para poder analisar os feixes gêmeos. 
Os feixes atravessam a lâmina de quarto de onda, batem contra o segundo espelho e logo após traspassam por segunda vez a lâmina. O fato de os feixes terem traspassado a lâmina duas vezes é análogo a atravessar apenas uma lamina de meia onda. Consequentemente a polarização horizontal dos feixes muda para vertical. Os feixes chegam ao segundo cubo é são refletidos fora da cavidade. A saída da cavidade é dirigida a um detector que vai obter um espectro de transmissão do tipo fig. 1.10b, a uma nova cavidade Fabry-Perot e uma cavidade de separação. É importante dizer que dependendo do ângulo da placa de quarto de onda, os feixes gerados conseguem ressonar com a cavidade ou simplesmente atravessam a cavidade sem cavitar. As cavidades Fabry-Perot e de separação (Filter Cavity) especialmente construídas serão explicadas em próximas seções.

\subsubsection{Caracterização da finesse e transmissão fora do regime 4WM}

O cavidade que conforma o OPO precisa ser caracterizada. Como no caso de uma Fabry-Perot e no caso geral de qualquer cavidade ótica, os parâmetros estudados na seção sec. 1.4 são de grande importância. A cintura da cavidade $\omega_{0}$, o raio de curvatura dos espelhos, o comprimento da cavidade $2 L$ e as perdas definem parâmetros próprios dela. Esses parâmetros são a Finesse, o intervalo espectral livre $F S R=\Delta \nu_{c}=c / 2 L$ e a largura de banda $\delta \nu_{c}$.

As fig. 3.12 são duas fotos da montagem real do OPO. A fig. 3.12a é a foto da cavidade sem o meio não linear, os átomos de rubídio. Observem-se os dois cubos PBS, o primeiro espelho sujeito a um PZT, o segundo espelho montado sob um carrinho com um parafuso micrométrico, a lâmina de quarto de onda, e o esquema de como seria o comportamento dos feixes fora e dentro da cavidade. O parafuso micrométrico serve para fazer um ajuste fino no comprimento da cavidade.

A fig. 3.12b é a foto da cavidade com a célula de rubídio coberta pelo fio resistor que permite esquentá-la. A célula encontra-se numa montagem variável, permitindo retirar ou colocar a célula a vontade. Esse truque é de importância na hora do alinhamento da cavidade e da caracterização.

A cavidade é bombeada com só um feixe de alta potência. Após da célula serão gerados os feixes sinal e complementar. A diferença entre os nomes sinal e complementar, e o prova e conjugado é só de nomenclatura. Quando a mistura de quatro ondas é gerada com o bombeio e um feixe semente ou prova, o terceiro feixe é chamado de conjugado. No caso do processo ser gerado com o feixe de bombeio, os dois feixes gerados intitulam-se de sinal e complementar. Para as saídas do OPO vão se denominar desse modo.

Construímos cavidade para ser duplo-ressonante com os feixes gerados sinal e complementar. Em outras palavras, que os dois feixes entrem em ressonância com os modos permitidos 
pela geometria da cavidade. Pelos resultados obtidos e explicados anteriormente, só o processo nos átomos de rubídio 85 serão levados em consideração. Por conseguente, pela diferença dos estados hiperfinos da linha D1 desse isótopo (fig. 1.1), os feixes sinal e complementar só podem ser gerados nas frequências $\Delta \pm 3 G H z$. Para obrigar aos dos feixes serem ressonantes, é preciso que o valor $3 \mathrm{GHz}$ seja um múltiplo inteiro do FSR da cavidade OPO

$$
3 \mathrm{GHz}=n F S R
$$

com $n=1,2,3$. No caso de ser gerado o processo nos átomos de rubídio 87, pela diferença de frequência dos estados hiperfinos base de $6.8 \mathrm{GHz}$ (fig. 1.2), os feixes sinal e complementar associados ao isótopo não irão ressonar com a cavidade. Pelo comprimento da célula $L_{c}=$ (78.05 \pm 0.05$) \mathrm{mm}$, os dois cubos de $12.5 \mathrm{~mm}$ e a lâmina de quarto de onda de aproximadamente $16 \mathrm{~mm}$, escolheu-se um FSR de $0.750 \mathrm{GHz}$. A cintura da cavidade é $\omega_{0}=112 \mu \mathrm{m}$, o qual é um valor importante. Com o valor da cintura e a potência do bombeio, foi possível calcular a intensidade sec. 3.1.3.

Após a construção, caracterizamos a finesse e perdas da cavidade. Na fig. 3.13a observa-se a finesse como função do ângulo da placa de quarto de onda, para as condições com e sem célula de rubídio. No caso da célula de rubídio a $25{ }^{0} \mathrm{C}$, estudou-se a finesse fora do regime da mistura de quatro ondas, porem na faixa de frequências de absorção natural do rubídio. Em outras palavras, o laser de diodo estava sendo varrido em frequência ao redor das linha D1.

A finesse máxima, em comparação a cavidades do tipo Fabry-Perot ou de filtro que são usadas no laboratório LMCAL é baixa. Os valores de finesse de 45 para o caso sem rubídio, e 24 com rubídio, estão de acordo com o esperado. A cavidade está composta por três elementos óticos que geram muitas perdas. Estos são os dois cubos e a placa de onda. Além disso ao colocar a célula, as interfases planas de vidro aumentam as perdas. Por essa razão é recomendado trocar a célula por uma que esteja desenhada no ângulo de Brewster para diminuir as perdas, como em [15]. Na fig. 3.13b foram calculados os valores da transmissão com a equação

$$
F=\frac{\pi}{2 \arcsin \left(\frac{1-\sqrt{R}}{2 \sqrt[4]{R}}\right)},
$$

no qual $T=1-R$ é a transmissão [35]. A mínima transmissão atingiu-se com o ângulo zero da placa para as duas condições estudadas. Mediu-se uma transmissão de $22 \%$ com a célula, valor que vai ser fixo nas medições futuras. A vantagem da cavidade com a lâmina de quarto de onda é sua finesse variável, mesmo sendo alterável numa faixa de finesse baixa. As perdas podem ser grandes no entanto a ganho do processo de mistura de quatro ondas é controlável o 
que é um fator de compensação.

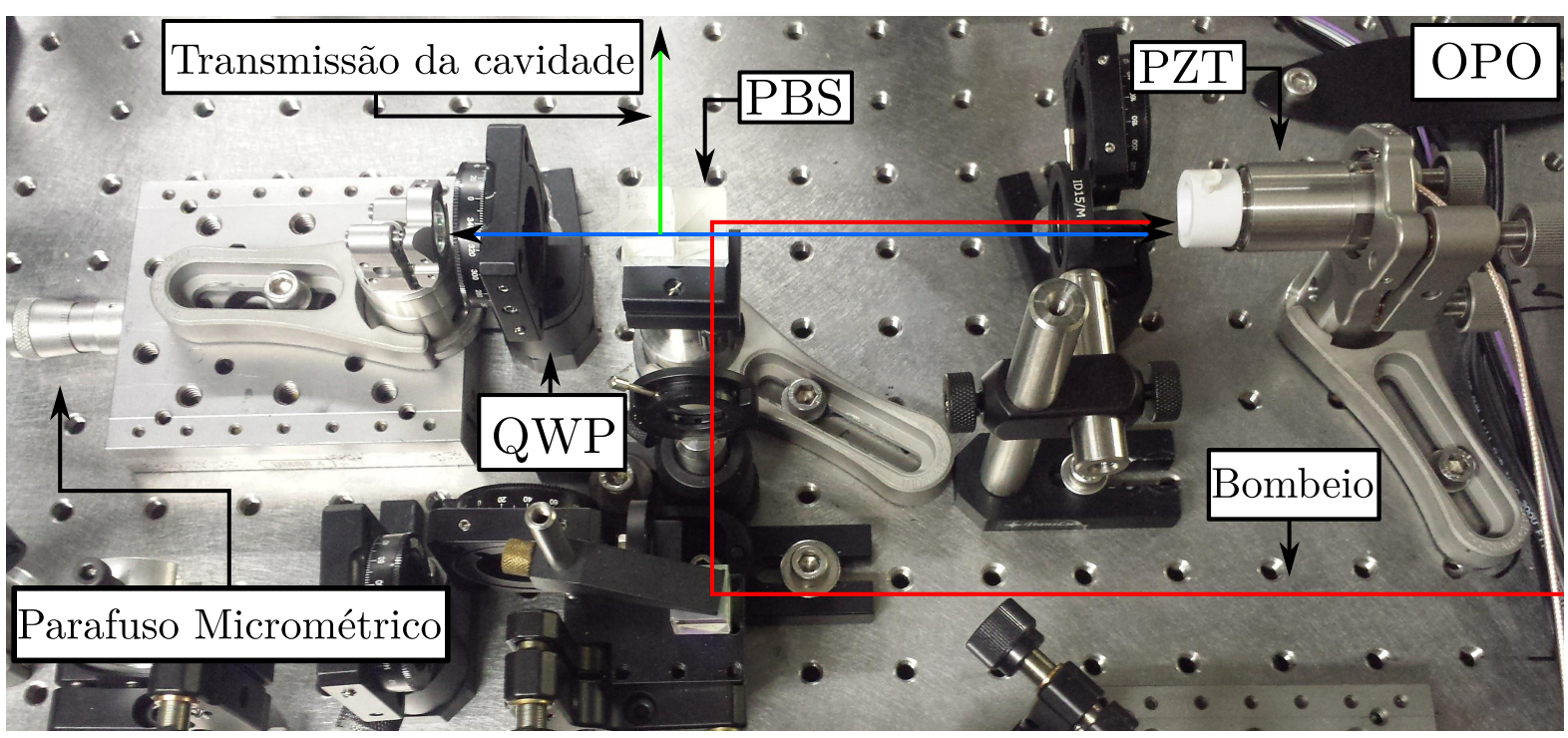

(a) Foto da cavidade OPO sem a célula de $R b$

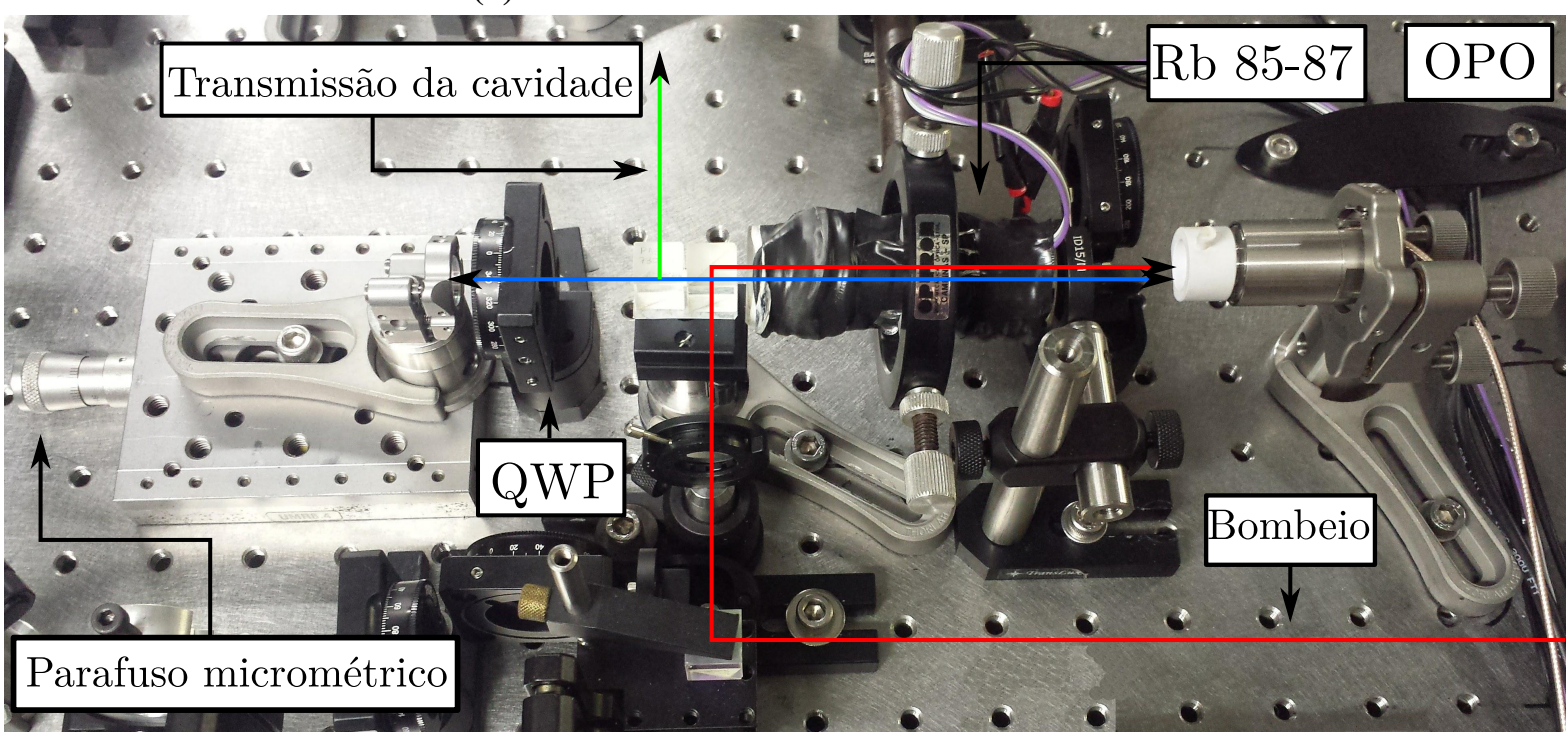

(b) Foto da cavidade OPO com a célula de $R b$. A célula esquentada é usada como meio de ganho (fig. I). É possível retirar a célula para realizar o alinhamento grosso da cavidade. (Ver fig. 3.11). Também é possível mudar o comprimento entre os dois espelhos com um parafuso micrométrico.

Figura 3.12 - Foto da cavidade OPO real. Ela é composta por dois espelhos curvos de alta reflectância, um dos quais está sujeito a um PZT, uma lâmina de quarto de onda (QWP) e dois cubos PBS que são usados para a entrada e a saída dos feixes. Do mesmo jeito que na montagem simples (fig. 1.9), o feixe de bombeio entra com polarização vertical. (Ver fig. 3.11) 


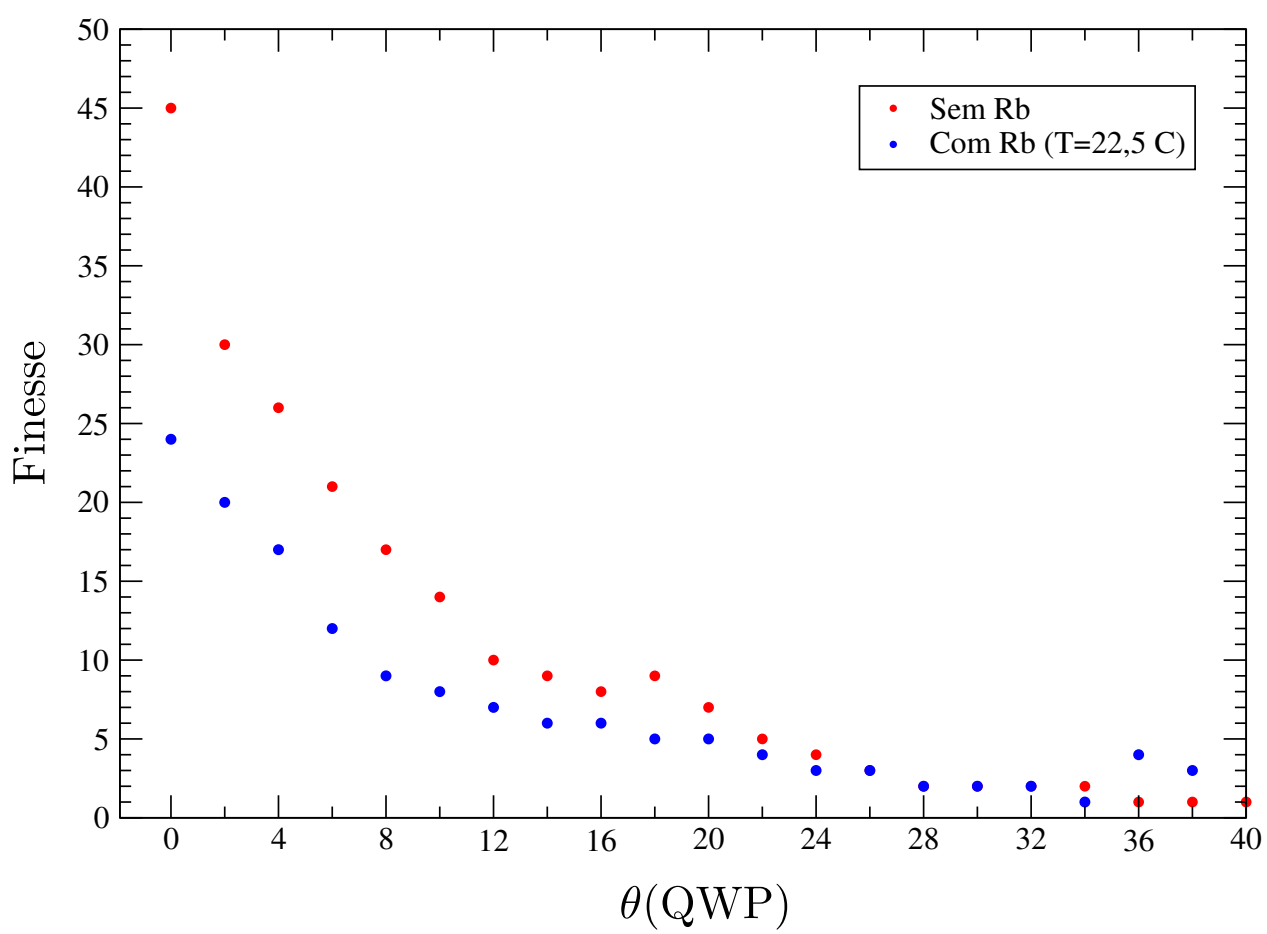

(a) Finesse do OPO. A Finesse do OPO é baixa em relação as cavidades de analise.

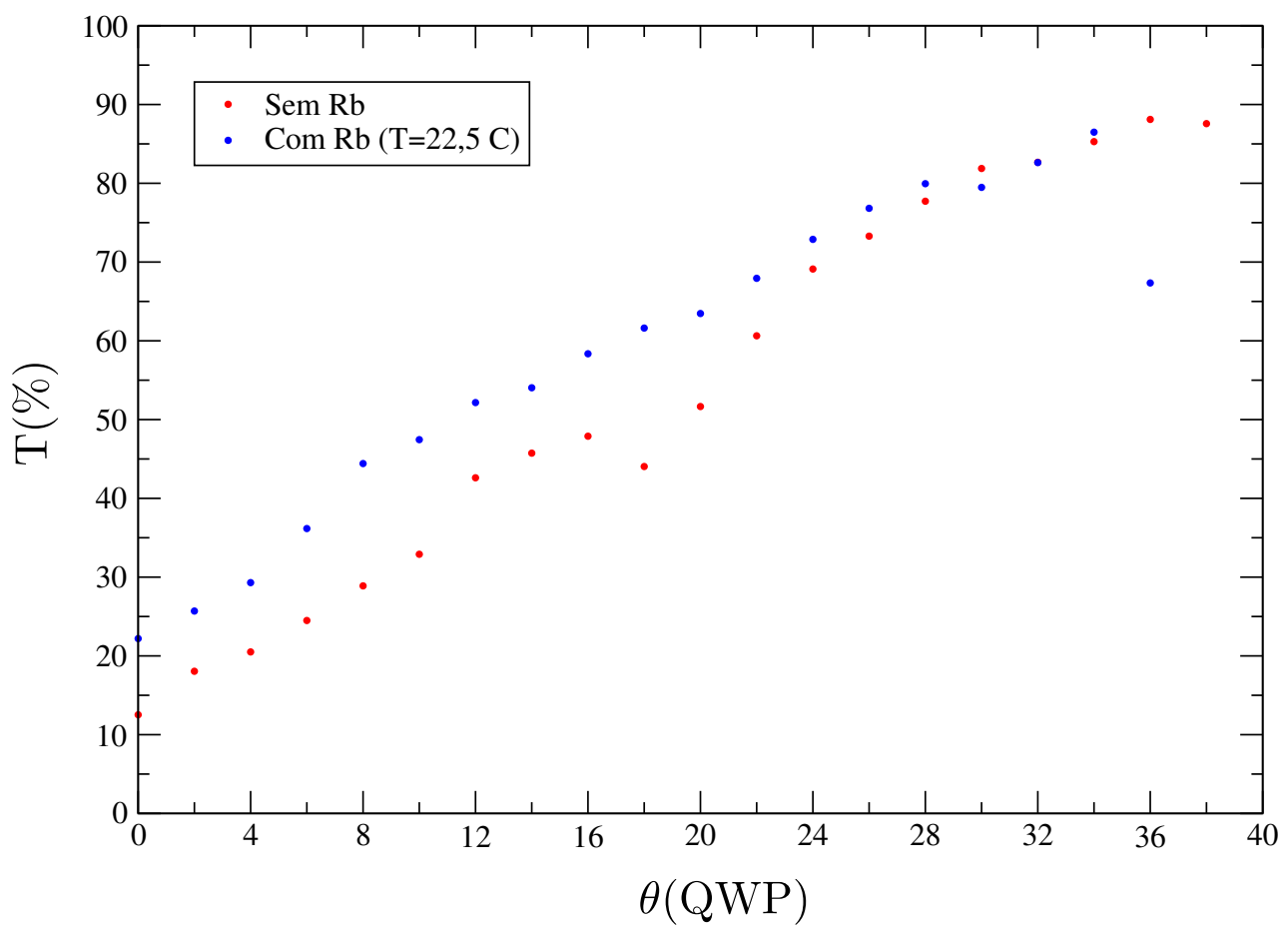

(b) Transmissão do OPO.

Figura 3.13 - Finesse e Transmissão da cavidade em função do ângulo da lâmina de onda (QWP) com e sem a célula de $\mathrm{Rb}$ (Ver fig. 3.12). Em geral, a Finnesse da cavidade é muito baixa fora do processo de mistura de quatro ondas, o que significa que as perdas são altas. No ângulo 0 da placa, a perda é a menor com $22.2 \%$. 


\subsubsection{Obtenção do OPO e caracterização do limiar de oscilação}

O feixe de bombeio foi sintonizado em quatro frequências nas quais observou-se o processo paramétrico. Foi feita a caracterização da intensidade dos picos de transmissão do OPO em função da potência de entrada do feixe de bombeio. As frequências foram $\Delta=$ $-3,36 ;-1.98 ;-0.39 ; 0.38 \mathrm{GHz}$ como representadas na fig. 3.15 e fig. 3.14. Essas frequências foram escolhidas por estarem na região ótima de amplificação do feixe de prova alta e absorção nula, além da intensidade do feixe conjugado alta.

Uma figura menor representa o espectro de absorção não saturada (azul) obtido na parte intitulada 4WM em fig. 3.11. Esse espectro obtido da mesma maneira do que em fig. 3.3b e fig. 3.3a é uma referência externa para conhecer os possíveis processos de mistura de quatro ondas que podem acontecer, por exemplo o degenerado e ao mesmo tempo a absorção.

Na figura fig. 3.14a a dessintonia do bombeio foi de $\Delta=-3.76 \mathrm{GHz}$ e a temperatura da célula de rubídio da cavidade $\mathrm{OPO}$ de $T=98^{\circ} \mathrm{C}$. Na mini-figura reparou-se o feixe de prova entrando pelo canal Stokes com uma amplificação perto de 1.5, para a parte intitulada 4WM fig. 3.11. No entanto o feixe de prova pelo canal Anti-Stokes não tem amplificação e uma absorção apreciável. A absorção desse feixe é dada pela cercania com o vale dos níveis hiperfinos ${ }^{85} \mathrm{Rb}: 5 S_{1 / 2}(F=2) \rightarrow 5 P_{1 / 2}\left(F^{\prime}\right)$. Consequentemente é de esperar-se que dentro da cavidade OPO sejam mais apreciáveis os efeitos de geração do sinal e complementar na frequência $\Delta-3 \mathrm{GHz}=(-3.76-3) \mathrm{GHz}=-6.76 \mathrm{GHz}$ e $\Delta+3 \mathrm{GHz}=(-3.76+3) \mathrm{GHz}=$ $0.76 \mathrm{GHz}$ respectivamente. Na mini-figura em vermelho apreciou-se um exemplo do espectro de transmissão com dos modos dentro da cavidade, no entanto o espectro tem uma configuração diferente do tipo fig. 1.10b. Na fig. 3.5a Stokes, para $\Delta=-3.76 \mathrm{GHz}$, a absorção é próxima a zero. O conjugado é gerado com baixa intensidade. Calculou-se o valor do limiar de oscilação (Threshold) com uma potência de $P_{\text {Thershold }}=6.89 \mathrm{~mW}$. Pode-se observar que a transição ao limiar de oscilação é abrupta.

Na fig. 3.14b a dessintonia do bombeio foi de $\Delta=-1.98 \mathrm{GHz}$ e a temperatura da célula de rubídio da cavidade OPO de $T=96^{\circ} \mathrm{C}$. Na mini-figura reparou-se o feixe de prova entrando pelo canal Stokes com uma amplificação perto de 5, para a parte intitulada 4WM fig. 3.11 e maior do que em fig. 3.14a. O feixe de prova pelo canal Anti-Stokes sofre uma absorção apreciável. De fato essa absorção é uma saturação do nível hiperfino ${ }^{85} \mathrm{Rb}: 5 S_{1 / 2}(F=$ $2) \rightarrow 5 P_{1 / 2}\left(F^{\prime}\right)$ fig. 2.6. Como consequência é de esperar-se que dentro da cavidade OPO sejam mais apreciáveis os efeitos de geração do sinal e complementar na frequência $\Delta-3 \mathrm{GHz}=$ $(-1.98-3) \mathrm{GHz}=-4.98 \mathrm{GHz}$ e $\Delta+3 \mathrm{GHz}=(-1.98+3) \mathrm{GHz}=1.02 \mathrm{GHz}$ respectivamente. $\mathrm{Na}$ mini-figura em vermelho apreciou-se um espectro de transmissão com pelo menos três modos que estão dentro da cavidade. Na fig. 3.5a Stokes, para $\Delta \approx-1.98 \mathrm{GHz}$ a absorção é próxima 
a zero. O conjugado é gerado com intensidade alta. Calculou-se o valor do limiar de oscilação (Threshold) com uma potência de $P_{\text {Threshold }}=4.1 \mathrm{~mW}$. Pode-se observar que a transição ao limiar de oscilação é abrupta.

$\mathrm{Na}$ fig. 3.15a a dessintonia do bombeio foi de $\Delta=-0.39 \mathrm{GHz}$ e a temperatura da célula de rubídio da cavidade OPO de $T=97^{\circ} \mathrm{C}$. Na mini-figura reparou-se o feixe de prova entrando pelo canal Anti-Stokes com uma amplificação perto de 2, a diferença do que em fig. 3.14b e fig. 3.14a. O feixe de prova pelo canal Stokes sofre uma absorção apreciável. De fato essa absorção é uma saturação do nível hiperfino ${ }^{85} \mathrm{Rb}: 5 S_{1 / 2}(F=3) \rightarrow 5 P_{1 / 2}\left(F^{\prime}\right)$ em fig. 2.6. Como resultado é de esperar que dentro da cavidade OPO sejam mais apreciáveis os efeitos de geração do sinal e complementar na frequência $\Delta-3 \mathrm{GHz}=(-0.39-3) \mathrm{GHz}=-3.39 \mathrm{GHz}$ e $\Delta+3 \mathrm{GHz}=(-0.39+3) \mathrm{GHz}=2.61 \mathrm{GHz}$ respectivamente. Na mini-figura em vermelho apreciou-se um espectro de transmissão com um modo de oscilação. É possível que este modo seja a soma dos modos do sinal, complementar e bombeio. Na fig. 3.5a Anti-Stokes, para $\Delta \approx-0.39 \mathrm{GHz}$ a absorção é alta pela cercania com as transições $5 S_{1 / 2}(F=1) \rightarrow 5 P_{1 / 2}\left(F^{\prime}\right)$ do ${ }^{87} \mathrm{Rb}$. O conjugado é gerado com intensidade apreciável. Calculou-se o valor do limiar de oscilação (Threshold) com uma potência de $P_{\text {Thershold }}=10.38 \mathrm{~mW}$. Pode-se observar que a transição ao limiar de oscilação é abrupta.

A fig. 3.15 b é a mais interessante, com uma dessintonia do bombeio de $\Delta=0.38 \mathrm{GHz}$ e a temperatura da célula de rubídio da cavidade OPO é $T=96^{\circ} \mathrm{C}$. Na mini-figura reparou-se o feixe de prova entrando pelo canal Anti-Stokes com uma amplificação perto de 2, a diferença do que em fig. 3.14b e fig. 3.14a, com o prova entrando pelo canal Stokes. O feixe de prova pelo canal Stokes sofre uma absorção apreciável. De fato essa absorção é gerada pela cercania com as transições dos níveis hiperfinos $5 S_{1 / 2}(F=3) \rightarrow 5 P_{1 / 2}\left(F^{\prime}\right)$ do ${ }^{85} \mathrm{Rb}$ fig. 2.6. Como resultado é de esperar que dentro da cavidade OPO sejam mais apreciáveis os efeitos de geração do sinal e complementar na frequência $\Delta-3 \mathrm{GHz}=(0.38-3) \mathrm{GHz}=-2.62 \mathrm{GHz}$ e $\Delta+3 \mathrm{GHz}=(0.38+$ $3) \mathrm{GHz}=3.38 \mathrm{GHz}$ respectivamente. Na mini-figura em vermelho apreciou-se um espectro de transmissão com um modo de oscilação. É possível que este modo seja a soma dos modos do sinal, complementar e bombeio. Na fig. 3.5a Anti-Stokes, para $\Delta \approx-0.39 \mathrm{GHz}$ a absorção é alta pela cercania com as transições $5 S_{1 / 2}(F=1) \rightarrow 5 P_{1 / 2}\left(F^{\prime}\right)$ do isótopo 87 . O conjugado é gerado com intensidade apreciável. Calculou-se o valor do limiar de oscilação (Threshold) com uma potência de $P_{\text {Threshold }}=27.5 \mathrm{~mW}\left(I_{\text {Threshold }}=69.78 \mathrm{~W} / \mathrm{cm}^{2}\right)$. Pode-se observar que a transição ao limiar de oscilação é mais suave do que nos casos anteriores fig. 3.14a, fig. 3.14b e fig. 3.15a.

A operação do OPO $\chi^{(2)}$ é bem conhecida, de fato em trabalhos do grupo faz-se referência ao calculo teórico do limiar de oscilação, como enunciado em [6, 17, 25]. Nesse caso a transição do limiar é abrupta. Isto como consequência dos baixos ganhos gerados pelo meio 
de ganho inserido dentro da cavidade, gerando assim a construção de cavidades muito fechadas (Finesse alta).

No caso de este trabalho, para o OPO com $\chi^{(3)}$ dos átomos, a transição pelo limiar de oscilação em fig. 3.15b é mais suave do que nos casos anteriores. Este é o resultado mais importante. A aproximação de que a intensidade de bombeio é muito alta em comparação a intensidade dos campos sinal e complementar já não é valida, fazendo que eq. (1.3.25) não seja mais certa na região perto do limiar. É preciso então voltar para a eq. (1.3.24). Em base a teoria, é provável que perto ao limiar de oscilação sejam gerados estados não-gaussianos. 


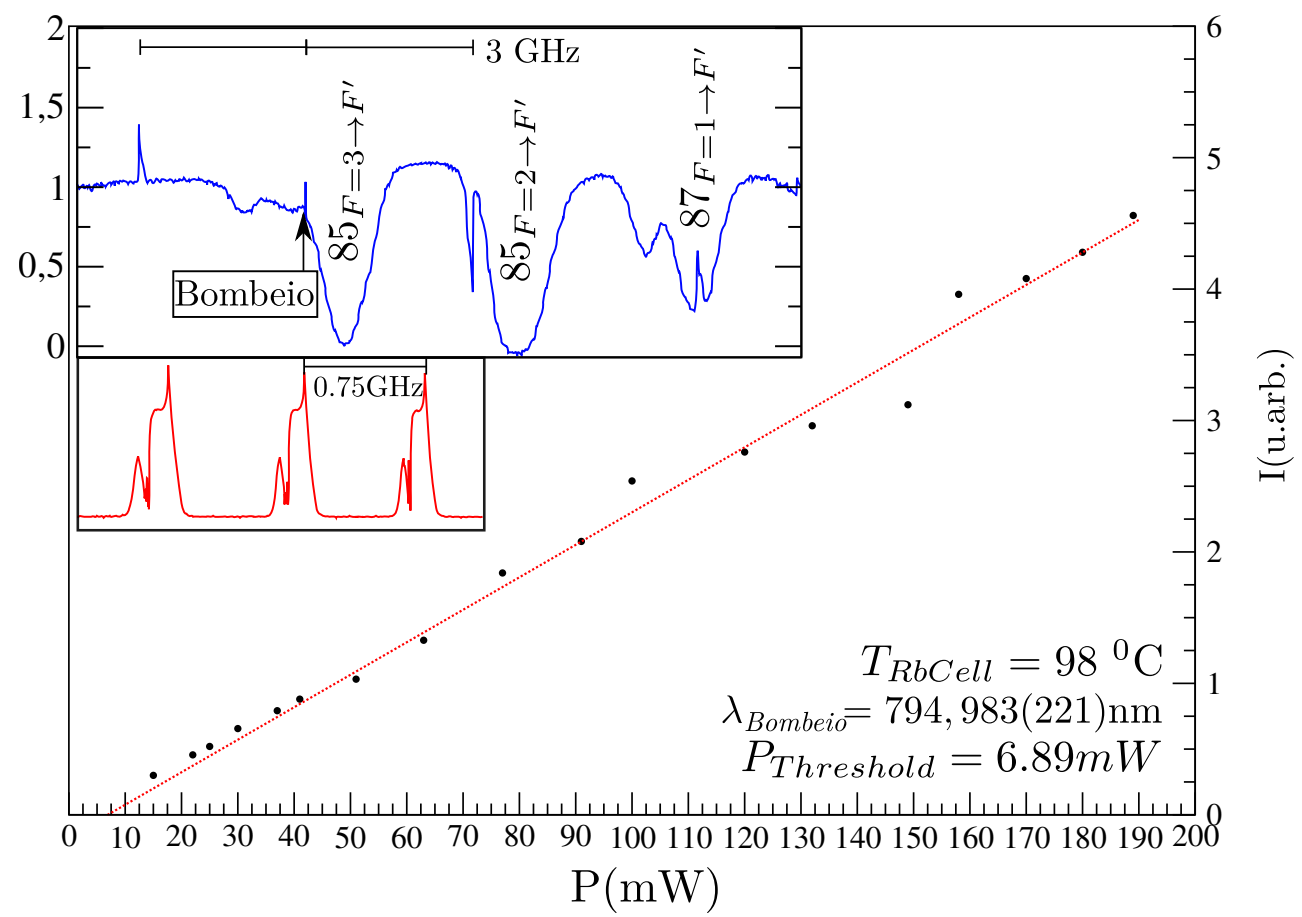

(a) Dessintonia do bombeio $\Delta=-3.37 \mathrm{GHz} . I_{\text {Threshold }}=17.48 \mathrm{~W} / \mathrm{cm}^{2}$

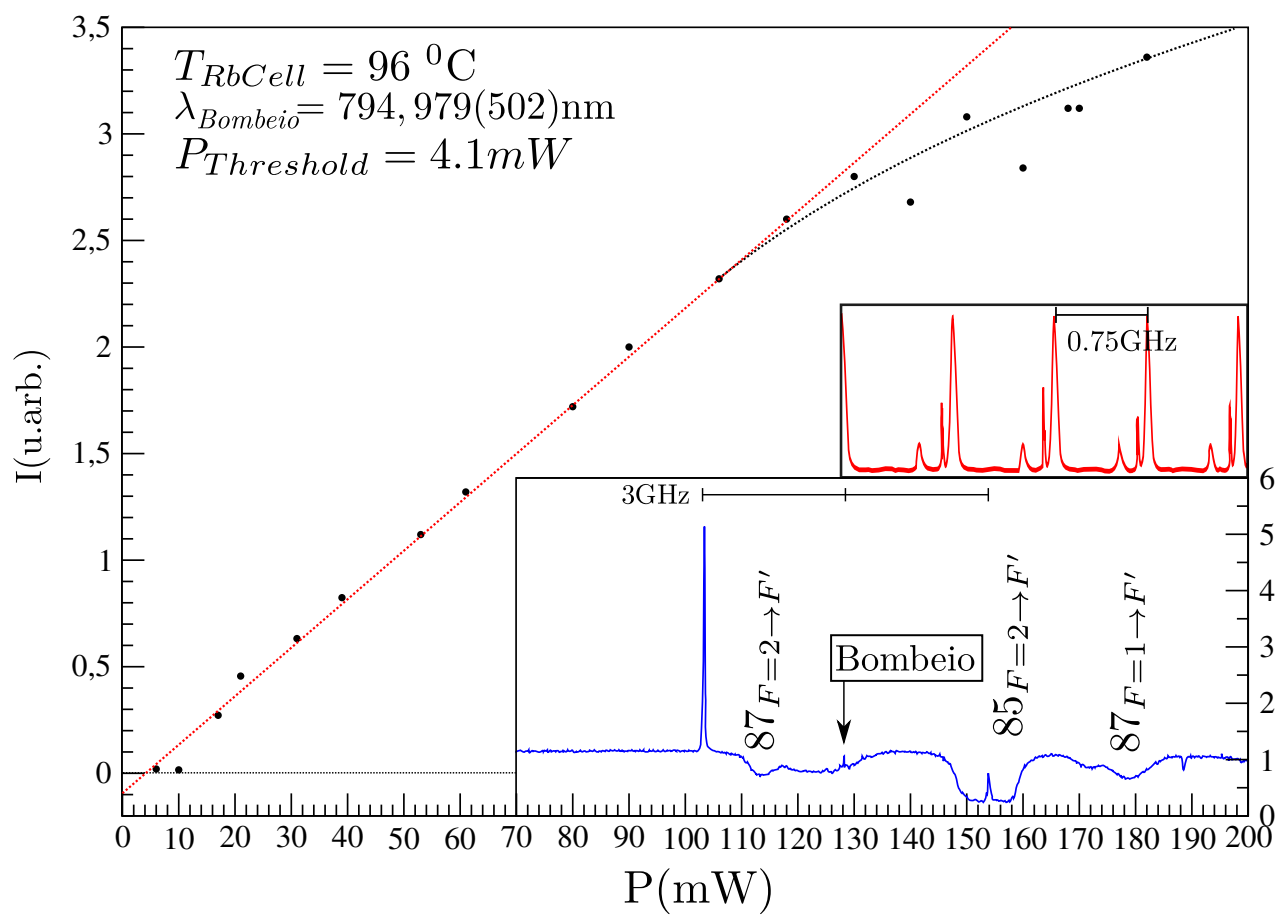

(b) Dessintonia do bombeio $\Delta=-1.98 \mathrm{GHz} . I_{\text {Threshold }}=10.40 \mathrm{~W} / \mathrm{cm}^{2}$

Figura 3.14 - Intensidade dos picos da cavidade OPO em função da potência do bombeio. Observa-se na figura pequena (Azul) a posição do bombeio em relação as linhas de absorção, a amplificação do feixe de prova nos canais Stokes e Anti-Stokes na disposição externa 4WM fig. 3.11. Também uma figura ilustrativa dos picos da cavidade nessa condição (Vermelha), em que aparecem novos picos. Dois comprimentos de onda: $\lambda_{\text {Pump }}=$ $794.983(221) \mathrm{nm}$ e $\lambda_{P u m p}=794.979(502) \mathrm{nm}$. O limiar de oscilação calculou-se para cada condição. 


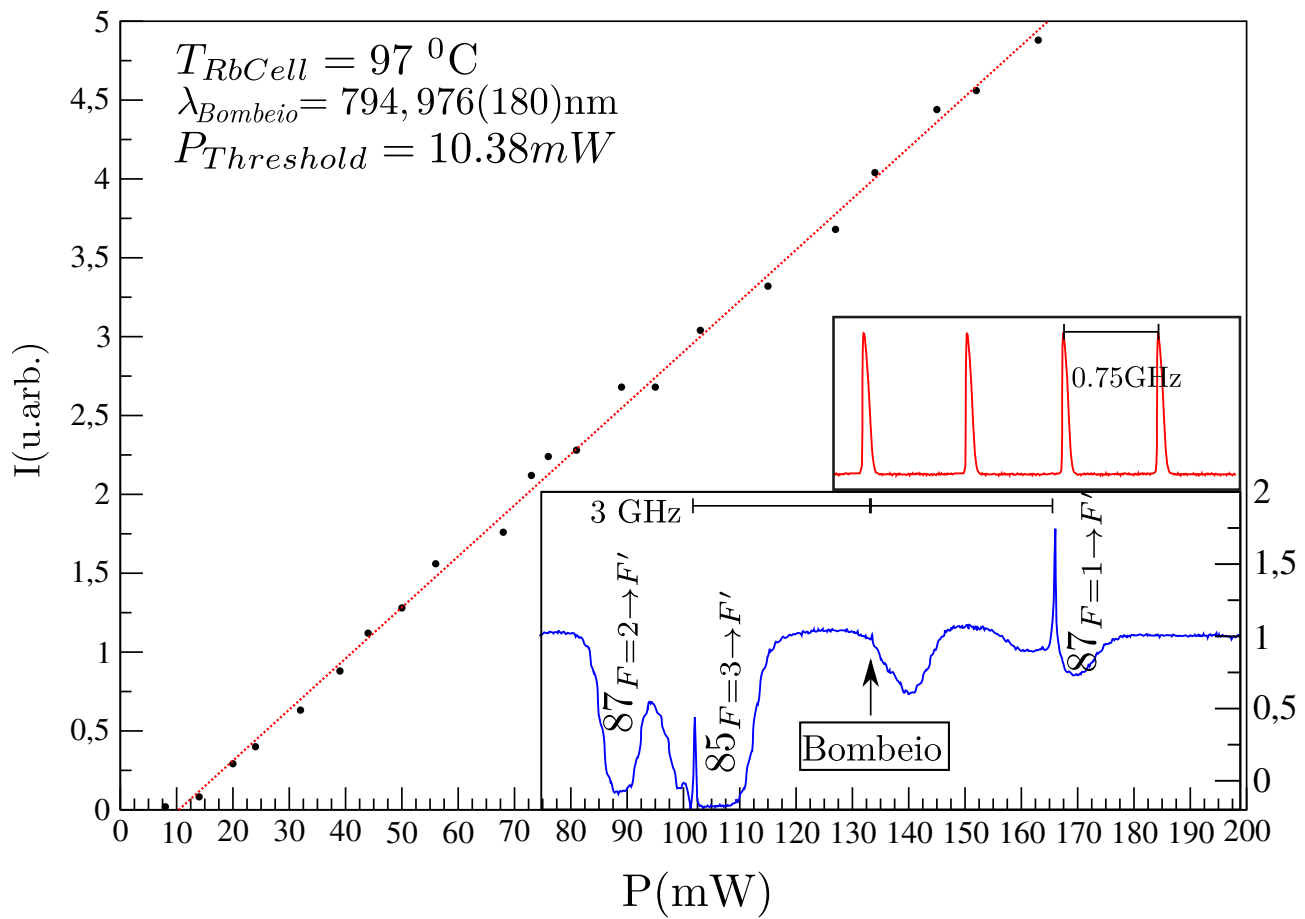

(a) Dessintonia do bombeio $\Delta=-0.39 \mathrm{GHz} . I_{\text {Threshold }}=26.33 \mathrm{~W} / \mathrm{cm}^{2}$

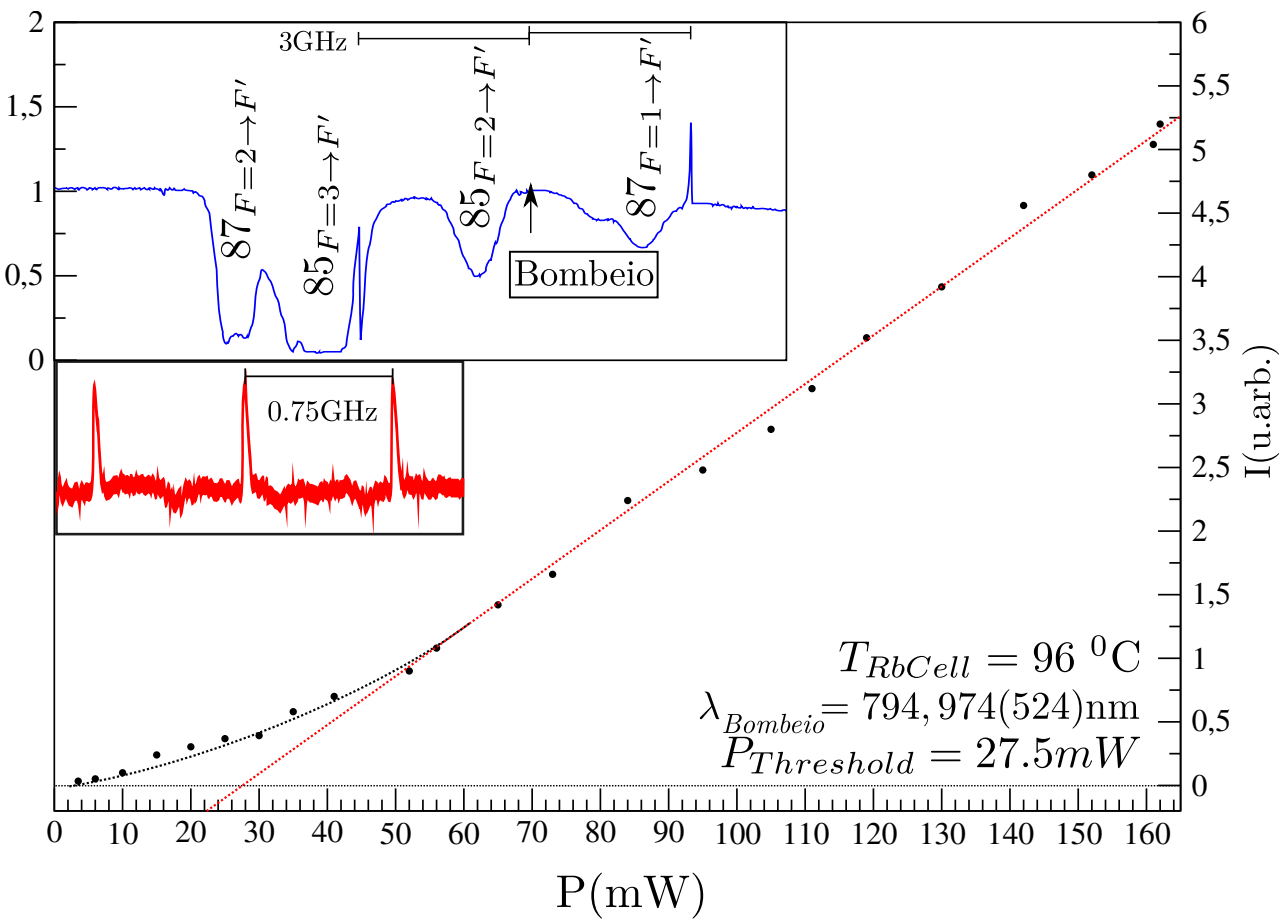

(b) Dessintonia do bombeio $\Delta=0.38 \mathrm{GHz} . I_{\text {Threshold }}=69.78 \mathrm{~W} / \mathrm{cm}^{2}$

Figura 3.15 - Intensidade dos picos da cavidade OPO em função da potência do bombeio. Observa-se na figura pequena (Azul) a posição do bombeio em relação as linhas de absorção, a amplificação do feixe de prova nos canais Stokes e Anti-Stokes na disposição externa 4WM fig. 3.11. Também uma figura ilustrativa dos picos da cavidade nessa condição (Vermelha), em que aparecem novos picos. Dois comprimentos de onda: $\lambda_{P u m p}=$ $794.974(529) \mathrm{nm}$ e $\lambda_{P u m p}=794.976(180) \mathrm{nm}$. O limiar de oscilação calculou-se para cada condição. 


\subsubsection{Próximos passos: Cavidades Fabry-Perot e de separação dos feixes}

O processo de mistura de quatro ondas acontece com certeza dentro da cavidade OPO, como consequência do observado no detector da referência externa intitulada 4WM em fig. 3.11. No entanto a construção da cavidade tem dos problemas a serem resolvidos.

Primeiramente o FSR de $0.750 \mathrm{GHz}$ faz que os picos de transmissão do feixe sinal sejam indistinguíveis com os picos correspondentes ao feixe do complementar. Como $4 \mathrm{FSR}=3 \mathrm{GHz}$ e os feixes sinal e complementar são gerados a $\pm 3 \mathrm{GHz}$ do bombeio em $\Delta$, os picos de transmissão serão a soma dos picos de transmissão individuais. Além disso é possível que um feixe gerado, por exemplo o sinal ao atravessar a célula por segunda vez atue como um novo bombeio gerando assim um feixe a $\Delta \pm 6 \mathrm{GHz}$. Também é possível a geração da mistura de quatro ondas degenerada em que os feixes sinal e complementar terão a mesma frequência $\Delta$ ( $t_{2}$ na fig. 3.4b e fig. 3.4b). Por essa razão não a certeza de qual processo aconteceu, mesmo sendo de mistura de quatro ondas.

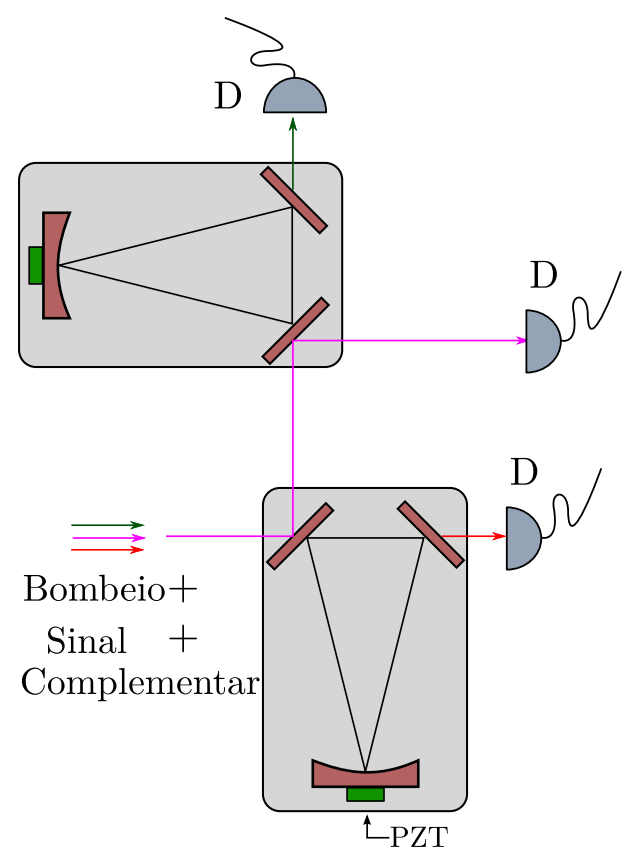

Figura 3.16 - Cavidades de Separação dos dois feixes gêmeos e o bombeio. As cavidades vão em seguida do OPO (fig. 3.11).

Construiu-se uma cavidade Fabry-Perot fig. 3.11 de aproximadamente 7GHz de FSR, com o objetivo de esclarecer as duvidas se os feixes de sinal e complementar foram gerados, se o remanescente do feixe de bombeio também fica ressonante e se o processo de mistura de quatro ondas é degenerado o não. $\mathrm{O}$ valor de $7 \mathrm{GHz}$ escolheu-se por que a diferença de frequência entre o sinal e complementar é $6 \mathrm{GHz}$, de tal modo que seja possível distinguir os feixes em um FSR 
de largura e não aconteça a superposição dos picos de transmissão dos feixes.

Em segundo lugar a cavidade é linear, de modo que qualquer feixe ressonante na cavidade ao sair pelo segundo cubo irá na mesma direção de propagação. Em outras palavras os feixes sinal, complementar e os possíveis resíduos do bombeio intenso sairão colineares. Construiu-se a primeira cavidade de separação como representado na fig. 3.16. Dependendo dos possíveis resultados obtidos com a Fabry-Perot, será construída mais uma cavidade de separação.

A ideia das duas cavidades de separação é simples. Os três feixes chegam colineares à primeira cavidade. As frequências $\Delta-3 \mathrm{GHz}, \Delta \mathrm{GHz}$ e $\Delta+3 \mathrm{GHz}$ dos feixes complementar, bombeio e sinal respetivamente serão separadas da seguente forma. A primeira cavidade será travada num dos picos de ressonância correspondente a um dos três feixes, refletindo os dois feixes restantes. Finalmente usando a segunda cavidade os dois feixes restantes serão separados da mesma forma. Os três feixes separados espacialmente serão levados para analises posteriores para melhorar a caracterização dos processos que acontecem dentro do $\mathrm{OPO}$, no continuo do projeto do grupo LMCAL. 


\section{Conclusões e perspectivas}

Nesta dissertação obtivemos e caracterizamos o processo de mistura de quatro ondas (4WM) no gás de isotopos de rubídio ${ }^{85} \mathrm{Rb}$ e ${ }^{87} \mathrm{Rb}$. Em segundo lugar e não menos importante, construímos e caracterizamos o limiar de oscilação do primeiro oscilador paramétrico ótico (OPO) tipo $\chi^{(3)}$ com meio atômico desenvolvido no LMCAL. A caracterização do 4WM foi feita na configuração duplo- $\lambda$ semelhante à usada em [26]. A dessintonia do feixe de bombeio $\Delta$ definiu-se em relação ao pico do crossover da transição $5 S_{1 / 2}(F=2) \rightarrow 5 P_{1 / 2}\left(F^{\prime}\right)$ do ${ }^{85} \mathrm{Rb}$ na linha D1. Essa dessintonia $\Delta$ variou-se, obtendo assim a amplificação do feixe de prova e geração do feixe conjugado nos canais de entrada Stokes e Anti-Stokes para o ${ }^{85} \mathrm{Rb}$ ao redor da linha D1. O 4WM não foi um processo importante no ${ }^{87} \mathrm{Rb}$, sendo este diminuído pela absorção.

Obtivemos amplificações do feixe de prova pelo canal Stokes de aproximadamente $550 \%$ ao redor da dessintonia $\Delta=-2.5 \mathrm{GHz}$, e de $250 \%$ ao redor da dessintonia $\Delta=1 \mathrm{GHz}$. Por outro lado, pelo canal Anti-Stokes para o feixe de prova a amplificação máxima foi de $450 \%$ ao redor da dessintonia $\Delta=0.77 \mathrm{GHz}$. Ao redor dessas mesmas frequências reparou-se a criação do feixe conjugado com alta intensidade. Concluímos que o valor da amplificação máxima é no canal Stokes do que no Anti-Stokes para o feixe de prova, e a absorção é menor no canal Anti-Stokes.

Estudamos o 4WM em função da intensidade do bombeio para quatro valores de $\Delta$ diferentes no ${ }^{85} \mathrm{Rb}$, ao redor da região ótima de baixa absorção. A amplificação e absorção do feixe de prova, como a intensidade do conjugado gerado, aumentam monotonamente com a intensidade do bombeio $\left(G, G_{E I A} \propto I_{B}\right)$. Além disso, analisamos o $4 \mathrm{WM}$ em função da temperatura da célula de rubídio para dois valores de intensidade de bombeio diferentes. A amplificação e absorção do feixe de prova, como a intensidade do conjugado gerado, aumentam monotonamente $\left(G, G_{E I A} \propto T_{R b}\right)$.

A região próxima à $\Delta=0.77 \mathrm{GHz}$ para o feixe de prova entrando pelo canal AntiStokes não apresenta absorção. Esta região é de muito interesse, pelas porcentagens altas de amplificação do feixe de prova e geração do conjugado. Entretanto, nessa mesma região com o feixe pelo canal Stokes a absorção é alta.

Como resultado é possível ajustar a amplificação e absorção, e intensidade de geração 
dos feixes de prova e conjugado, respectivamente. Este ajuste pode ser feita através dos parâmetros experimentais anteriormente descritos.

Em base nesses resultados construímos uma cavidade OPO com finesse variável e meio não linear atômico. É possível aumentar ou diminuir as perdas da cavidade, ao rodar uma placa de quarto de onda dentro da cavidade que forma o OPO. Caracterizamos a potência de saída em função da potência de bombeio de entrada, para quatro valores de $\Delta$ distintos. ao mesmo tempo usou-se uma montagem externa do 4WM para referencia de que o processo acontecia. Calculamos o limiar de oscilação para todos os casos. Para três valores a transição ao limiar de oscilação foi abrupta e o valor é baixo, porém para o valor $\Delta=0.38 \mathrm{GHz}$ essa transição foi suave e o valor do limiar foi máximo com uma potência de $27.5 \mathrm{~mW}$.

Este comportamento suave é de muita importância por que irá possibilitar o estudo de correlações quânticas entre os feixes sinal e complementar gerados e observados na saída do OPO, perto do limiar de oscilação. Para isso será necessário separar os feixes co-propagantes de saída da cavidade que conforma o OPO, para ter certeza da geração dos feixes sinal e complementar em frequências de $\Delta+3 \mathrm{GHz}$ e $\Delta-3 \mathrm{GHz}$ respetivamente. Isso será possível com ajuda das cavidades Fabry-Perot de $\approx 7 \mathrm{GHz}$ de FSR e das cavidades de separação já descritas. Em segundo lugar, irá permitir a geração de estados quânticos não gaussianos.

O próximo passo será complementar a caracterização do OPO para uma faixa maior de frequências, com a possível obtenção de regiões com melhor comportamento do limiar suave de transição. A célula de rubídio irá ser trocada por uma com fases planas com uma inclinação igual ao ângulo de Brewster para diminuir as perdas indesejadas. O sistema de controle de temperatura dessa célula será melhorado. 


\section{Bibliografía}

[1] Almeida, M. P., de Melo, F., Hor-Meyll, M., Salles, A., Walborn, S., Ribeiro, P. S., e Davidovich, L. (2007). Environment-induced sudden death of entanglement. science, 316(5824):579-582. xiii

[2] Ballentine, L. E. (2014). Quantum mechanics: a modern development. World Scientific Publishing Co Inc. 4, 5, 13, 18, 23

[3] Barbosa, F., Coelho, A., De Faria, A., Cassemiro, K., Villar, A., Nussenzveig, P., e Martinelli, M. (2010). Robustness of bipartite gaussian entangled beams propagating in lossy channels. Nature Photonics, 4(12):858-861. xiii

[4] Barnett, S. M. e Radmore, P. M. (2002). Methods in theoretical quantum optics, volume 15. Oxford University Press. 18, 23

[5] Boyd, R. W. (2008). Nonlinear Optics. Academic Press, third edition edition. ch. 1. 3, 8, $10,12,13,14$

[6] Brasil, T. B. (2015). Caracterização clássica e quântica de um oscilador paramétrico ótico bombeado em $780 \mathrm{~nm}$. Master's thesis. 11, 22, 68

[7] Bristol Instruments (2016a). 671 Series Features: operational features of the 671 Laser Wavelength Meter. 42, 49

[8] Bristol Instruments (2016b). 671 Series Laser Wavelength Meter - Data Sheet: technical specifications of the 671 Laser Wavelength Meter. 42, 49

[9] Camparo, J. C. (1985). The diode laser in atomic physics. Contemp. Phys., 26(5):443-477. 29,30

[10] Campopiano, D. d. M. F. (2013). Construção e Caracterização de um Laser Contínuo de Titânio-Safira. Master's thesis, IFUSP. 38 
[11] Coelho, A., Barbosa, F., Cassemiro, K., Martinelli, M., Villar, A., e Nussenzveig, P. (2015). Analyzing the gaussian character of the spectral quantum state of light via quantum noise measurements. Physical Review A, 92(1):012110. xiv

[12] Corzo, N. V., Glorieux, Q., Marino, A. M., Clark, J. B., Glasser, R. T., e Lett, P. D. (2013). Rotation of the noise ellipse for squeezed vacuum light generated via four-wave mixing. Phys. Rev. A, 88(043836). 46

[13] da Cruz, L. S. (1998-1999). Estabilização de Lasers de Diodo para Experiências de Ótica Quântica e Não-Linear com Átoos Frios. Material interno do LMCAL. 31

[14] Foot, C. J. (2005). Atomic Physics. Oxford master series in atomic, optical and laser physics . Oxford University Press. ch. 1,8. 3, 4, 5, 6, 7, 9, 35, 44

[15] Glorieux, Q. (2010). Etude Theorique et Experimentale des Correlations Quantiques Obtenues par Melange a Quatre Ondes dans une Vapeur Atomique. $\mathrm{PhD}$ thesis, Laboratoire Matériaux et Phénomènes Quantiques. xiv, 3, 11, 13, 16, 25, 29, 33, 59, 64

[16] Glorieux, Q., Guidoni, L., Guibal, S., Likforman, J.-P., Coudreau, T., et al. (2010). Strong Quantum Correlations in Four Wave Mixing in ${ }^{85} \mathrm{Rb}$ Vapor. Proceedings of SPIE, 7727(772703). 18, 23

[17] González Arciniegas, C. A. (2017). Properties of the light emitted by a silicon on-chip optical paramatric oscillator $(O P O)$. $\mathrm{PhD}$ thesis, Instituto de Física Universidade de São Paulo. 23, 25, 68

[Inc] Inc, C. T. Acousto-Optic application note - modulator model 3000 series. 32

[19] Jackson, J. D. (1999). Classical electrodynamics. 14, 19

[20] Jasperse, M. (2010). Relative Intensity Squeezing by Four-Wave Mixing in Rubidium. Master's thesis, School of Physics. The University of Melbourne. 3, 13, 18, 25, 29

[21] Kane, D. (1994). Ti: sapphire laser cavity mode and pump-laser mode calculations. Applied optics, 33(18):3849-3856. 37, 38

[22] Kogelnik, H. e T. Li (1966). Laser beams and resonators. Proceedings of the IEEE, 54(10). 19,22

[23] MacAdam, K. B., Steinbach, A., Wieman, C., et al. (1992). A narrow-band tunable diode laser system with grating feedback, and a saturated absorption spectrometer for $\mathrm{Cs}$ and $\mathrm{Rb}$. Am. J. Phys., 60. 29, 30, 31, 35 
[24] Mandl, L. e Wolf, E. (1986). Optical Coherence and Quantum Optics. University Science Books. ch. 9.18

[25] Martinelli, M. (2002). Compressão de ruído quântico e efeitos transversos em osciladores paramétricos óticos. $\mathrm{PhD}$ thesis, Instituto de Física, Universidade de São Paulo. ch. 1. 3, $11,22,23,68$

[26] McCormick, C., Boyer, V., Arimondo, E., e Lett, P. (2007). Strong relative intensity squeezing by 4-wave mixing in Rb vapor. Opt. Lett., 32(178). xiv, 13, 18, 23, 25, 29, 33, 36, 41,75

[27] McCormick, C., Marino, A. M., Boyer, V., e Lett, P. D. (2008). Strong low-frequency quantum correlations from a four-wave mixing amplifier. Phys. Rev. A, 78(043816). 29

[28] Melles Griot, C. (2009). Tutorial: Gaussian Beam Optics. . 19

[29] Nakamura, M., Aiki, K., Chinone, N., Ito, R., Umeda, J., et al. (1978). Longitudinal-mode behaviours of mode-stabilized $\mathrm{Al}_{x}-\mathrm{Ga}_{1-x}$-As injection lasers. J. Appl. Phys., 49(9). 29

[30] Nielsen, M. A. e Chuang, I. L. (2000). Quantum computation and quantum information. Quantum, 546:1231. xiii

[31] Pooser, R. C., Boyer, V., Marino, A. M., Lett, P. D., et al. (2008). Squeeed light and entangled images from four-wave-mixing in hot rubidium vapor. Em Meyers, R., Shih, Y., e Deacon, K., editores, Quantum Communications and Quantum Imaging VI, volume 70920G1. 29

[32] Pooser, R. C., Marino, A. M., Boyer, V., Jones, K. M., Lett, P. D., et al. (2009). Quantum correlated light beams from non-degenerate four-wave mixing in an atomic vapor: the D1 and D2 lines of ${ }^{85} R b$ and ${ }^{87} R b$. Optics Express, 17(19). 29

[33] Ricci, L., Weidemüller, M., Esslinger, T., Hemmerich, A., Zimmermann, C., Vuletic, V., König, W., e Hänsh, T. (1994). A compact grating-stabilized diode laser system for atomic physics. Optics Comunications, 117:541-549. 29, 30

[34] Rojas, H. (2017). Caracterização da amplificação paramétrico no processo de mistura de quatro ondas na configuraçã duplo lambda em vapor de rubídio. Master's thesis, Instituto de Física Universidade de São Paulo. 41

[35] Saleh, B. E. A. e Teich, M. C. (1991). Fundamentals of Photonics. Wiley Series in Pure and Applied Optics. John Wiley \& Sons. 19, 30, 33, 38, 39, 64 
[36] Scully, M. O., Zubairy, M. S., et al. (1997). Quantum Optics. Cambridge University Press. $3,13,15,17,18,23$

[37] Siegman, A. (1986). LASERS. university science books. ch. 1-7. 6, 19

[38] Slusher, R. E., Yurke, B., Grangier, P., LaPorta, A., Walls, D. F., e Reid, M. (1987). Squeeed light generation by four-wave mixing neat an atomic transition. J. Opt. Soc. Am. B, 4(10):1453-1464. xiv

[39] Spectra Diode Labs (1996). SDL-7630/8630, Tunable 0.5W CW External Cavity Laser Diode. 36

[40] Steck, D. A. (2003). Rubidium 87 D Line Data. Technical report, Los Alamos National Laboratory. 3, 5, 29

[41] Steck, D. A. (2013). Rubidium 85 D Line Data. Technical report, Los Alamos National Laboratory. 3, 4, 29

[42] Thorlabs Inc. (2006). Guide to Connectorization and Polishing Optical Fibers. 40

[43] Thorlabs Inc. (2017a). Fotodetectores Amplificados de Transimpedância InGaAs. Catálogo de Produtos. 42

[44] Thorlabs Inc. (2017b). Sensores Fotodiodo de Potência (Série C). Catálogo de Produtos. 49

[45] Villar, A., Cruz, L., Cassemiro, K., Martinelli, M., e Nussenzveig, P. (2005). Generation of bright two-color continuous variable entanglement. Physical review letters, 95(24):243603. xiv

[46] Villar, A. S. (2008). The conversion of phase to amplitude fluctuations of a light beam by an optical cavity. American Journal of Physics, 76(10):922-929. 22

[47] Walls, D. F. (2007). Quantum optics. Springer-Verlag. 23

[48] Wavelength Electronics (2011). Temperature controllers HTC 3000 Series. 31

[49] Yuen, H. P. e Shapiro, J. H. (1979). Generation and detection of two-photon coherent states in degenerate four-wave mixing. Optics Letters, 4(10). 23 